University of Redlands

\title{
Improving Clean Water Conservation in Western Ethiopia Using ArcGIS Server
}

\author{
A Major Individual Project submitted in partial satisfaction of the requirements \\ for the degree of Master of Science in Geographic Information Systems \\ by \\ Apollinaire William
}

Douglas M. Flewelling, Ph.D., Committee Chair

Fang Ren, Ph.D.

August 2010 
Improving Clean Water Conservation in Western Ethiopia Using ArcGIS Server

Copyright (C) 2010

by

Apollinaire William 
The report of Apollinaire William is approved.

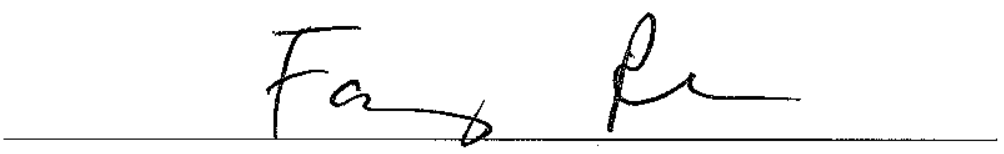

Fang Ren, Ph.D.

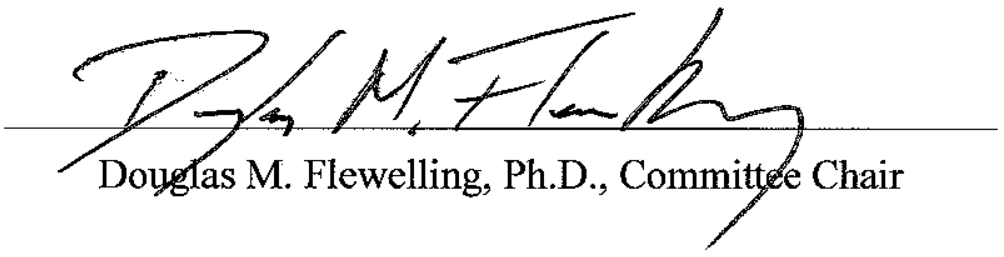

August 2010 



\section{Acknowledgements}

My Major Individual Project would not have known success if not for the help, guidance, encouragement and valuable contributions from the Faculty members of the MSc GIS program of the University of Redlands. It is of a great privilege to cover their names here and anticipate my apologies for any omission that might have crept in from my fallible mind.

My first and foremost special thanks to Mrs. June Morrison and the Morrison Family Trust for the funding that enabled me to accomplish this MS GIS program. My special acknowledgments conveyed to Dr. Douglas M. Flewelling for his support and his guidance in the course of the project development and implementation. My special thanks also to Debra Riley and Dr. Fang Ren and Dr. Ruijin Ma for their unfailing moral support, attention and care. Dr. Mark Kumler deserves my gratitude for his great contribution to the cartographic facet of this project. His comments on my work were a valuable source of inspiration.

I particularly owe a precious gratitude to Dr Larry Thomas, the chair of the Tropical Health Alliance Foundation, for his financial, logistic and moral support during data collection in Ethiopia, and his valuable input through the whole process of the project execution. My further gratitude is dedicated to Editor Lynn Flewelling for her syntactic touch and care about semantics that shape this project report.

To all who contributed to my success in the program in one way or another, through their support, encouragements, and care, I express my profound gratitude. 



\begin{abstract}
Improving Clean Water Conservation in Western Ethiopia

Using ArcGIS Server

by

Apollinaire William

A Web map application was developed to disseminate information on the locations of freshwater springs and their status in Western Ethiopia. Ethiopia suffers an insufficient clean water supply. Only one-third of the rural population has access to safe drinking water. Various organizations have been involved in protecting water springs, but these efforts were not well coordinated due to the lack of spatial information about the locations of springs and their status in the area of intervention. The Tropical Health Alliance Foundation (THAF) is one of the organizations that have been committing its efforts and funds to protect springs in Western Ethiopia. THAF identified the need to improve communication by virtue of a Web-based interactive mapping in order to help coordinate interventions and attract more funds from various donors by providing better information shared over the Web. A Web GIS application proves to be an effective tool for ensuring water security for Ethiopia in the coming years.
\end{abstract}





\section{Table of Contents}

Chapter 1 - Introduction 1

1.1 Client 2

$\begin{array}{lll}1.2 & \text { Problem Statement } & 2\end{array}$

$\begin{array}{lll}1.3 & \text { Proposed Solution } & 2\end{array}$

1.3.1 Goals and Objectives 3

$\begin{array}{lll}\text { 1.3.2 Scope } & 3\end{array}$

$\begin{array}{lll}\text { 1.3.3 Methods } & 4\end{array}$

$\begin{array}{lll}1.4 & \text { Audience } & 5\end{array}$

$\begin{array}{lll}\text { 1.5 Overview of the Rest of this Report } & 6\end{array}$

Chapter 2 - Background and Literature Review $\quad 7$

$\begin{array}{lll}2.1 & \text { Maps as spatial abstraction tools } & 7\end{array}$

$\begin{array}{lll}2.2 & \text { Web-GIS environment for a global outreach } & 8\end{array}$

2.3 Summary 9

Chapter 3 - Systems Analysis and Design 11

$\begin{array}{lll}3.1 & \text { Problem Statement } & 11\end{array}$

$\begin{array}{lll}3.2 & \text { Requirements Analysis } & 11\end{array}$

$\begin{array}{lll}3.3 & \text { System Design } & 14\end{array}$

$\begin{array}{lll}3.4 & \text { Project Plan } & 16\end{array}$

3.4.1 Initiation and requirement analysis phase 16

$\begin{array}{ll}\text { 3.4.2 Design and Implementation phase } & 17\end{array}$

$\begin{array}{lll}\text { 3.4.3 Rollout phase } & 18\end{array}$

$\begin{array}{lll}3.5 & \text { Summary } & 19\end{array}$ 
Chapter 4 - Database Design $\quad 21$

$\begin{array}{lll}4.1 & \text { Conceptual Data Model } & 21\end{array}$

$\begin{array}{lll}4.2 & \text { Logical Data Model }\end{array}$

$\begin{array}{lll}4.3 & \text { Data Sources } & 25\end{array}$

$\begin{array}{lll}4.4 & \text { Data Collection Methods }\end{array}$

4.5 Data Scrubbing and Loading $\quad 27$

$\begin{array}{llr}4.6 & \text { Summary } & 27\end{array}$

$\begin{array}{lr}\text { Chapter } 5 \text { - Implementation } & 29\end{array}$

$\begin{array}{ll}5.1 & \text { Database implementation }\end{array}$

$\begin{array}{lll}5.2 & \text { Geodatabase Loading } & 30\end{array}$

5.3 Map Document Authoring $\quad 32$

5.4 Web Map Prototype Application 36

5.5 User Web Interface Design 38

$\begin{array}{lll}5.6 & \text { Page design } & 39\end{array}$

5.7 JavaScript for a dynamic Web application 40

5.7.1 Functions used with JavaScript $\quad 43$

$\begin{array}{ll}\text { Chapter } 6 \text { - Results and Analysis } & 47\end{array}$

6.1 Web Mapping Application 50

Chapter 7 - Conclusions and Future Work 55

$\begin{array}{lr}\text { Works Cited } & 59\end{array}$

Appendix A. Overall Project Flow $\quad 61$

Appendix B. Web Mapping Application Programming Code 62

Appendix C. Questionnaire about springs surveyed 70 
Appendix D. Project Timeline

Appendix E. Spring Data Table

72 



\section{Table of Figures}

Figure 3-1: System design for the project............................................................ 15

Figure 3-2: Initiation and requirement analysis workflow .................................. 17

Figure 3-3: Database development workflow ................................................... 17

Figure 3-4: Web GIS Prototype Design and Implementation Workflow .................. 18

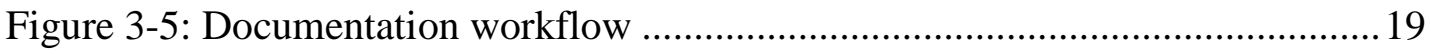

Figure 4-1: Main components of the conceptual model ........................................21

Figure 4-2: UML model of the Spring Project...................................................... 23

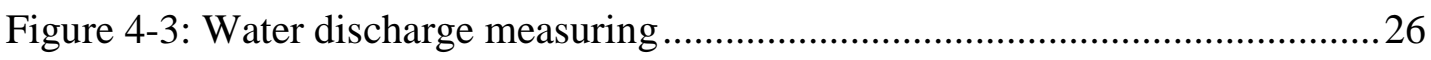

Figure 4-4: A screenshot of an Excel spread sheet prepared for data loading...........27

Figure 5-1: Schema report created using ArcGIS Diagrammer.............................. 30

Figure 5-2: Loading the spring table into a file geodatabase ................................. 31

Figure 5-4: Creating protected and unprotected spring layers ................................33

Figure 5-5: Layers added to the map document................................................. 34

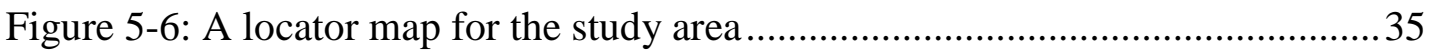

Figure 5-7: Data report with ArcGIS Diagrammer ............................................. 36

Figure 5-8: ArcMap interface to publish map document to ArcGIS Server..............37

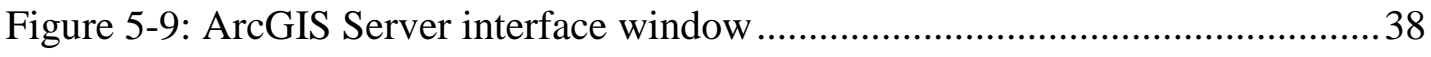

Figure 5-10: Coding system pros and cons (Source: Fowler and Stanwick (2004)

Figure 5-11: A sample code from ArcGIS Resource Center ..................................42

Figure 5-12: Firebug window for HTML code................................................ 43

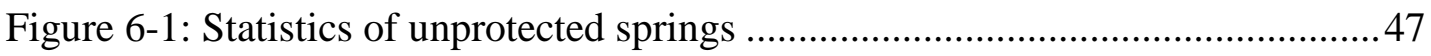


Figure 6-2: Statistics of protected springs ........................................................ 48

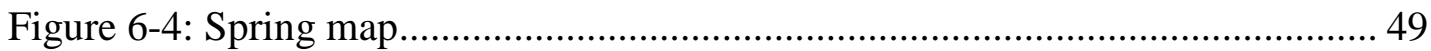

Figure 6-5: Web application user interface .................................................. 50

Figure 6-6: Web application interface with an InfoWindow ................................ 51

Figure 6-7: Small-scale zoom of the map application....................................... 52

Figure 6-8: Photograph of an unprotected spring............................................. 53

Figure 6-9: Photograph of a protected spring.................................................. 53

Figure 6-10: Description pane for the Web application interface ............................ 54 


\section{List of Tables}

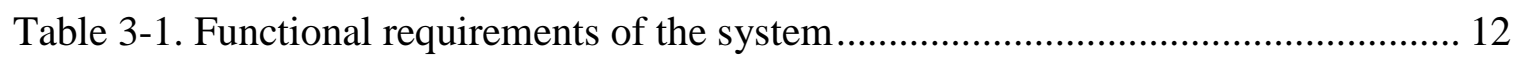

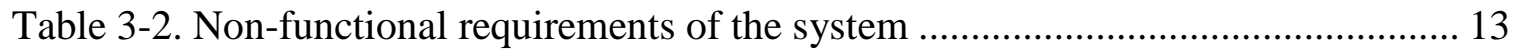

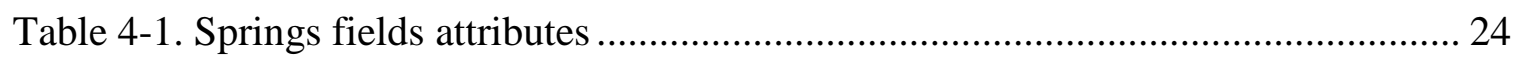

Table 4-2. Road line feature class fields and properties ............................................ 24

Table 4-3. Province boundary polygon feature class fields and properties ..................... 25

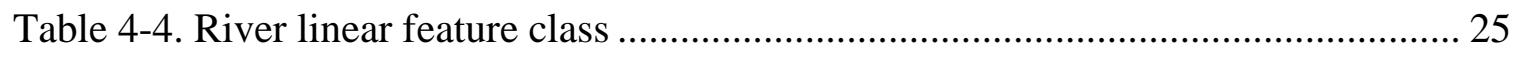

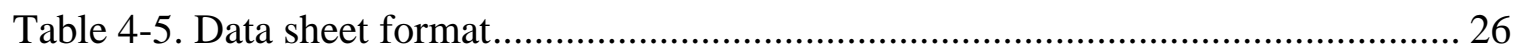




\section{List of Acronyms and Definitions}

\begin{tabular}{|c|c|}
\hline API & Application Programming Interface \\
\hline CSS & Cascading Style Sheets \\
\hline DHTML & Dynamic Hyper Text Markup Language \\
\hline ESRI & Environmental Systems Research Institute \\
\hline FGDC & Federal Geographic Data Committee \\
\hline GIS & Geographic Information Systems \\
\hline GPS & Global Positioning System \\
\hline HTML & Hyper Text Markup Language \\
\hline НTТP & Hyper Text Transport Protocol \\
\hline OGC & Open Geospatial Consortium \\
\hline REST & Representational State Transfer \\
\hline SOC & Server Object Containers \\
\hline SOM & Server Object Manager \\
\hline THAF & Tropical Health Alliance Foundation \\
\hline UML & Unified Modeling Language \\
\hline URL & Uniform Resource Locator \\
\hline \multirow[t]{2}{*}{ UNICEF } & United Nations Children's Fund (formerly United Nations International \\
\hline & Children's Emergency Fund) \\
\hline WHO & World Health Organization \\
\hline WWW & World Wide Web \\
\hline XML & Extensible Markup Language \\
\hline
\end{tabular}




\section{Chapter 1 - Introduction}

The benefits of visualizing and exploring digital spatial data is becoming increasingly and widely recognized (Rhyne, 1997; Kraak and MacEachren, 1999), and the Internet is an efficient and effective tool for spatial data dissemination (Huang et al., 2001). Web-based GIS technology offers public access to spatial data and related services, and software applications such as Google Earth have provided millions of users with instantaneous access to digital geographic data and tools that previously were restricted to GIS professionals (Jankowski et al., 2007; Kraak, 2004). Future developments in geographical information systems (GIS) will center on Internet GIS, with more capabilities to access geospatial data and conduct geospatial analysis on the Internet (Plewe, 1997; Peng, 1999; Peng and Tsou, 2003).

These new technologies come at a time when as much as 80 percent of public and private decision-making involves spatial analysis of one sort or another (Dessart, 2002). Internet GIS technology offsets the limited capacity for small organizations to buy GIS software, programs that are expensive for some small organizations to afford and designed for GIS-professionals (Peng and Zhang, 2004). Internet GIS offers an intuitive, user-friendly interface with simple functionality to zoom-in or -out and pan. The map can also be queried, and clicking a symbol can give access to the database behind the map. Simple operations such as measuring distance or areas can often be executed (Kraak, 2004).

There are many humanitarian-based opportunities for Internet GIS in developing countries, where the deployment of mapping technology is still at its early stage. Clean water supply continues to be one of the greatest challenges, and various projects invest their efforts to supply clean water in rural areas. The population of Ethiopia, in particular, is facing a serious water crisis. Only one-third of the rural population has access to clean water for domestic use. Most of the communities depend on unclean water from contaminated springs, ponds, streams, and muddy puddles. The main problem is increased susceptibility to water-borne diseases such as diarrhea and dysentery, waterwashed diseases such as trachoma and scabies, water-based diseases such as worms, and water-related insect vectors including malaria. In Ethiopia, an estimated three-quarter of children's the health problems and communicable diseases originate from the environment.

Various organizations, including the Tropical Health Alliance Foundation, have been working in the most affected rural areas to supply clean water by building spring protection structures and wells. However, the lack of efficient global and regional information sharing has jeopardized coordination and monitoring. Moreover, efforts have been disproportionately focused on some particular areas (mostly the most accessible), whereas remote areas - those probably needing greater assistance-were left on their own, helpless.

The following chapters of this report focus on a Web map application that was developed to disseminate spatial information about location and protection status of water springs in the Sayo District, Western Ethiopia. This is a live example of one of the efficient tools that support sharing of spatial information at a global and regional level. This application will be leveraged by the Tropical Health Alliance Foundation (THAF) to 
attract more donations for protection of freshwater springs and will help various partners, including governmental and non-governmental organizations, focus their interventions in a more coordinated way.

\subsection{Client}

The Tropical Health Alliance Foundation (THAF) is a nonprofit organization, based in the United States. Its mission is to help people in developing countries live healthier lives by providing medical assistance, educational training, and poverty reduction. This organization provides funding to various projects involved in various programs related to health and sanitation. In the case of Ethiopia, THAF has been focusing on interventions in the western part of the country where it is helping provide clean water supplies by funding spring protection structures. THAF, the client for this project, is interested in providing Web-based maps of the locations of over 100 springs situated in the western part of Ethiopia, their status in terms of protection, and their accessibility by local communities. THAF works both individually and with other organizations to accomplish its mission. Dr. Larry Thomas is currently the chair of THAF and point of contact and client for this project.

\subsection{Problem Statement}

Most of the population in Ethiopia, especially in remote rural areas, is still underserved and cannot access clean water. In fact, there is a gap due to the lack of effective communication among various stakeholders involved in spring protection. Lack of spatial information on spring status and distribution in the country makes it difficult to better orient interventions and conduct effective coordination and monitoring. The Tropical Health Alliance Foundation identified the need to use a Web mapping application tool to disseminate information about spring location and status in western Ethiopia, with subsequent extension to other parts of Ethiopia to increase awareness and support efficient interventions to protect springs.

\subsection{Proposed Solution}

An interactive Web-based GIS application was created to help visualize and disseminate spatial and tabular data to a large group of end-users via a Web browser. Data to be displayed pertains to the locations and condition of water springs in western Ethiopia. THAF, as well as the worldwide users of the published service, will be able to retrieve, query, and copy data as much as needed. A GIS Web page was designed, developed, and implemented using ArcGIS Server 9.3.1 technology. This technology allows publishing geospatial services and tasks, using powerful and easy-to-use frameworks for creating Web applications. It allows the use of base maps and geospatial services in Web applications. The service supports JavaScript and HTML APIs to create a user-friendly interface for end-users. A master list of all springs surveyed, along with attribute data, can be displayed as well. A package of spring status photographs is also integrated in the Web application to display the condition of each individual spring.

This Web application can also be used by the client to inform various conservation stakeholders in Ethiopia about the location and status of springs in the Sayo District. 
Governmental as well as non-governmental agencies will use the products of the systems to better monitor spring protection progress and focus their intervention efforts in the neediest areas.

In order to develop this application, data on spring locations and status were collected and tabulated. A normalized geodatabase was created and populated with processed data and accuracy and integrity rules were set in the database to ensure processing efficiency and logical linkages between related datasets and tabular data. This process enables further data updating and additional data entry as the project expands its spatial scope. The geodatabase helps generate various summary statistics, including household distribution graphs that help various project partners and stakeholders see the relative number of households served by any particular spring, and, therefore, have an intuitive sense of which springs need to be protected in the first place.

The use of this new technology as a solution is supported by well-known scientists in the field and appears to be the framework for future developments in geographic information systems (Plewe, 1997; Peng, 1999; and Peng and Tsou, 2003). This application is a prototype and, along with related documentation, allows the client to do much more extensive work to cover other areas in Ethiopia.

\subsubsection{Goals and Objectives}

The ultimate goal of this project was to develop a Web-based GIS prototype for the status and locations of freshwater springs in the Sayo District, western Ethiopia, built upon ArcGIS Server technology. Before, there was limited access to water supply information by the global audience. This problem was due to the fact that data were collected and stored in centralized GI Systems in the form of traditional paper maps or digital maps and used exclusively by professionals, thus restricting any participatory opportunity by nonprofessionals. This process resulted in uncoordinated interventions and in a lack of effective monitoring. A Web application helps disseminate information to the global audience, helps fundraising, targeted interventions to the neediest, and facilitates monitoring and interventions oriented towards spring protection. This goal was achieved though the following objectives:

- Mapping existing protected and unprotected water springs in the Sayo District

- Creating a database that enables updating and easy processing of data to create maps, graphs and tables

- Publishing map services and creating a user-friendly interface using JavaScript and HTML APIs

\subsubsection{Scope}

A scope for the project was thoroughly investigated through a client's needs analysis, and was defined as a result of a discussion with the client. Information Products Descriptions (IPDs) and a Master Input Data List (MIDL) were created in the initial phase of the project in order to determine the scope, and the system functional and technical requirements involved for the success of the project. The client's requirements were met by collecting data on protected and unprotected springs locations and their status in the Sayo District, western Ethiopia, by developing a file geodatabase for storing, managing 
data, and authoring a map document to be published, and by developing and implementing a prototype Web GIS application.

The client's expectations were to have a minimum of 100 springs covered, but it was agreed that the coverage would depend on the timeframe allocated for data collection, that is, from mid-November 2009 through January 7, 2010. A created database would be scalable, maintain data integrity, ensure a good data processing performance, and enable the creation of a map document to be published on ArcGIS Server using ArcGIS technologies.

Data was collected in the field, a map service was created, and a Web GIS application prototype was designed, developed, and deployed to disseminate spatial information of spring locations and status to an online audience via a browser over the internet. A Web-based user-friendly interface was created. It offers commonly used tools for intuitive navigation, and has an attractive look and feel. It is designed and intended for people with limited or no GIS experience. The JavaScript environment was chosen to provide client-side interactivity to Web pages, to implement query tasks over the Web. ArcGIS API for JavaScript runs easily in any browser and does not require plug-ins such as Adobe Flash Player. The site of interest for the project is in western Ethiopia, Welega Province, around Dembidolo town, and extending five miles from the town, into rural areas.. Furthermore, information and photographs pertaining to the status of springs were compiled as part of information products to be delivered to the client.

The client's needs were successfully met by developing a Web GIS application that displays locations of 92 surveyed springs with a rendered symbology that distinguishes protected springs (in blue) from unprotected ones (in red). There are navigation tools for panning and zooming. A mouse click on a point feature on a map prompts an InfoWindow that provides information about the spring name, its assigned identification number, its geographic location, the number of households served by each individual spring, and a link to a photograph showing the status of the spring. The application also shows a list of all 92 springs covered during the study, along with their detailed attributes and links to related photographs that show the condition of each spring. Finally, the application provides a descriptive outline of the project, summary statistics about covered springs, and hyperlinks to other useful resources pertaining to water conservation issues. Satellite imagery coupled with rivers, roads, and Dembidolo town, serve as a background for reference and display purposes.

\subsubsection{Methods}

A successful completion of the project was achieved using various methods and techniques in three main areas: data collection, geodatabase development, and Web map application development.

Ground surveying using the Global Positioning System (GPS) was used to capture spring location data. This method proved to be the best way to obtain highly accurate point locations. Three GPS units were used at the same time to ensure the accuracy of collected data. GPS units were positioned in spots with a wide and unobstructed view of the sky to reduce position errors or avoid no position reading.

A few weeks prior to data collection, the Catholic Church Mission in the area submitted spring protection application forms to surrounding villagers. These forms had been completed and approved by the local government before they were returned to the 
Catholic Mission office in Dembidolo town. Each form included a name of a spring, its village location, and the number of families served by it. In addition, the Catholic Mission and the local government provided people to facilitate interviews with villagers at every spring visited. Spring users, particularly adults, were prepared in advance so that they would be available at a particular spring to answer questions.

Questions include the following:

- What is the name of the spring?

- What is the name of the village the spring is located in?

- What are the names of villages that use the spring?

- How many households from each village use the spring?

- What are the problems related to the sanitation of the spring?

Pictures of the spring were captured using a digital camera with a maximum resolution of 5184 x 3456 pixels and a minimum resolution of 2592 x 1728 pixels. The sensor size was $22.3 \times 14.9 \mathrm{~mm}$. Data was stored and managed in a file geodatabase for ArcGIS 9.3.1. Conceptual, logical, and physical designs were implemented using the Unified Markup Language (UML) from Microsoft Visual Studio 2008, ArcGIS Diagrammer, and a file geodatabase from ArcGIS 9.3.1 respectively. Data preparation was done with ArcCatalog, authoring used ArcMap, and map services were published using ArcGIS Server 9.3.

World Imagery from ESRI ArcGIS Online services was used as a background image for the interactive web map application. This application was implemented using JavaScript API and ArcGIS Server technology. A user needs analysis helped in determining the core information to be included as content of the website, as well as functionalities to be used for querying and retrieval tasks by end users. Also, the GIS website was built using HTML to suit the look and feel of the THAF main web site. GIS applications were built using JavaScript API while utilizing the Dojo toolkit widgets tools to improve the appearance and usability of applications.

Measures of liters of water discharged by the spring per minute were made using plastic containers with known capacity. These included jerycans of 5 liters, 25 liters, and 30 liters. Spring discharge was calculated by dividing the number of liters by the amount of time spent collecting that volume. For example, if a 30 liter container filled in 120 seconds, then the discharge would be 15 liters/minute.

\subsection{Audience}

The present project report is intended for two categories of audience: professionals familiar with GIS tools and GIS non professionals. The vocabulary and jargon used in this report accommodates both categories' interest. This project report is primarily addressed to potential donors interested in the conservation of water resources, the Tropical Health Alliance Foundation and its various partners involved in improving health or supplying safe drinking water to human communities, particularly in western Ethiopia. Stakeholders from governmental and non governmental agencies will substantially benefit from this report, as they understand how a web map application can be used in portraying and monitoring water resources and how it helps disseminate information globally and effectively.

For a novice in the field of GIS, this report offers an interesting illustration on how GIS can use a Web platform to disseminate spatial information and analysis to a global audience. 


\subsection{Overview of the Rest of this Report}

Chapter Two provides background material, reviews pertinent literature from authoritative sources, and places the rationale of the project in a scientific realm context.

Systems analysis and design are discussed in chapter Three, with a particular focus on the design that addresses the client's need for the project. This chapter also describes in detail the project plan and resources involved in accomplishing various tasks of the project.

Chapter Four describes the database design through its different phases that include conceptual and logical data models. This chapter will also expose the reader to data collection methodology and the results. How data sets were prepared and loaded into the geodatabase is also documented in this chapter.

Chapter Five documents the implementation of the project. It presents, in a detailed description, and step-by-step, all the work involved in developing a web map application prototype. This chapter provides an inspiring experience for any GIS novice or professional interested in implementing a similar project using similar datasets. Chapter Six discusses the results and analyses of the proposed solution. Conclusions and future work are presented in chapter Seven. 


\section{Chapter 2 - Background and Literature Review}

Effective water planning policies and management in developing countries in particular are inhibited by a limited availability of data on many aspects of water supply and use at the local, national and regional level. Many regions of developing countries experience widespread cases of waterborne diseases due to a lack of sufficient clean drinking water and sanitation services (Gleick, 1998). In Ethiopia, an estimated 60\% of the rural population still lacks access to improved water sources (WHO/UNICEF, 2006). A study conducted in Robe Gabia, a rural community located $50 \mathrm{~km}$ north of Addis Ababa found that most people drank water from unprotected springs and rivers (Boisson et al., 2009). Samples from twelve different water sources (10 springs and 2 streams) taken from around the study site revealed high levels of fecal contamination (Boisson et al., 2009).

In most developing countries, interventions oriented toward insuring a clean water supply have so far proven ineffective due to the lack of sufficient information about water supply location and status. Related published work is intended mostly for professional scientists, therefore making it hard for the general public, including potential donors and stakeholders, to participate in the planning and decision process (Peng, 2001).

\subsection{Maps as spatial abstraction tools}

Geographic Information Systems (GIS) have been recognized as a geospatial data integration tool for decision support and planning analysis and has been widely implemented in many public and private organizations during the last couple of decades. GIS helps represent an abstraction of spatial objects and fields in the form of maps, in a simplified way. Maps are popular, not only because they are convenient to use and they simplify the representation of surroundings, but also because they are credible in a sense that they claim to show how things really are and they have strong visual impact in creating direct and lasting impressions of the environment (Kimberling et al., 2009). Kraak (2004) emphasizes the role of maps in GIS, stating that "maps not only present the final results of the spatial analysis but they are also critical during the whole iterative process of geospatial data handling."

GIS is essential as a decision support to address various geospatial issues. It helps strategy planners and decision makers make right decisions based on spatial facts and patterns. GIS has been used extensively to map water resources around the world. Ayenew (2001) effectively used groundwater flow models to study regional groundwater dynamics in Ethiopian Rift and adjacent highlands.

The Tropical Health Alliance Foundation has been providing funds to improve freshwater springs in western Ethiopia without the benefit of any GIS support. This has resulted in inefficient fund allocation. THAF now recognizes the crucial importance of using maps to effectively locate needy areas for spring protection. GIS will, in this particular instance, help improve interventions and allocate funds more effectively for spring improvement.

The IMPETUS research project (Integrated Approach to the Efficient Management of Scarce Water Resources in West Africa) is incorporating GIS in the Spatial Decision Support Systems that are being developed (Laudien et al., 2009) in an attempt to solve present and possible future problems with regard to freshwater supply in West Africa. 
Similar studies have been conducted in northern, central, southern, and eastern Ethiopia. However, no research has been conducted in the western part of Ethiopia with regard to freshwater supply. Therefore, any initiative oriented towards the improvement of water supply would lack sufficient information about freshwater supply status and location in that part of the world.

\subsection{Web-GIS environment for a global outreach}

The emergence of the World Wide Web technologies in the last decade has given rise to developments in map-based scientific visualization, making GIS more mobile, powerful, and flexible and better able to share and communicate geographic knowledge (Peng and Tsou, 2003; Jankowski et al., 2007). The Internet allows not only for dynamic presentation but also for user interaction. The Web displays and disseminates geospatial data and maps to unlimited number of users who can access the map anywhere any time (Kraak, 2004).

The internet is affecting GIS in three major areas: GIS data access, spatial information dissemination, and GIS modeling/processing. The Internet provides GIS users easy access to acquire GIS data from different providers. The U.S. Geospatial Data Clearinghouse Activities under the Federal Geographic Data Committee (FGDC) has been working to build a distributed archive of information for universal access (Peng and Tsou, 2003). Peng and Tsou (2003) also argue that the Internet enables the dissemination of GIS analysis results and spatial information to a much wider audience than does traditional GIS, and acknowledges the fact that the Internet is becoming a means to conduct GIS processing. This Web mapping technology constitutes a major advancement in cartography. In this Web-GIS environment, maps can function as an index to other information. The hyper-linked nature of the Web allows map elements to be linked to other geographic data sets, photographs, texts, or videos. New technological developments, as well as the nature of the Web user, need to be carefully considered for when designing Web maps (Kraak, 2004).

Web application developers can take advantage of client-side Web technologies like Cascading Style Sheets (CSS) and JavaScript to allow global GIS professionals and nonprofessionals to interact with published map services through an Internet browser. CSS provides a unified method for controlling the appearance of user interface elements in a Web application. For example, the user can control the way the page looks, from font sizes and colors, to spacing, and the positioning of elements (Eernisse, 2006). The scripting language JavaScript is well-known for its widespread use and availability. An effective user-friendly interface created with JavaScript facilitates and stimulates interactive consumption of published map services and promotes the dissemination of information products to the intended audience. The most commonly used browsers, including Internet Explorer, Netscape Navigator, Mozilla Firefox, and others support JavaScript technology. VBScript is supported only by Internet Explorer running on the Windows operating systems. However, it is difficult to determine which scripting language is the most powerful and useful (Wilton, 2004).

Kraak observes that currently most Web-GIS application use is limited to mapping

applications. This is illustrated by luck of tools for user-friendly queries and retrieval when studying the massive amount of data for instance produced by sensors, now available via the Web. In addition, the performance of working in a Web-GIS 
environment is subjected to various technological constraints including Internet connection, traffic intensity, data efficiency, and the capacity of the client and server machines. This problem can be addressed by making map services very simple and less elaborate, paying more attention to their crucial intended content rather than unnecessary design additions.

Desktop GIS involves a complicated user interface, interoperability issues, and an expectation of professional expertise of the user. Therefore, this limits the general public to the use of the tools. Internet GIS proves to be a remedy to these constraints (Peng \& Zhang, 2004).

Another question is to know how Internet GIS can use data from any source and any format together. Currently, the Open Geospatial Consortium (OGC) is leading the development of standards for geospatial and location based services, including data interoperability. In fact, Web mapping has been characterized by lack of publicly available interface standards and harmonization to empower technology developers to make complex spatial information and services accessible and useful with all kinds of applications. In fact, Web mapping has been developing independently, with different data set formats and structures (Tsou, 2004). Some web mapping models have been designed to meet these challenges and allow users to integrate and compare different data formats for visualization and query (Eleveld et al., 2007). In 2000, the OGC organized its Interoperability Program, institutionalizing support for an ongoing series of interoperability initiatives.

Conservation of natural resources has been an application area of Web-based GIS applications. In data-scarce tropical Africa, researchers are using GIS-based hydrological modeling to investigate the impact of climatic and land use change on water resources. (Legesse et al., 2006). Jankowski (2007) demonstrates how Web-GIS can be effectively applied to water conservation and water quality monitoring in the San Diego Bay Watershed of California.

\subsection{Summary}

Maps serve as decision support tools for effective water planning policies and management practices. Geospatial data can now be accessed quickly by multiple users on the Web. The chapter outlined the development of Internet technologies since the early 1990s and how Web application developers can take advantage of client-side Web technologies like CSS and JavaScript to allow global GIS professionals and nonprofessionals to interact with published map services through an internet browser. Moreover, the chapter addressed concerns raised by GIS users in regard to data formats and discusses interoperability standard platform initiatives that have been undertaken by OGC. Web map applications can now be published to the Internet using OGC established standards.

Web GIS proves to be an effective tool for aiding humanitarian interventions for water resources conservation. Its value to coordinate among stakeholders and attract donors is undisputable. 



\section{Chapter 3 - Systems Analysis and Design}

The client's needs were fully investigated prior to the development and the implementation of the project. During the needs assessment and requirement analysis phases, the system analysis and design were carefully tailored to functional and nonfunctional requirements to ensure the success of the project by meeting the client's expectations. This chapter offers a brief description of requirements involved in the project by addressing the following: a problem statement that outlines the rationale for the project, a requirements analysis that highlights the needs assessment; the client and the project requirements; the system design that focuses on the conceptual, logical, and physical design and implementation of the geodatabase; the development and customization of the Web-GIS application; and the implementation of a Web map service served through ArcGIS Server. In addition, this chapter looks at the major tasks involved in developing and implementing the project, and a risk analysis of major challenges and opportunities to be anticipated.

\subsection{Problem Statement}

Current efforts to protect and improve the water quality of springs in western Ethiopia rely on random site visits. No map is used as a guiding tool. Only information from local communities helps locate springs.

This has resulted in an inefficient assessment of the needs of communities and an unequal distribution of spring protection services in the region. In fact, as outlined in Chapter 1 , the issue of concern is ineffective communication among various stakeholders involved in water spring improvement. Lack of spatial information on spring status and distribution in the country makes it difficult to better orient interventions and conduct coordination and monitoring more effectively.

The Tropical Health Alliance Foundation (THAF) is a non-profit California-based organization that has been funding projects involved in water spring improvement in Ethiopia through the Catholic Church Mission based in Dembidolo town, in Welega Province. THAF identified the need to use a Web mapping application tool to disseminate information about the location of springs and their status in western Ethiopia in order to expand awareness and support efficient interventions for spring protection. A Web-based application will disseminate information to a global audience, help in fundraising, target interventions to the neediest locales, and facilitate monitoring of springs.

\subsection{Requirements Analysis}

In order to successfully achieve the goals and objectives of the project, a requirements analysis and needs assessment were conducted in collaboration with the client. The requirements were divided into two main categories: functional and non-functional system requirements. Functional requirements are concerned with required and optional tasks that the Web map application prototype will have to perform (Table 3-1). 
Table 3-1. Functional requirements of the system

\begin{tabular}{|l|l|}
\hline Number & Description \\
\hline 1.0. General requirements \\
\hline 1.1. & $\begin{array}{l}\text { Support integrated and coordinated efforts oriented towards } \\
\text { spring protection }\end{array}$ \\
\hline 1.2. & $\begin{array}{l}\text { Support effective resource allocation and management for } \\
\text { spring protection and orient priorities in decisions making }\end{array}$ \\
\hline 2.0. Specific requirements \\
\hline 2.1. & $\begin{array}{l}\text { Storing, updating, and retrieval of spatial and non-spatial data } \\
\text { should be supported by the system }\end{array}$ \\
\hline 2.2. & $\begin{array}{l}\text { The system should have rules that govern data formats, } \\
\text { consistent logical relations among stored data sets and data } \\
\text { redundancy cleanup }\end{array}$ \\
\hline 2.3. & $\begin{array}{l}\text { The system should incorporate standardized symbology for all } \\
\text { generated and displayed maps according to the Open Geospatial } \\
\text { Consortium (O.G.C) }\end{array}$ \\
\hline 2.4 & $\begin{array}{l}\text { The application of the system should provide navigation tools } \\
\text { including zoom in, zoom out, panning, backward previous } \\
\text { window, forward previous window, and attributes }\end{array}$ \\
\hline 2.7. & $\begin{array}{l}\text { The system will enable users to select and copy data they need } \\
\text { from the Web application }\end{array}$ \\
\hline 2.6. & $\begin{array}{l}\text { The system should display, on a Web map, protected springs } \\
\text { and unprotected springs located in Sayo District, West Welega } \\
\text { Province }\end{array}$ \\
\hline $\begin{array}{l}\text { The system should allow for a ranking priority for springs to } \\
\text { protect and display summary statistics and graphs }\end{array}$ \\
$\begin{array}{l}\text { The Web map application should display a base map showing } \\
\text { the geographic location of the area of focus for the project }\end{array}$ \\
\hline 2. &
\end{tabular}

The non-functional requirements for the project defined the technology required to support functional requirements at their implementation phase. Some of the aspects are related to the software to be used, the client-side APIs, the scalability and accuracy of the geodatabase, and the Web application interface design (Table 3-2). 
Table 3-2. Non-functional requirements of the system

\begin{tabular}{|l|l|}
\hline Number & \multicolumn{2}{l|}{ Description } \\
\hline 1.0. General requirements & \multicolumn{2}{|l|}{$\begin{array}{l}\text { The system should be scalable and replicable in } \\
\text { similar projects conducted in different areas of the } \\
\text { world }\end{array}$} \\
\hline 1.1. & $\begin{array}{l}\text { The system should show accuracy and } \\
\text { completeness, and be structured to allow effective } \\
\text { monitoring of spring status and updates }\end{array}$ \\
\hline 2.0. Specific requirements & \multicolumn{2}{|l|}{} \\
\hline 2.1. & $\begin{array}{l}\text { The system should use ArcGIS Server 9.3 to } \\
\text { develop and implement its system design }\end{array}$ \\
\hline 2.2. & $\begin{array}{l}\text { The Web map application should support the } \\
\text { Hyper Text Markup Language (HTML) and } \\
\text { JavaScript Application Programming Interface } \\
\text { (API) tools }\end{array}$ \\
\hline 2.3. & $\begin{array}{l}\text { The Web map application should run in any } \\
\text { browser and run under low internet bandwidths }\end{array}$ \\
\hline 2.5. & $\begin{array}{l}\text { The Web application interface will be user- } \\
\text { friendly and intuitive to both GIS professional } \\
\text { users and non-professional users }\end{array}$ \\
\hline 2.4. & $\begin{array}{l}\text { The Web application interface should have the } \\
\text { look and feel of THAF's web site, and integrate } \\
\text { with the organization's main site smoothly }\end{array}$ \\
\hline
\end{tabular}

ArcGIS software was chosen for its functional capabilities. It offers a standardsbased platform for spatial analysis, data management, and mapping. Its scalability allows for data updates. In addition, ArcGIS Desktop 9.3 in particular provides tools needed for publishing geospatial data via the Web. ArcGIS Desktop 9.3 also supports a geodatabase that serves data storage and management and integrates rules and relationships to maintain integrity and reliability of spatial data with a consistent, accurate database. Furthermore, ArcGIS Desktop 9.3 ensures interoperability by offering a Geodatabase XML that allows geospatial information exchange between geodatabases and other 
external systems between ArcGIS users. The software was used to store and manage data about water springs in western Ethiopia with a potential to add more data or update the existing collection, thus take advantage of the scalability the software offers.

ArcGIS Server was used as an appropriate platform to develop and disseminate the created map application across the Web, as it allows for quick publication and easy user access of published services.

\subsection{System Design}

A system design was chosen based on an understanding of client requirements. The system enabled the dissemination of geospatial information about water spring locations and their status in the Sayo district, west Welega Province, Ethiopia. The system presents three major components: a desktop GIS that contains file geodatabase and software for map creation, an arcGIS server for storing and managing published map services, and a client-side browser (Figure 3-1). A file geodatabase was created using ArcCatalog, one of the ArcGIS desktop applications. Its main function is to store feature datasets, features and feature classes, relationship classes, annotation classes, spatial references, objects and object classes, validation rules, and geometric networks. ArcMap is another application of ArcGIS that supports editing tools and was used for rendering the map document.

A database was designed to maintain data consistency and integrity, reduce data redundancy, increase system performance, and maintain maximum user flexibility. The desktop GIS offered tools to prepare a map of spring locations. After spring location way points were collected from the Sayo District with a GPS, the data were entered and used to create a map document that was published and disseminated through the Web. A file geodatabase was used to store and manage data that was used to develop the Web map service.

ArcGIS Server is a second component of the system design and comprises two elements: a GIS server and a Web server. A Web server is responsible for storing and exchanging information with a browser. This transaction is possible by virtue of a communication protocol of the Web, HyperText Transfer Protocol (HTTP). A GIS server on the other hand, allows geospatial data to be stored, queried, and rendered from geodatabase tables as published services that can be consumed by Web browser-based end users. The GIS Server component of the system design hosts maps, and any other publishable data, and exposes them as services to client applications. The GIS server itself is composed of two distinct parts: the server object manager (SOM) and server object containers (SOCs). As the name implies, the SOM manages the services running on the server. When a client application requests the use of a particular service, it is the SOM that actually provides one for the client to use. The Web server hosts Web applications and services that use the resources running on the GIS server. 


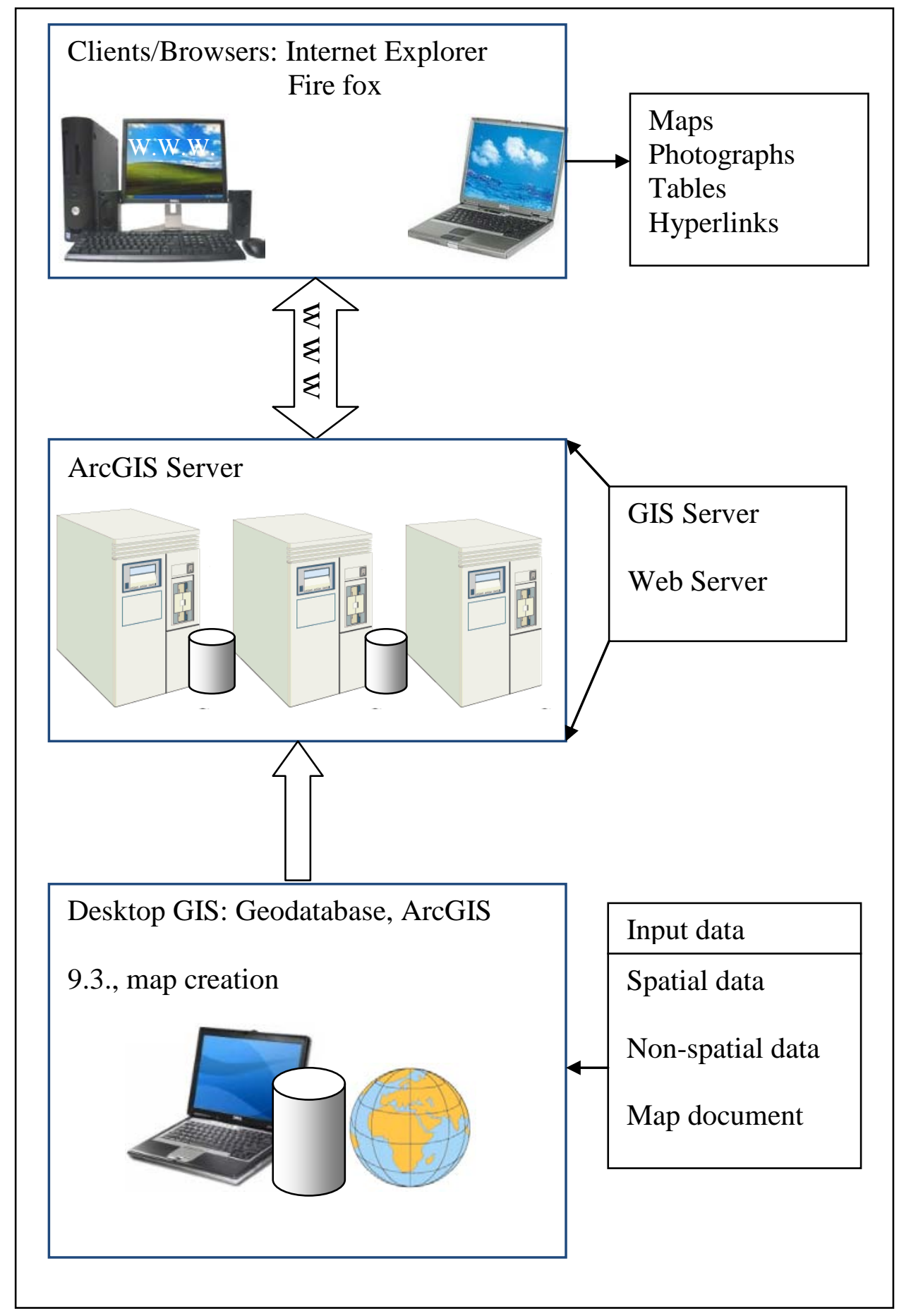

Figure 3-1: System design for the project

ArcGIS Server 9.3, used for this project, also includes JavaScript APIs as one of its parts. The use of JavaScript application programming interface (APIs) with ArcGIS Server serves to embed access to ArcGIS Server in the developed Web map application. All the code runs in the browser, and neither the client nor the Web server needs to have any GIS software installed. Clients in this system design context are defined as Web, 
mobile, and desktop applications that connect to ArcGIS Server Internet services or ArcGIS Server local services.

ArcGIS Desktop served to author the GIS maps and other GIS resources, including photographs of springs and non-spatial data that were then published. In this respect, ArcCatalog and ArcMap were the main ArcGIS Desktop applications used. Furthermore, it is worth mentioning that ArcCatalog was essential for creating cached map services.

\subsection{Project Plan}

The project plan was prepared to meet the client's needs. It was comprised of the following main phases:

- Initiation and requirement analysis

- Design and implementation

- Rollout

This plan highlights the major components of the project. Details about the major tasks involved, as well as a diagram of the project workflow, are detailed here.

\subsubsection{Initiation and requirement analysis phase}

Four main tasks were planned for the initial phase of the project. The first task involved the needs assessment. Through face-to-face and phone interviews with the client, the needs were described, and then a list of expected information products was generated and analyzed. The client described in detail information products he expected from the system. The third task was the system requirement analysis, which consisted of checking if the system requirements were met for the application to be developed. The last main task planned for this initial phase was the feasibility analysis that examined the constraints and opportunities involved in the realization of the project, as well as relevant approaches to address potential challenges to ensure the success of the project.

Since there were no data available, arrangements were made with the Tropical Health Alliance Organization for data collection in western Ethiopia. Data about freshwater spring locations and their status were then collected in the Sayo District from 14 December 2009 through 8 January 2010. The data were then organized in compliance with the needs assessment conducted at the beginning of the project. The process is outlined in Figure 3-2. 


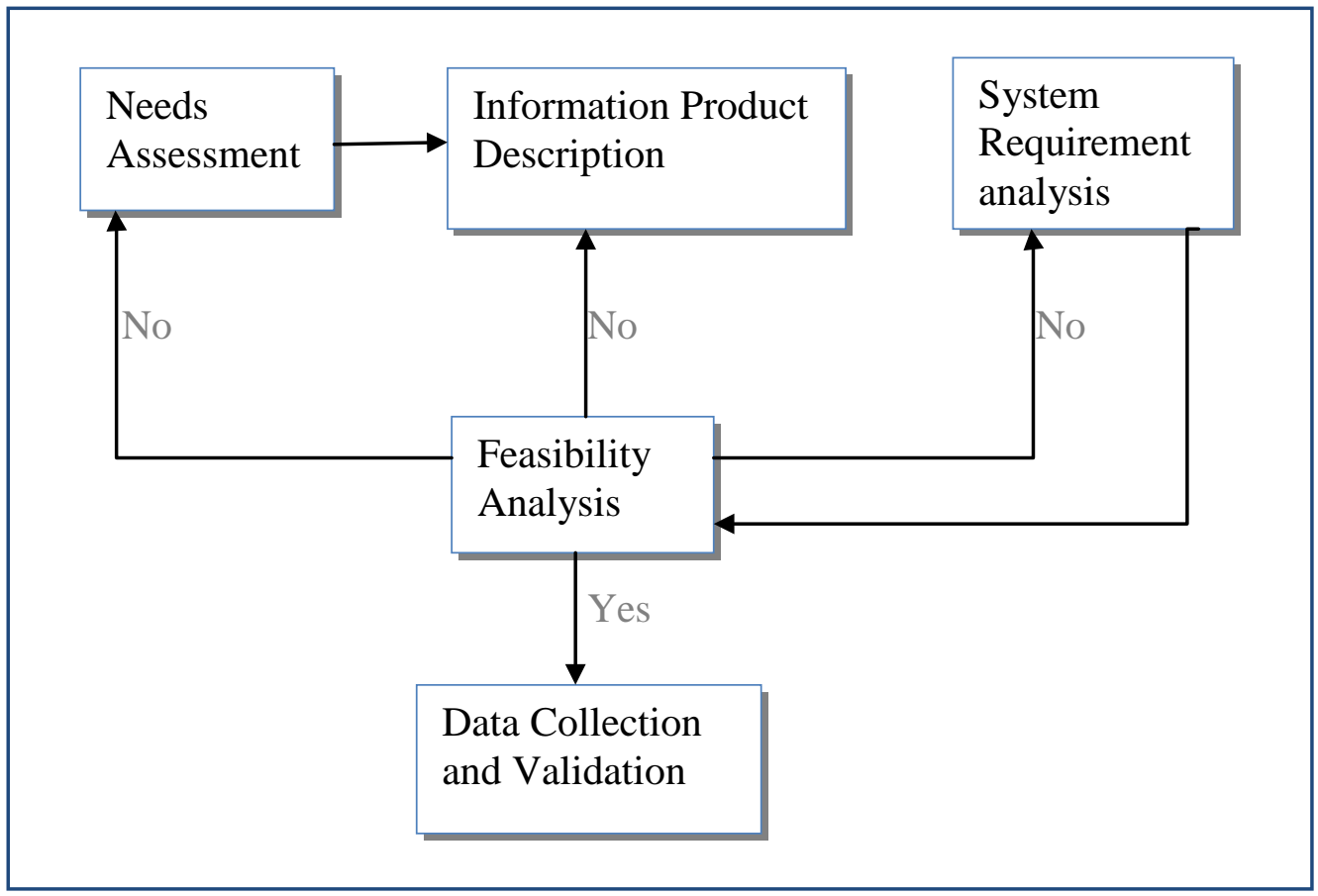

Figure 3-2: Initiation and requirement analysis workflow

\subsubsection{Design and Implementation phase}

The main focus for this step was the geodatabase and the Web map application design and development (Figure 3-3).

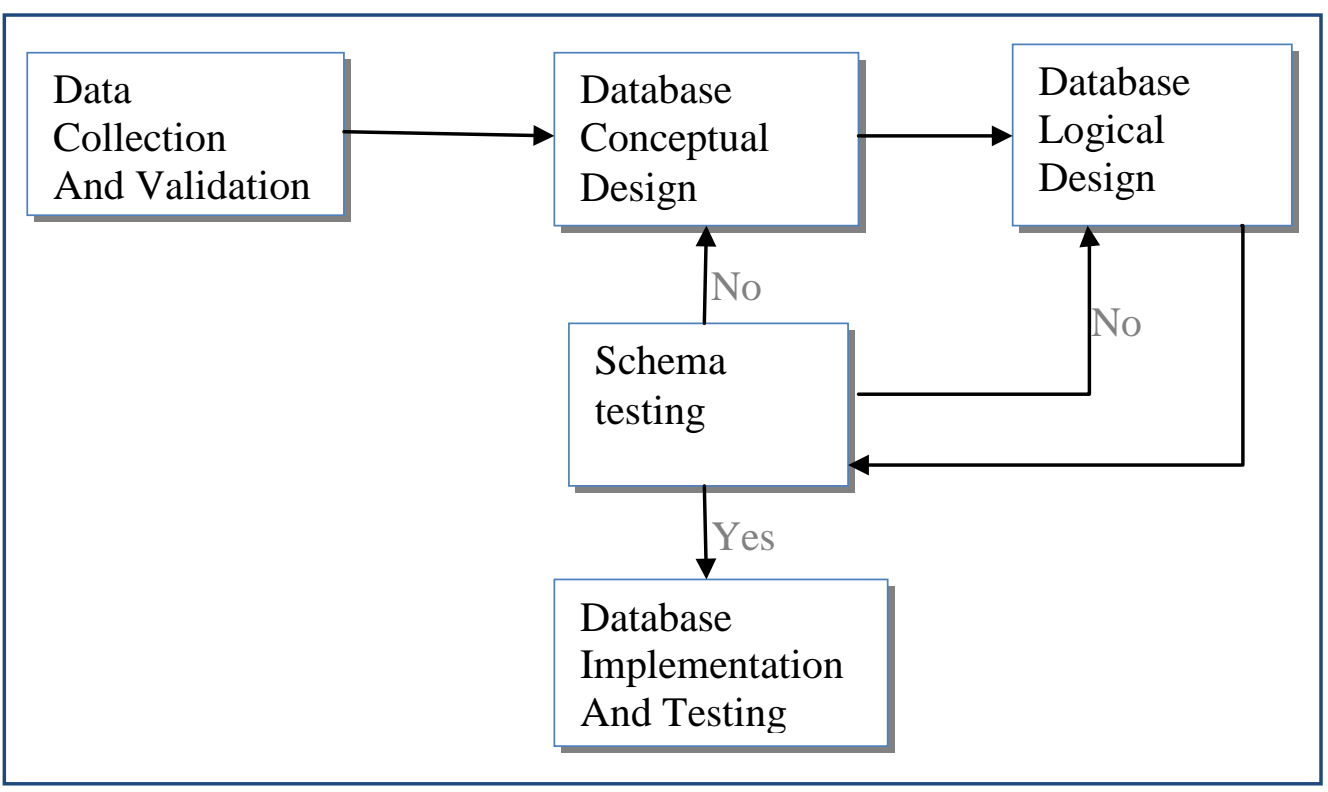

Figure 3-3: Database development workflow 
Prior to the physical design of the database, it was essential to develop its conceptual and logical models. A conceptual data model was designed to depict data structure and content and to describe entity classes, their attributes, as well as relationships involved, in the form of a schema. The logical design presented a detailed arrangement of the data into a logical structure, including data behaviors. The schema was discussed and approved. The greatest part of database development was collecting data in the field, since the client for the project did not have any data about spring location and status. The schema was analyzed and tested using the ArcGIS diagrammer tool.

Software and hardware were selected. ArcGIS Server 9.3 was used to develop the prototype and served as the platform for the web services. ArcGIS Desktop 9.3 was used to author the map before publishing. JavaScript application programming interface (APIs) served to embed access to ArcGIS Server and design a customized Web interface.

The Web map application prototype was tested by peers, the client for the project, and their feedback was implemented. Figure 3-4 outlines the main tasks involved in the Web GIS design and implementation workflow.

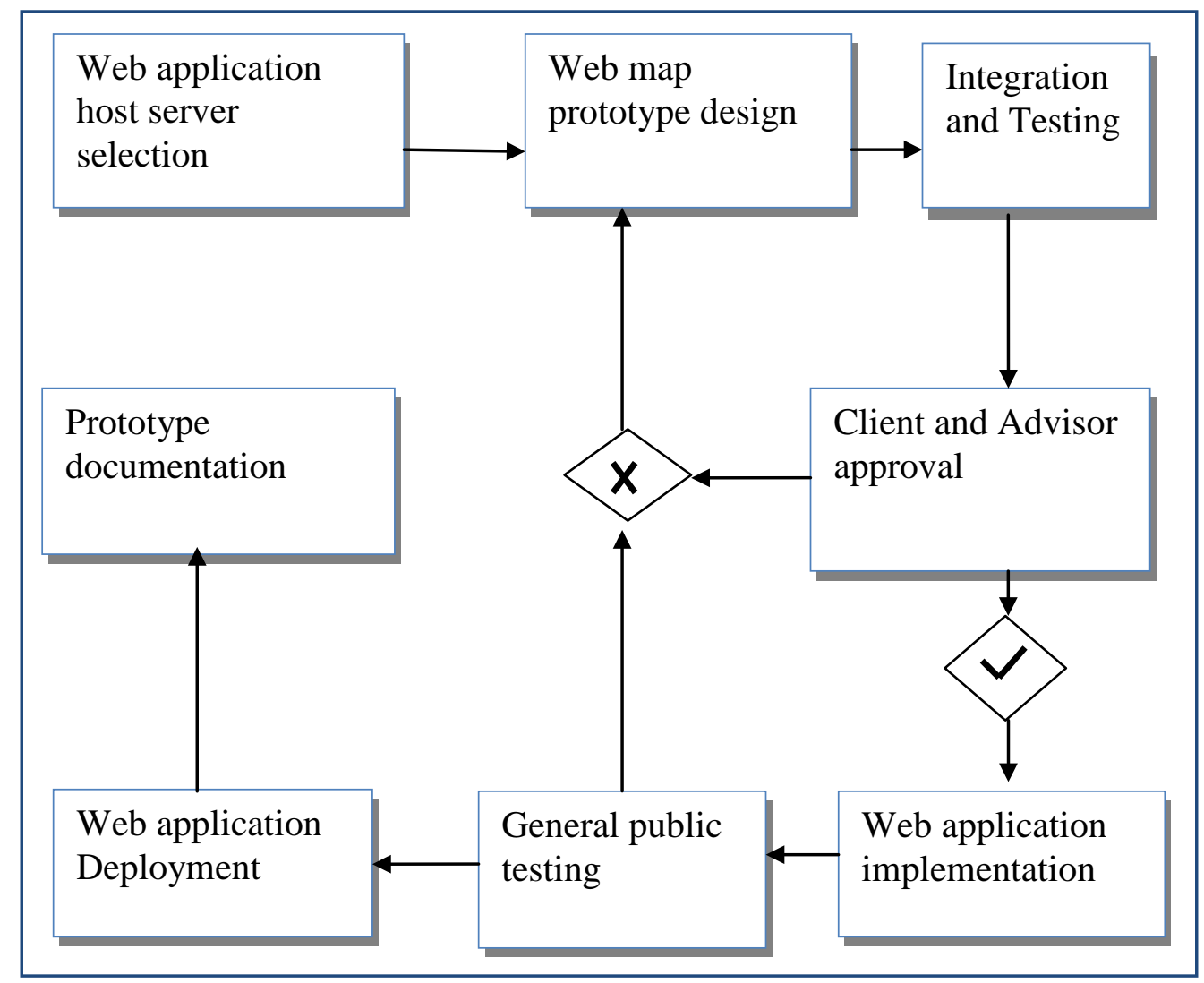

Figure 3-4: Web GIS Prototype Design and Implementation Workflow

\subsubsection{Rollout phase}

The rollout phase involved project documentation following a workflow illustrated by Figure 3.5. This stage included metadata creation, documentation of all the aspects of the 
projects in a report that highlighted the various steps of the preparation, development, implementation, and deployment of the project. A careful description of how the Web map application should be updated was documented. Additional presentations in a written form (posters) or oral ones (conferences) were planned as an opportunity to publicize the Web map application.

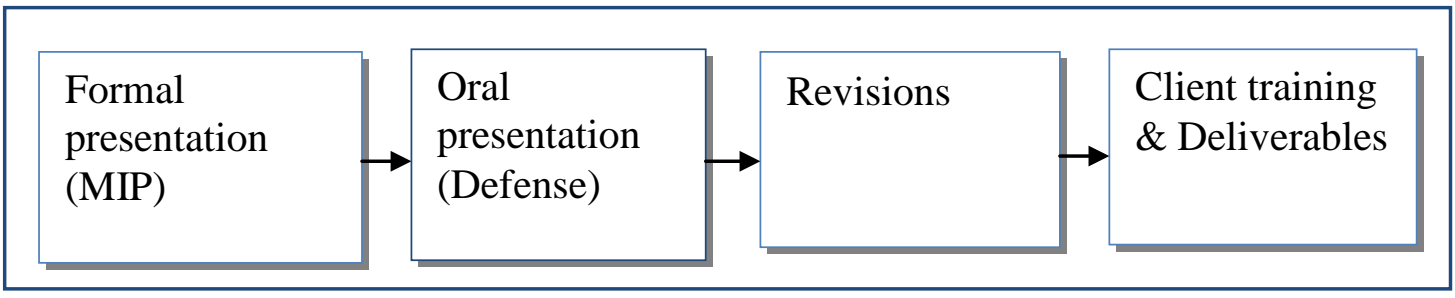

Figure 3-5: Documentation workflow

\subsection{Summary}

Following the client's needs assessment and the system analysis for the project, a system design was created to support dissemination of information about the location of freshwater springs and their status in western Ethiopia.

The system design highlighted the three major components essential for the creation of the required information products: a desktop GIS that supports ArcGIS 9.3 software to accommodate the geodatabase and to serve the creation of maps; an ArcGIS Server that supports a GIS server and a Web server to host and publish the map application, attributes and photographs about spring locations and their status, over the Web; and finally a client component which consists of a browser that requests the Web map application hosted by the server.

This chapter also described what the project plan was when the project started with a sequential workflow. There were three major phases of the project plan: the initiation and requirement analysis phase; the design and implementation phase; and the rollout phase. Major tasks and resources allocated to each phase were identified. A description of the plan execution demonstrated how it entailed changes that were not previously expected. 



\section{Chapter 4 - Database Design}

A database is essential for storing and managing organized data for a specific use. An effective database implementation involves two important steps: a conceptual database design and a logical database design. A database design was tailored to the requirements imposed by a Web map application design, to store geospatial and non spatial data. The design fit the requirement needs of the client by accommodating scalable feature datasets, feature classes, and tables and by supporting validation rules and relationships between database components. The selection of a database design was governed by the client needs requirement analysis, by the accessibility and availability of the system software for data storage and management, and also by the bulk and type of data, and the application data are intended for. The overall goal of database design was to allow the creation of a robust geodatabase that would serve the Web map application development and deployment by ArcGIS Server. This chapter describes data design models, data collection methods, as well as how data was cleaned-up and loaded into the geodatabase.

\subsection{Conceptual Data Model}

The conceptual model was designed to meet the goals of this project. The model identified and described the entities required for the database, their integration, and their relationships (Figure 4-1).

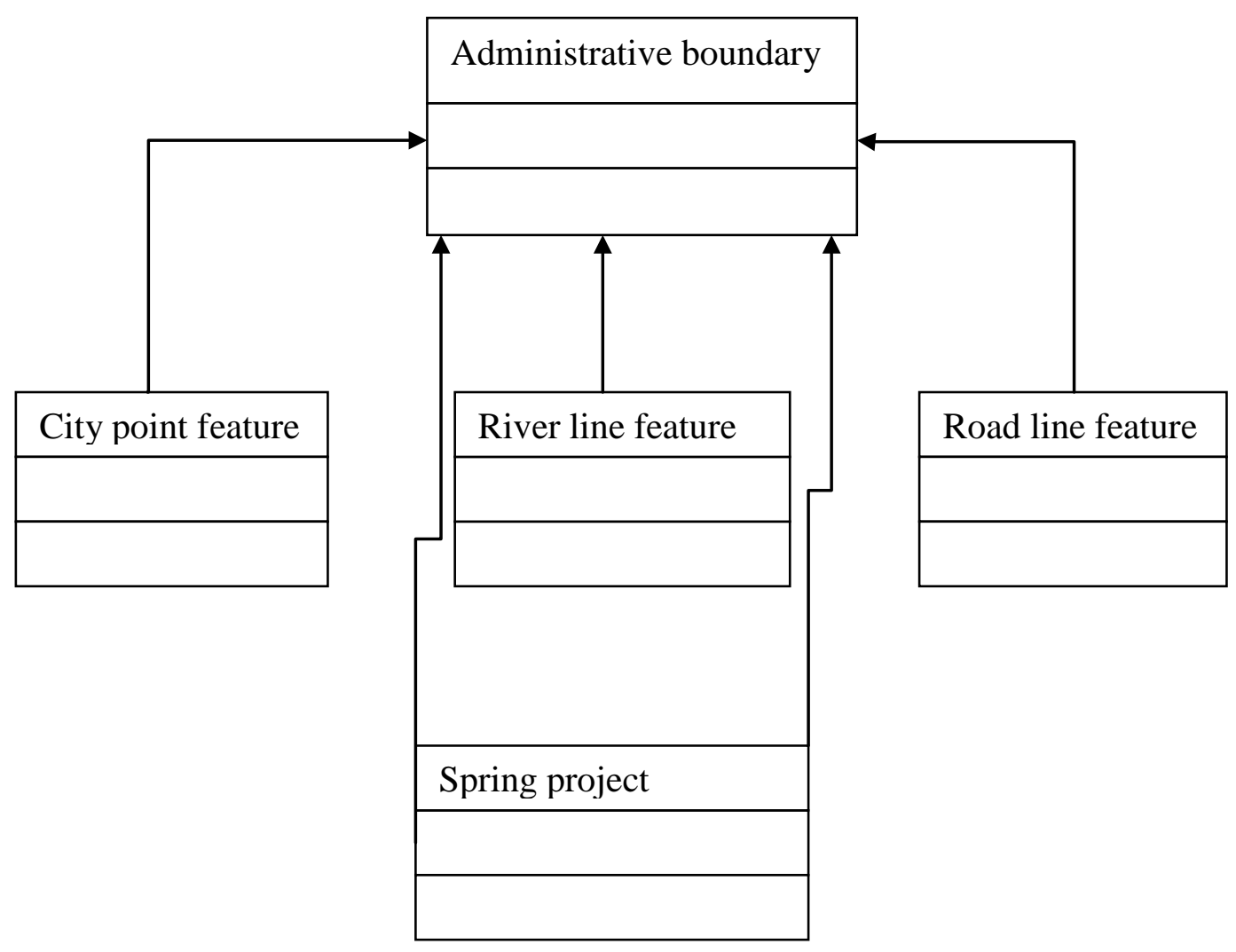

Figure 4-1: Main components of the conceptual model 
The design was to fit with data needed to generate required information products. A Unified Modeling Language (UML) model was used to depict a conceptual design for this project. The main components described by this model include a spring class, a West Welega Province boundary, Dembidolo, roads, and rivers. These entities were organized into sketches of class diagrams with attributes and associations as properties for defined classes. Actual information products expected from the project were generated by the Spring entity. Roads, rivers, Dembidolo town served orientation and display purposes.

\subsection{Logical Data Model}

In this section, entities defined in the previous section are presented in detail (Figure 4.2). Feature classes and tables required for the Web-GIS implementation are described.

The Microsoft Office Visio 2007 supports a Unified Modeling Language (UML) that was used to develop a logical data model for this project. UML helps define the class attributes and set relationships and cardinality rules between classes. This step made a transition towards a physical ArcGIS Geodatabase that actually was essential for the implementation of the Web GIS application for this project. The first component of the database design is the administrative boundary entity. It is a polygon feature class and comprises two classes: Ethiopia national boundary and the province boundary. This component served to indicate where surveyed springs are located. The second component consists of a point feature of Dembidolo town. This again gives a better orientation to the location of the springs in Sayo District. This is complemented by two additional line feature classes: a road line feature and a river line feature classes. Finally, the fourth and the most important component of the database design is the Spring class. This feature class has the following attributes: "Spring ID" attributes that uniquely and unequivocally identifies each individual row in the spring attribute table. Values of the primary key are of "double" type. The design is such that no null values are allowed. This ensures that every spring recorded has an identity to allow querying.

Latitude and longitude coordinates are included in the attribute table. It was essential display spring location coordinates. In fact, since there is no detailed road map available at the district level, visits to any particular spring of interest would require the use of a GPS unit. Values in this field are of "float" type since they represent coordinates in decimal degree units.

The “Spring_Name”, “Location_Village”, “Location_Kabale” are other three attribute fields. They are of "text" type with a length set to a maximum of 20 characters to avoid long texts in the field. The importance of these fields is twofold. First, governmental and non -governmental agencies, individuals or any other stakeholder who is interested in monitoring, visiting, or protecting can use that information to access to any particular spring by just asking villagers or local authorities. Second, a query can easily help identifies which springs are in which village or Kabale, or which and how many springs are located in a given village. It is worth mentioning here that Kabale is a sub-unit of a district. A district is composed of many Kabale.

The "Status" field describes the condition of springs in terms of whether any particular spring is protected or not. Being protected basically means that water is collected and distributed through a system of pipes so that it comes out clean. The attribute values are in a form of a text with a maximum length of twelve character, long enough to accept "Protected" or "Unprotected" text length as the only option. Notice that 
this field does not allow null values, because a spring is either protected or not. This setting makes the query much easier and avoids errors and ambiguity.

The "No_Households" is a "double" data type field and it refers to the number of households served by any given spring. The "Outflow" field is also a "double" data type field that refers to the number of liters of water discharged per minute for a given spring. The "Sponsor" field is in a form of a text and captures information about organizations or individuals who funded the protection of any particular spring. This information includes the name and an email address and/or a telephone number. This field allows a maximum of 50-character text to comply with the requirements of the sponsor's information.

Lastly, the "Photo" field captures the names of photographs files that were linked to in a client side JavaScript code. A photograph folder is stored in C: IInetup $\backslash$ wwwroot $\backslash$. This field allows for null values because the photo might not be available yet or might be of bad quality and needs to be replaced.

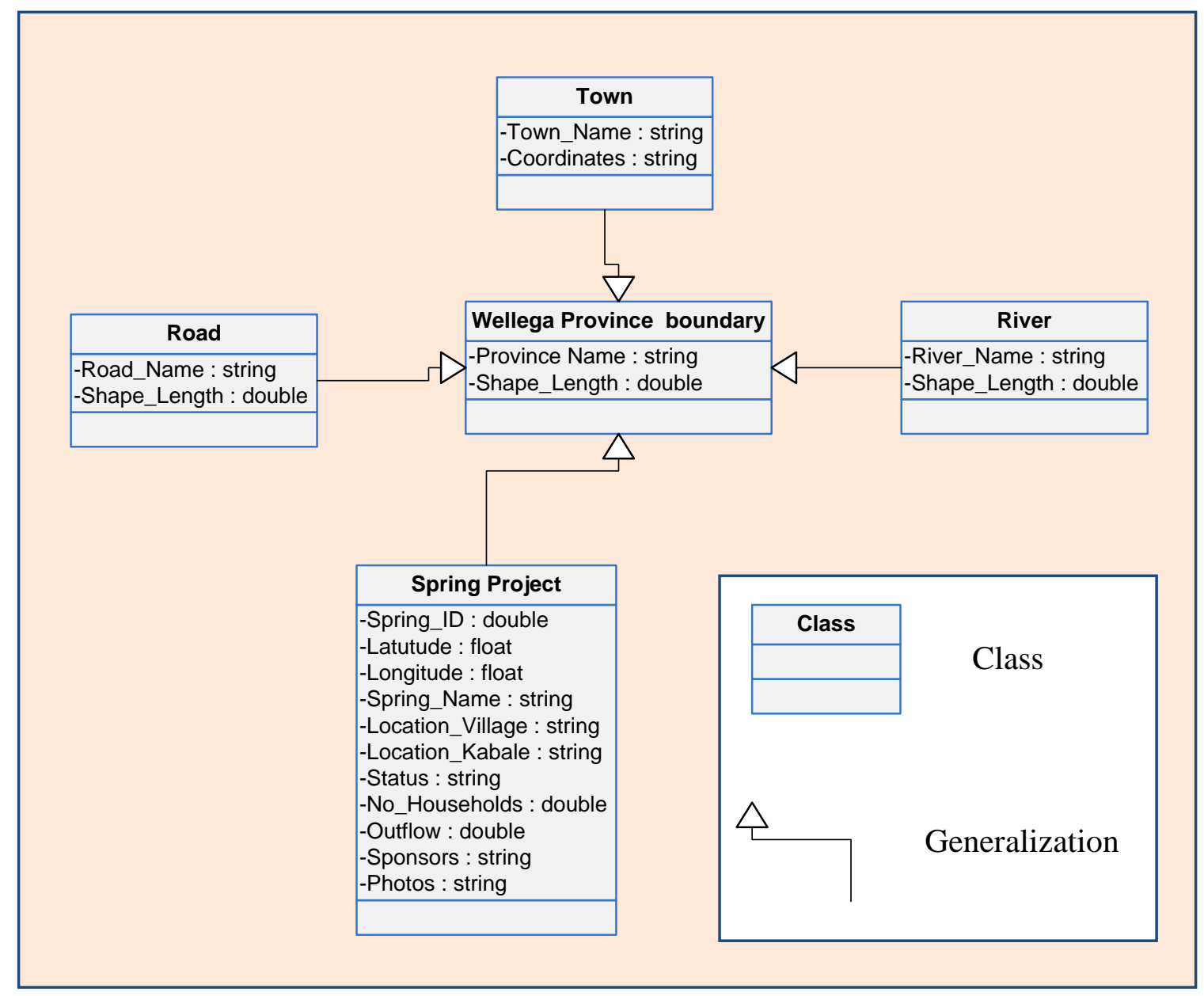

Figure 4-2: UML model of the Spring Project

The representation of the conceptual model in the GIS's logical model did not require any major compromises. A file geodatabase from ArcGIS Desktop 9.3 was 
selected and set to support the design. Nevertheless, tables and shapefiles attributes had to be defined according to the schema supported by the geodatabase. Springs fields attributes (Table 4-1), roads, rivers, and province boundary fields' attributes and properties were defined (Table 4-2, Table 4-3, and Table 4-4) to ensure data integrity and improve the performance of the database.

Table 4-1. Springs fields attributes

\begin{tabular}{|c|c|c|c|c|}
\hline Field Name & $\begin{array}{l}\text { Data } \\
\text { Type }\end{array}$ & $\begin{array}{l}\text { Allow NULL } \\
\text { Values }\end{array}$ & $\begin{array}{l}\text { Default } \\
\text { Values }\end{array}$ & Length \\
\hline OBJECTID & Object ID & & & \\
\hline Shape & Geometry & Yes & & \\
\hline Spring_ID & Double & No & & \\
\hline Latitude & Float & No & & \\
\hline Longitude & Float & No & & \\
\hline Spring_Name & Text & No & & 20 \\
\hline Location_Village & Text & No & & 20 \\
\hline Location_Kabale & Text & No & & 20 \\
\hline Status & Text & No & Unprotected & 12 \\
\hline No_Households & Double & No & & \\
\hline Outflow & Double & Yes & & \\
\hline Sponsors & Text & Yes & & 50 \\
\hline Photos & Text & Yes & & 15 \\
\hline
\end{tabular}

Table 4-2. Road line feature class fields and properties

\begin{tabular}{|l|l|l|l|}
\hline Field Name & Data Type & $\begin{array}{l}\text { Allow NULL } \\
\text { Values }\end{array}$ & Shape \\
\hline OBJECTID & ObjectID & & \\
\hline SHAPE & Geometry & Yes & Line \\
\hline SHAPE_Length & Double & Yes & \\
\hline
\end{tabular}


Table 4-3. Province boundary polygon feature class fields and properties

\begin{tabular}{|l|l|l|l|}
\hline Field Name & Data Type & $\begin{array}{l}\text { Allow NULL } \\
\text { Values }\end{array}$ & Shape \\
\hline OBJECTID & ObjectID & & \\
\hline SHAPE & Geometry & Yes & Line \\
\hline SHAPE_Length & Double & Yes & \\
\hline SHAPE_Area & Double & Yes & \\
\hline
\end{tabular}

Table 4-4. River linear feature class

\begin{tabular}{|l|l|l|l|}
\hline Field Name & Data Type & $\begin{array}{l}\text { Allow NULL } \\
\text { Values }\end{array}$ & Shape \\
\hline OBJECTID & ObjectID & & \\
\hline SHAPE & Geometry & Yes & Line \\
\hline SHAPE_Length & Double & Yes & \\
\hline River_Name & Text & Yes & \\
\hline
\end{tabular}

\subsection{Data Sources}

The data used to create this Web map application came directly from field work. These data include spring location coordinates, their attributes, related demographic information, and photographs identifying a spring's condition. Data that served for the background were retrieved directly or indirectly from ESRI ArcGIS online Web services. These include satellite imagery, a street map from which arteries of interest were digitized, and a topographic map from which other roads and rivers were digitized. Metadata for ESRI online data was included in the service, but metadata about spring data was developed in the course of this project since no data about springs in western Ethiopia existed before.

\subsection{Data Collection Methods}

Data used in this project was primarily collected directly from the field. Other data used was obtained from secondary sources provided by ESRI online services. A GPS receiver device was used to collect data about spring point locations. Latitude and longitude coordinates were recorded using decimal degree units, since ArcMap 9.3 can display spatial data using latitude and longitude in those units. Prior to visits into the field, the local government, in conjunction with the local Catholic Church Mission based in Dembidolo town facilitated the gathering of information about springs in the Sayo District. This information was about the spring's local names, its location, as well as the number of households served by each spring. They would also provide a brief description of the status of the springs. This was coupled by the fact that, during field visits, at least one church leader and one local government agent or any other educated person who was acquainted with the area and could provide needed information about a particular spring 
helped with data collection. At each site spring visit, village elders or other educated people would provide necessary information. This information was checked against the one that had earlier been submitted to the church mission and checked by the local government. For every spring, at least one photograph was taken that shows the status of the spring. Data were recorded on hard paper forms in a format illustrated by Table 4-5.

Table 4-5. Data sheet format

\begin{tabular}{|l|l|l|l|l|l|l|l|l|l|l|l|l|l|l|}
\hline $\begin{array}{l}\text { Date } \\
\text { Tim } \\
\mathrm{e}\end{array}$ & $\begin{array}{l}\text { Sprin } \\
\mathrm{g} \\
\text { name }\end{array}$ & $\begin{array}{l}\text { X, Y } \\
\text { coor- } \\
\text { dinate } \\
\mathrm{s}\end{array}$ & $\begin{array}{l}\text { Village } \\
\text { locatio } \\
\mathrm{n}\end{array}$ & $\begin{array}{l}\text { Kabal } \\
\mathrm{e}\end{array}$ & \multicolumn{2}{l}{$\begin{array}{l}\text { Names } \\
\text { of }\end{array}$} & \multicolumn{2}{l}{$\begin{array}{l}\text { Number of } \\
\text { Villages } \\
\text { household } \\
\text { s served } \\
\text { served }\end{array}$} & $\begin{array}{l}\text { Protecte } \\
\text { d by } \\
\text { whom? } \\
\text { When? }\end{array}$ & $\begin{array}{l}\text { Water } \\
\text { discharg } \\
\text { e }\end{array}$ & $\begin{array}{l}\text { Trave } \\
\text { I } \\
\text { (mn) }\end{array}$ \\
\hline & & & & & 1 & 2 & 3 & 1 & 2 & 3 & & & \\
\hline & & & & & & & & & & & & & & \\
\hline & & & & & & & & & & & & & \\
\hline
\end{tabular}

The water discharge per minute was measured for every spring using local containers the volume of which was known.

In some cases, a spring was not running, and then a different method would be used. A known water volume would be drawn from the spring natural collection reservoir, all at once, and then time for refilling from level $\mathrm{A}_{2}$ back to level $\mathrm{A}_{1}$ would be measured (Figure 4.3).

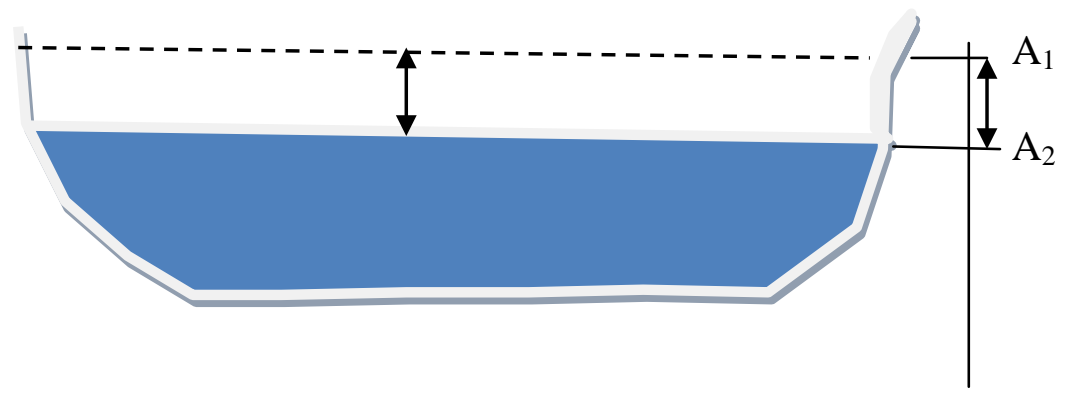

Figure 4-3: Water discharge measuring

Photographs of springs were taken using a digital camera. Date and time every picture was taken were recorded and were associated with the coordinates in order to keep pictures organized. At least one photo was taken for every spring. Therefore, it was possible to select the best pictures to use in the Web application implementation. Pictures were downloaded into a laptop computer at the end of every fieldwork day.

A total of 92 springs were surveyed and were found located in 71 villages, serving an estimated 6,342 households. Sixty-two springs were unprotected, and 30 were protected at different levels. Some had a complete set of structures required for standard spring protection, including a head structure, a collection point, a reservoir, a distribution point, and a washing slab. Some others lacked one or many of these basic structures. 
Unprotected springs were located in 53 villages. Protected springs were only located in only 27 villages. The water discharge ranged between 36 and 1.25 liters per minute.

\subsection{Data Scrubbing and Loading}

First, surveyed data was entered into a Microsoft Excel spreadsheet. Data scrubbing consisted of correcting errors detected during the process of data clean-up. This step was essential for preparing data before they were loaded into the file database. Only attributes required to make the information product for the project were prepared and organized in corresponding fields. Those attributes include latitude and longitude coordinates, names of springs, their villages and Kabales of location, their protection status, a number of households served by each spring, water discharge, and names of photograph files. Unnecessary data were left out. These include detailed information about the names of villages served by each spring as well as the number of households served from each of those villages. Primary keys that uniquely identify springs were defined and created. A thorough check was done to remove redundancies within records, to fill in unnecessary gaps , and to make sure that values in every field were conformed with defined data type (Figure 4-4). A final result of the data as loaded in a file geodatabase is illustrated in Appendix E.

\begin{tabular}{|c|c|c|c|c|c|c|c|c|c|c|}
\hline \multicolumn{10}{|c|}{ ⿶ㅣㄹ Spring_Ethiopia.xlsx } & \multirow{2}{*}{$\begin{array}{cc}- & x \\
& =\end{array}$} \\
\hline 4 & A & B & C & D & E & $\mathrm{F}$ & G & $\mathrm{H}$ & 1 & \\
\hline 1 & Spring_ID & Latitude & Longitude & Spring_Name & Location_Village & Location_Kabale & Protected & N0_Households & Water_discharge & Photos \\
\hline 2 & 1 & 8.52298 & 34.82797 & Badessa & Kasea wachu & Ifa Galaanoo & No & 90 & 9.9 & img1.JPG \\
\hline 3 & 2 & 8.56583 & 34.80025 & Yase & Jaarsoo & Yaangi & Yes & 73 & 10.3 & img2.JPG \\
\hline 4 & 3 & 8.52754 & 34.83374 & Tinga & Onu & Ifa Galaanoo & No & 60 & 7 & img3.JPG \\
\hline 5 & 4 & 8.53072 & 34.83314 & Mume & Jarso & Hacalaanoo & No & 40 & 5.2 & img4.JPG \\
\hline 6 & 5 & 8.49412 & 34.83315 & Mitiko Meleta & Bocoloo & Danka parish & No & 42 & 4.9 & img5.JPG \\
\hline 7 & 6 & 8.44631 & 34.84415 & Laga badu & Laga badu & Walgai bubuka & Yes & 70 & 13 & img6.JPG \\
\hline 8 & 7 & 8.45695 & 34.85967 & Butuji & Butuji & Walgai bubuka & Yes & 150 & 7.8 & img7.JPG \\
\hline 9 & 8 & 8.5783 & 34.84663 & Dawoshulki & Limo & Amomekail & Yes & 170 & 13.2 & img8.JPG \\
\hline 10 & 9 & 8.58001 & 34.81893 & Hachoo & Suphinsa & Aleku Abboo & No & 76 & 6.6 & img9.JPG \\
\hline 11 & 10 & 8.58052 & 34.83809 & Totto & Kota'o & Aleku Abboo & Yes & 120 & 7 & img10.JPG \\
\hline 12 & 11 & 8.63989 & 34.80976 & Chancho & Dinbanko & Aleku Abboo & Yes & 30 & 5.1 & img11.JPG \\
\hline 13 & 12 & 8.63322 & 34.80663 & Walamo & Walamo & Aleku Abboo & No & 25 & 6.3 & img12.JPG \\
\hline 14 & 13 & 8.64508 & 34.81948 & Lagaa Adii & Baru & Ambela & No & 40 & 7.9 & img13.JPG \\
\hline 15 & 14 & 8.63571 & 34.79581 & Chai & Aleku Abboo & Aleku Abboo & Yes & 23 & 6.7 & img14.JPG \\
\hline 16 & 15 & 8.64375 & 34.8141 & Danissa Handagwe & Aleku Kaisa & Aleku Kaisa & Yes & 22 & 8 & img15.JPG \\
\hline 17 & 16 & 8.64371 & 34.81428 & Danissa (Spring on Spot) & Aleku Kaisa & Aleku Kaisa & Yes & 30 & 9 & img16.JPG \\
\hline 18 & 17 & 8.63943 & 34.81385 & Danissa3 & Aleku Kaisa & Aleku Kaisa & Yes & 80 & 9.7 & img17.JPG \\
\hline
\end{tabular}

Figure 4-4: A screenshot of an Excel spread sheet prepared for data loading

\subsection{Summary}

This chapter described the conceptual and logical design of the database. An effective physical database design depends largely on the logical design and a compromise is essential between both to ensure compatibility in format and style. A UML database model was selected to show how objects and object classes are organized and related to each other in a dataset. The choice for the design was driven by the client's requirement analysis and the foreseen availability of the system design to integrate the model. Components of the database design and data source were exhaustively explained. The backbone of the data was from a 
primary source, since the client did not have any data readily available to process. Data collection and preparation methods were documented so that the reader can easily replicate the same approach and expect similar results. It is important that the format of the to be loaded can be easily integrated by the database system that will process the data. A brief summary of findings was also presented to offer a panoramic picture of results and patterns. 


\section{Chapter 5 - Implementation}

This chapter describes in more details the implementation aspect of the steps discussed in Chapter Three. The main topic discussed in this chapter is the implementation of a geodatabase and a Web-based GIS prototype application. It builds on the problem statement, requirements analysis, and the system design to meet the client requirements. A rationale for the selection of a file geodatabase that is supported by ArcCatalog is offered. The geodatabase schema was created and analyzed and validated. Data loading using ArcTool Box in ArcCatalog environment, map document authoring and publishing to ArcGIS Server using ArcMap, applications of ArcGIS 9.3.1, are further detailed. In addition, the chapter looks at the process of the Web application configuration and customization through JavaSript API integration, after the map document was authored and published to the ArcGIS Server.

Details on steps involved in the creation of the map service using ArcCatalog from ArcGIS 9.3, and the creation of a user-friendly client-side interface are presented. A particular attention is drawn to the development of specific tasks and information products required of the Web map application to satisfy the user needs as initially defined in the project plan. This chapter is of a particular interest for GIS professional or novice. It unveils, step by step, in a clear and understandable language, what was done to successfully implement the project plan, so that, using similar data sets, the work can be replicated and generate similar results.

\subsection{Database implementation}

As indicated previously, a file geodatabase was selected to support the physical design of the database. The selection was dictated by the following factors: (1) a greater data storage compared to a personal geodatabase that can only hold no more than two gigabytes, (2) scalability property allowing the client to further populate for expansion purposes and update data as needed since the study area covered by this project served just as a starting point, (3) capability to support geospatial data including map projections and transformations options, (4) capability to govern the behaviors of datasets, feature classes, and tables used in the geodatabase, (5) the handling of data in a relational database management system which offer the advantage of storing, querying, manipulating, and managing geographic information and spatial data, and finally (6) the capability to package the data and/or the schema in an Extensible Markup Language (XML) format that can be transferred through the Web to other GIS users or directly to other geodatabases including particularly the ArcGIS Server geodatabase that was used to publish the Web map application for this project .

The file geodatabase fit the requirements of the logical design described in Chapter Four of this document and it is fully supported by ArcCatalog. In order to ensure the reliability and a satisfactory performance of the implemented geodatabase, its schema was analyzed using ArcGIS Diagrammer, a productivity tool for GIS professionals to create, edit or analyze geodatabase schema as will be further demonstrated in this chapter. The schema analysis was implemented for the spring project and imperfections were fixed before the data was actually loaded into the geodatabase. Figure 5.1 illustrates, 
in a screenshot, the results of the geodatabase schema analysis for the spring project , using ArcGIS Diagrammer.

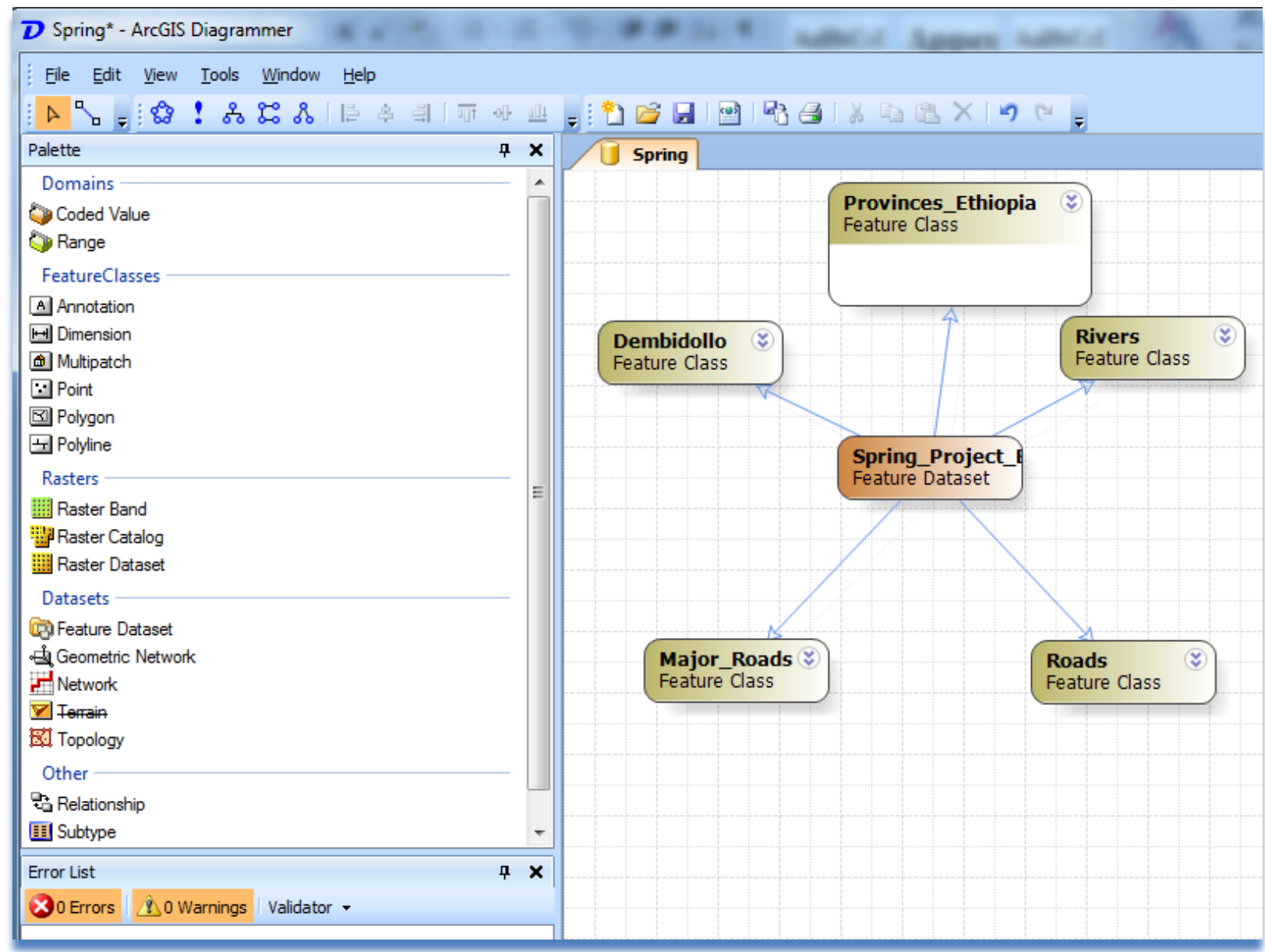

Figure 5-1: Schema report created using ArcGIS Diagrammer

\subsection{Geodatabase Loading}

The spring data collected from the field were initially recorded on hardcopy data sheets, and then they were entered in a digital format in an Excel spreadsheet. Latitudes and longitudes coordinates were in decimal units in order to be easily integrated by ArcGIS, therefore data conversion was not necessary. However, care was taken to ensure the consistency and correctness in data entry, while maintaining the format assigned to every field as defined in the logical model.

The length and type of data were set for every field to improve querying performance and to minimize errors during the updating and the adding of new data in the future. Data entry met the logical design of the database. Gaps in data were carefully checked. Primary keys were assigned to springs in order to uniquely identify every individual spring. When the data clean-up was completed, the loading process was initiated. 
Spring data contained in the Excel spreadsheet was loaded using ArcToolbox (Figure 5.2). A Table to Table tool from the Conversion Tools was selected. The entered Excel spreadsheet was loaded by navigating to its location. This location was the same as the file geodatabase created. The output for the loaded spreadsheet was set to be in the created geodatabase. The advantage of using this tool is that you can delete fields that are not needed for the geodatabase and keep the required ones. The same results can be achieved by directly importing a table into the geodatabase, the process requires the same Table- to-Table tool in order to execute successfully.

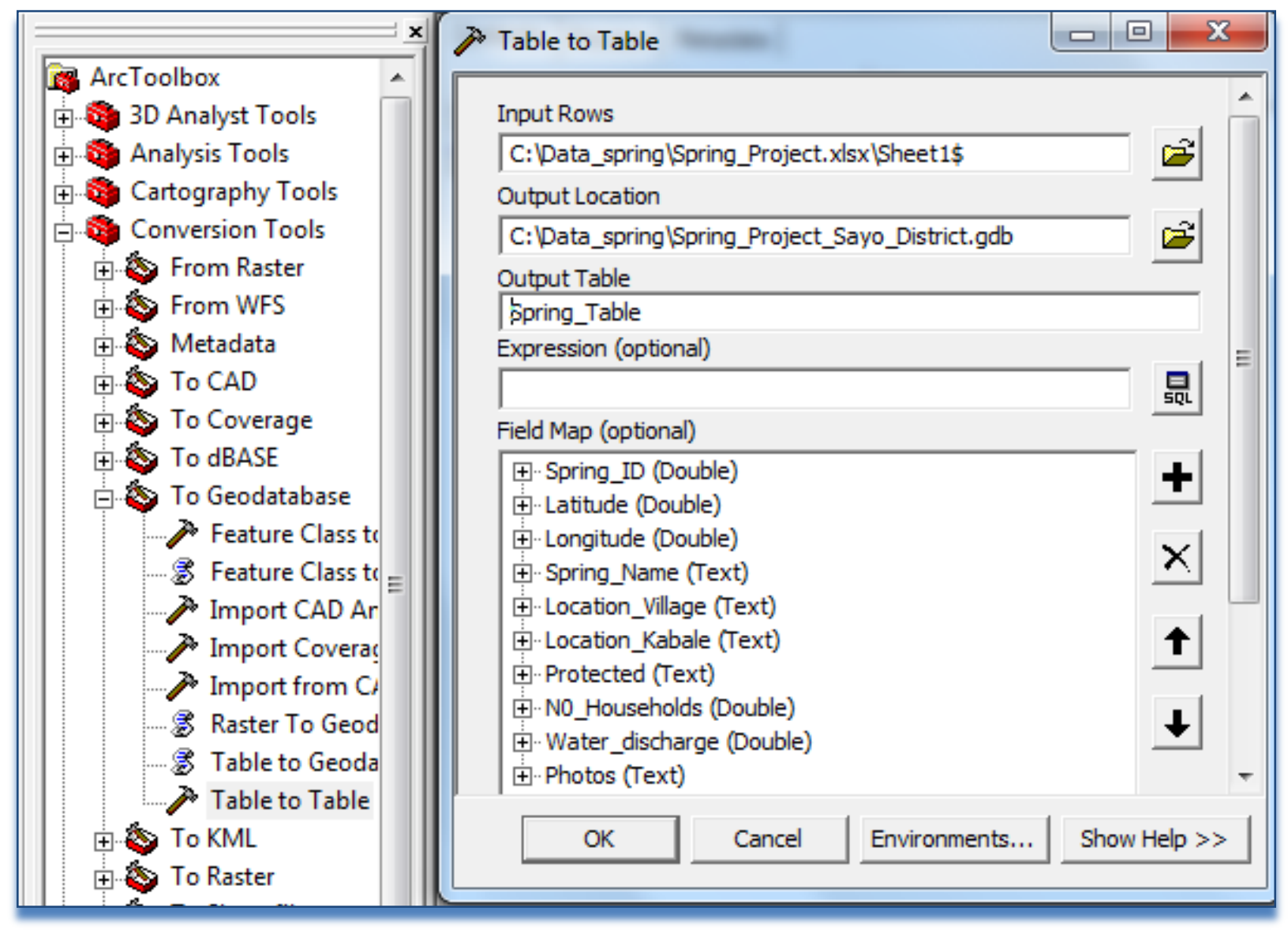

Figure 5-2: Loading the spring table into a file geodatabase

Stored data was further loaded from the Geodatabase into ArcMap to create a spring shapefile. First a new empty map was opened and saved in the geodatabase under the name "Ethiopia Spring Project". The spring table was added as XY data by navigating to its location in the geodatabase and loading it. A Geographic Coordinate System was set to GCS_WGS_1984 since this is the one used by ArcGIS Server to publish Web map applications. 


\subsection{Map Document Authoring}

In order to make effective map documents that were published to ArcGIS Server, it was necessary to author the map in ArcMap. The advantage of working in ArcMap environment is that layer files support symbology rendering, attributes as well as other data properties that include the projection and the coordinate system, within the geodatabase framework. Spaces or special characters in data frame or layer names were avoided simply because ArcGIS Server cannot interpret the spaces or special characters. The fill colors of Ethiopia national boundary and provinces shapefiles were set to hollow and outlines were assigned a white color to establish a contrast with the background satellite imagery. ArcMap environment allows the conversion of the spring XY Event Source into a shapefile and subsequent discriminative retrieval of protected and protected springs by creating new shapefiles for each one. A query builder tool was used to create protected and unprotected spring shapefiles respectively (Figure 5.4). The creation of these two shapefiles allowed a customized rendering of the symbology for each of the layers. Once the Web map application published, the symbols were displayed on the map. By clicking on a symbol, depending of the choice of the target spring type for query, the point feature represented by a symbol would display related attribute information, embedded in an easy-to-understand information pop-up.

The symbols were made identical. Simple marker symbols such as circles and squares are best suited. They are optimized to appear quickly. The right symbols were picked after checking how quickly they are rendered on the screen and that they are standard for the geographic maps as supported by Fowler and Stanwick (2004). A legend for symbols used was also provided to facilitate map reading and querying. Cartographic standard lines with properties of width color were used for rivers and roads, in light of suggestions by Zeiler (1999). The only distinguishing aspect between spring symbols was the color assigned to each one of them. 


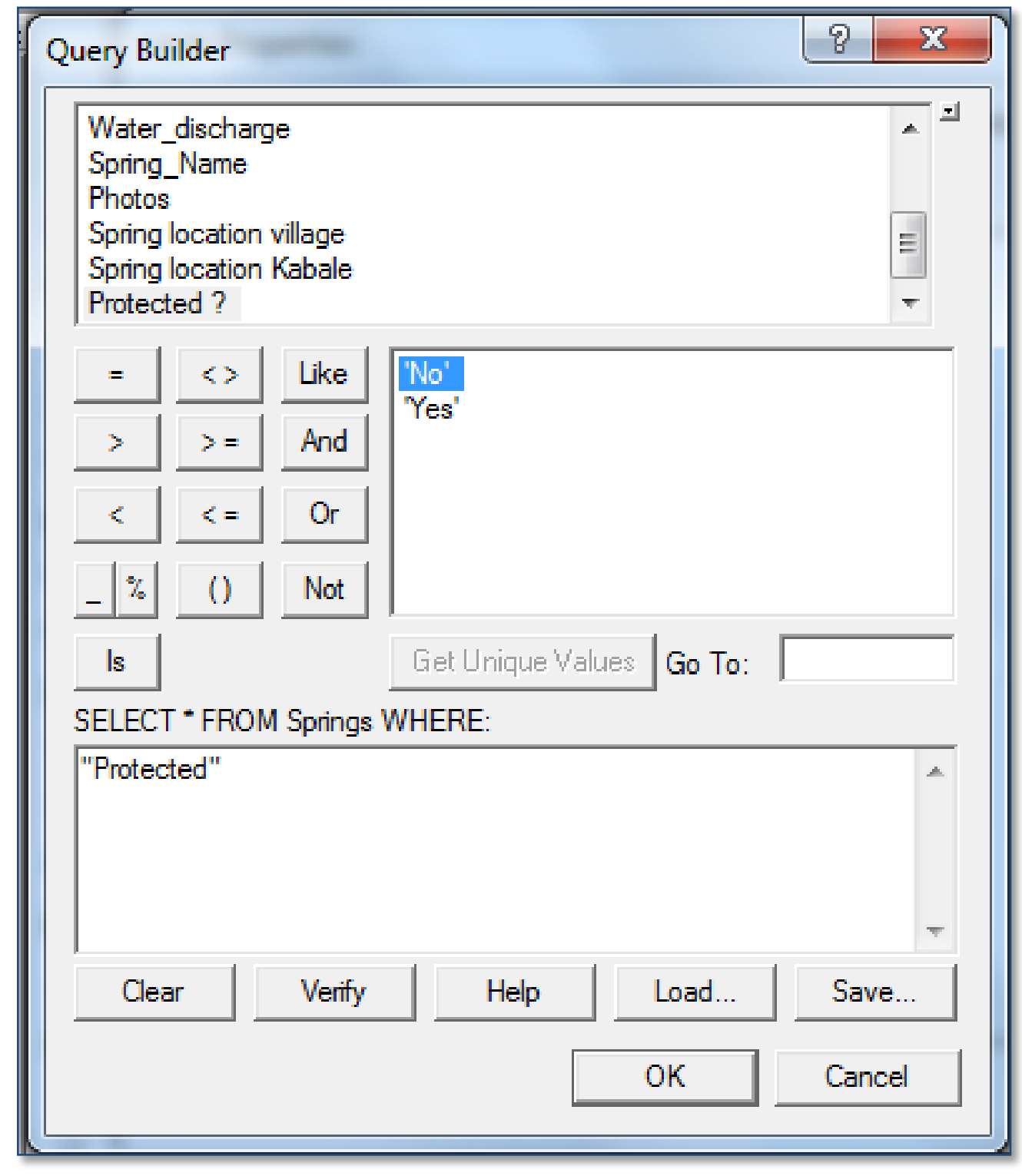

Figure 5-3: Creating protected and unprotected spring layers

Initially, the symbology to be used would be created from pictures and customized to reflect springs without any accompanying legend and therefore facilitate intuitive navigation, but it was decided that a simple solid circle symbology was more convenient to ensure a better performance. Spring point features represented the backbone of the Web map application and the other layers added represented a secondary importance.

Layers of the following features classes were added to the map document: a point feature class of Dembidolo town, a linear feature classes of roads, an Addis-Ababa Gambela major road, and rivers; and finally a polygon feature class of provinces that included Welega province. These secondary data reinforced the satellite imagery that was used as the main base map after the Web application was published on the server. In order to avoid overloading the database and increase the performance, only the most 
important features were retrieved from ArcGIS online street maps and topographic maps by digitizing (Figure 5-5).

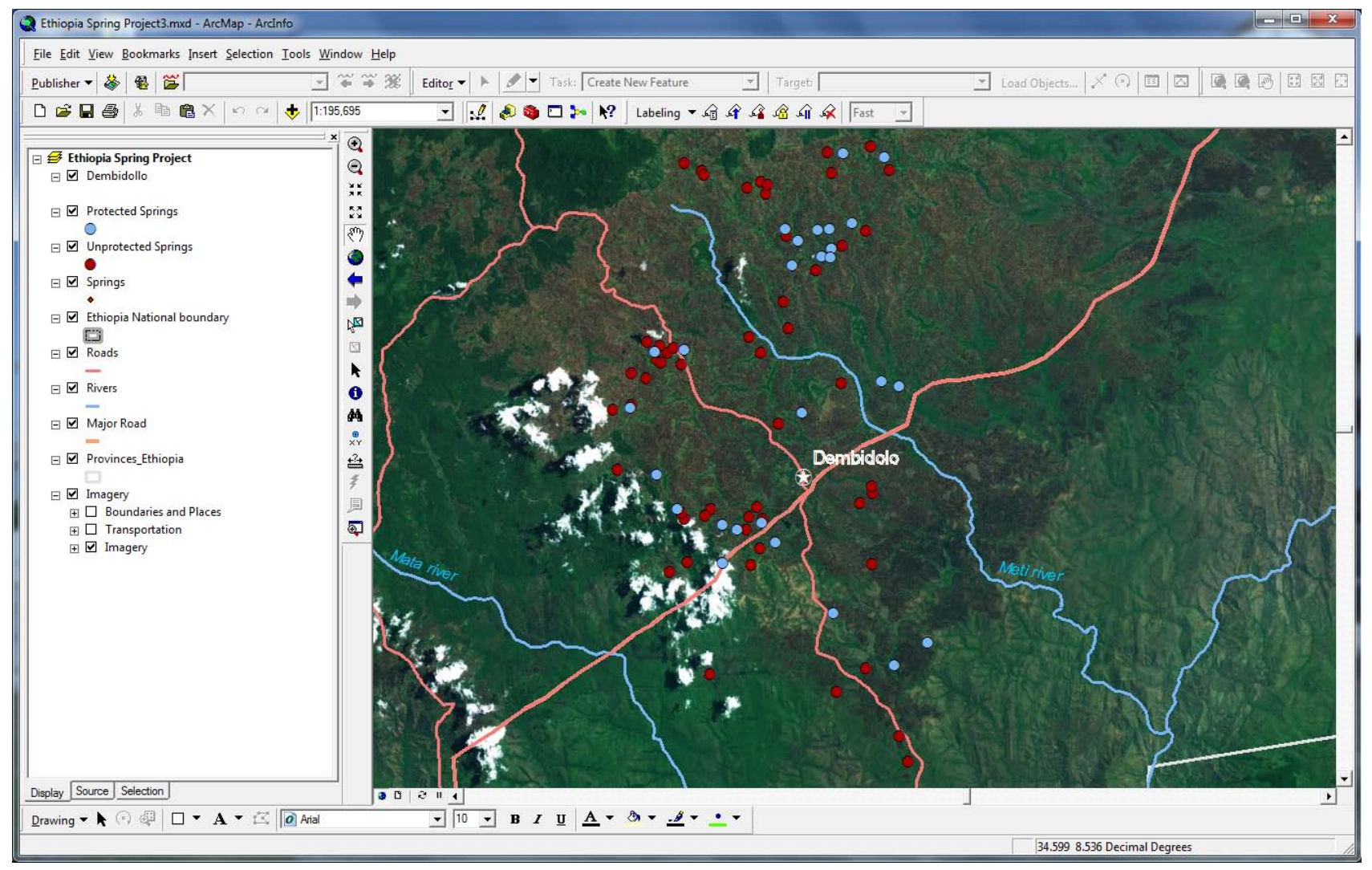

Figure 5-4: Layers added to the map document

Only streets and rivers located in Welega Province were digitized. They, along with the satellite imagery, served for a spatial reference purpose by helping users to locate spring features in Sayo District and have the best guess of directions to any particular spring location. A locator map of Ethiopia showing the location of Welega Province and Dembidolo town was retrieved from the ESRI online data and published as an image as an additional reference (Figure 5-6). An alternative to this approach was a table that showed geographic coordinates of each spring location. Therefore, GPS users can easily locate springs. 


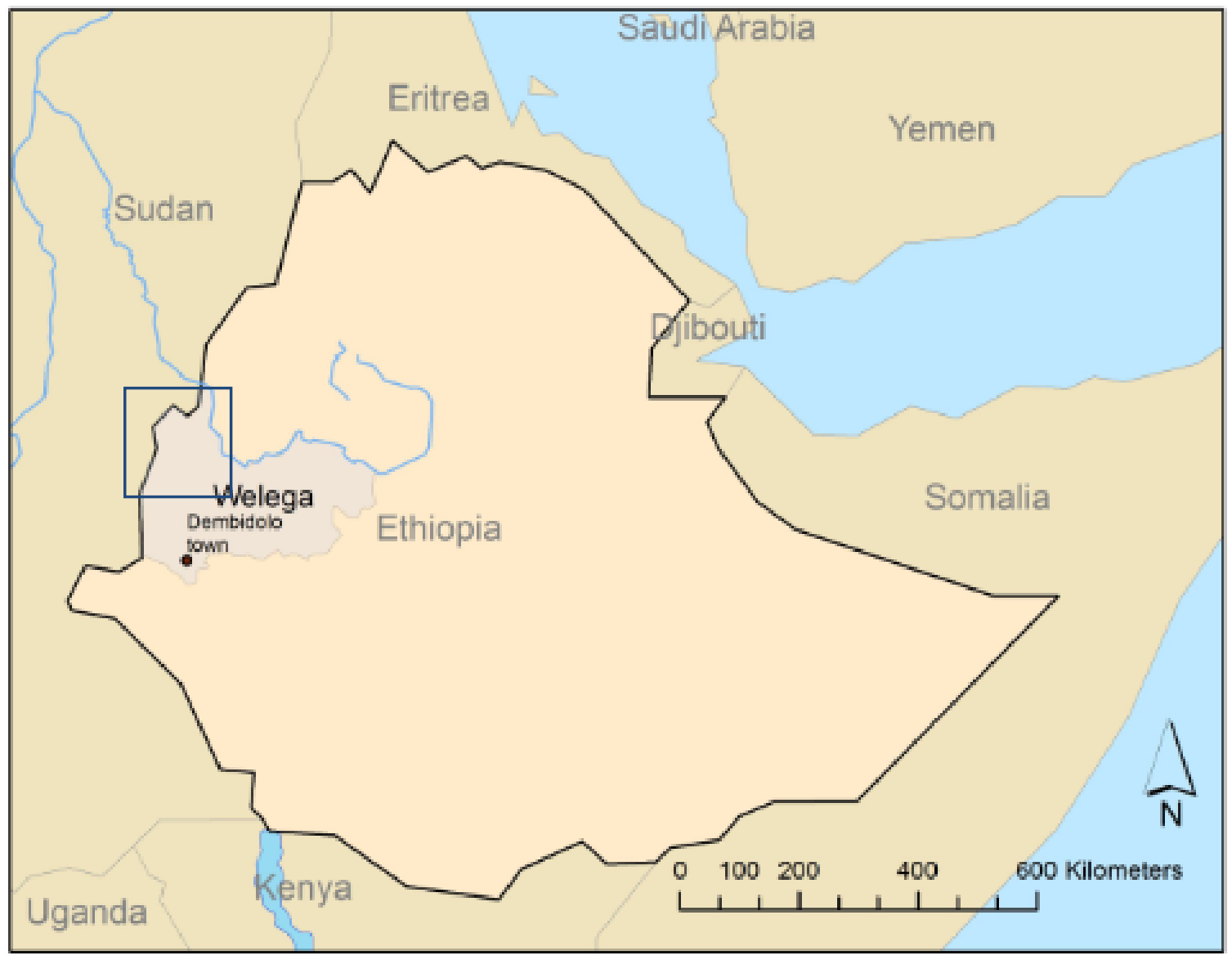

Figure 5-5: A locator map for the study area

When map authoring was completed, ArcGIS Diagrammer was used again to provide the report for the data before the map document was published. 


\begin{tabular}{|c|c|c|c|c|}
\hline ObjectClass Name & Type & Geometry Subtype & Total Extent & Snapshot \\
\hline \multicolumn{5}{|c|}{ Spring_Project_Ethiopia } \\
\hline Dembidollo & $\begin{array}{l}\text { Feature } \\
\text { Class }\end{array}$ & Point & $\begin{array}{r}34.8010666220001 \\
34.8010666220001 \\
18.53573449500004 \\
8.53573449500004\end{array}$ & 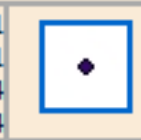 \\
\hline Major_Roads & $\begin{array}{l}\text { Feature } \\
\text { Class }\end{array}$ & Polyline & \begin{tabular}{|l|l|}
34.5885664438 \\
35.836047926 \\
3.13939146900003 \\
9.19937948700004
\end{tabular} & \\
\hline Protected_Springs & $\begin{array}{l}\text { Feature } \\
\text { Class }\end{array}$ & Point & $\begin{array}{r}34.71893000000001 \\
34.8596700000001 \\
30.44631000000004 \\
8.72419000000002\end{array}$ & \\
\hline Provinces_Ethiopia & $\begin{array}{l}\text { Feature } \\
\text { Class }\end{array}$ & Polygon & $13 \begin{array}{r}32.9918002200001 \\
47.9882452800001 \\
3.40666408400006 \\
14.8836091790001\end{array}$ & \\
\hline Rivers & $\begin{array}{l}\text { Feature } \\
\text { Class }\end{array}$ & Polyline & $39 \begin{array}{r}34.16645356800001 \\
36.1777090940001 \\
7.99773228300006 \\
9.01673888000005 \\
\end{array}$ & \\
\hline Roads & $\begin{array}{l}\text { Feature } \\
\text { Class }\end{array}$ & Polyline & $23 \mid \begin{array}{r}33.8097681420001 \\
35.9300751320001 \\
8.01445535200003 \\
9.19937948700004\end{array}$ & \\
\hline Springs & $\begin{array}{l}\text { Feature } \\
\text { Class }\end{array}$ & Point & $\begin{array}{r}34.7103700000001 \\
92 \\
34.8596700000001 \\
8.40063000000004 \\
8.73537000000005\end{array}$ & \\
\hline Unprotected_Springs & $\begin{array}{l}\text { Feature } \\
\text { Class }\end{array}$ & Point & $62 \mid \begin{array}{r}34.71037000000001 \\
34.8507500000001 \\
8.40063000000004 \\
8.73537000000005\end{array}$ & \\
\hline \multicolumn{5}{|c|}{ Stand Alone ObjectClass(s) } \\
\hline Spring_Table & Table & - & 92 No Extent & - \\
\hline
\end{tabular}

Figure 5-6: Data report with ArcGIS Diagrammer

\subsection{Web Map Prototype Application}

ArcGIS 9.3 was used to publish the authored map document. ArcMap application provides a publishing tool that makes the map service available on ArcGIS Server as a map service for users' consumption. The tool is intuitively simple to use. A right click on the map document (.mxd) to be published gives access to "Publish to ArcGIS Server" option that leads through the rest of the steps (Figure 5-8). However, ArcGIS Server Manager can also be used to publish a map document. Prior to publishing to an ArcGIS Server, an administrative connection within ArcCatalog's GIS Servers folder was created first.

Figure 5-9 shows the main interface of a displayed window when ArcGIS Server Manager is launched. This window comprises a menu used to create a Web application and publish it as a Web map service. The Web application customization was necessary to meet the client's requirements and the system design of the project. 
Choose the ArcGIS Server you wish to publish to:

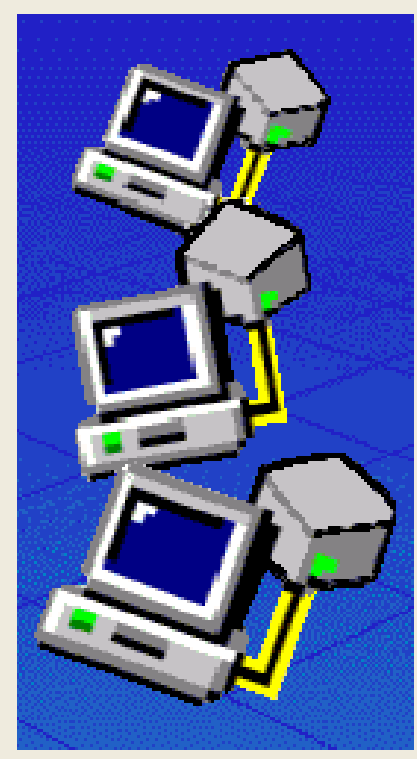

ArcGIS Server: $664-04$

Service Name:

Ethiopia Spring Project3

Publish to folder

(- Use an existing folder

Folder Name:

664-04 (root)

$C$ Create a new folder

Folder Name:

Figure 5-7: ArcMap interface to publish map document to ArcGIS Server 


\section{Welcome to ArcGIS Server Manager}

With ArcGIS Server, you can share your geographic information in many ways.

What do you want to do?

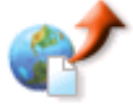

Publish a map, globe or other GIS resource as a service

Create a web application

Create a mobile project

Manage my GIS server

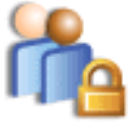

Manage security

Figure 5-8: ArcGIS Server interface window

\subsection{User Web Interface Design}

A client-side Web interface was developed and created. Users can interact with a site by moving and clicking the mouse. These interactions are prompted by the graphic user interface of the site as represented by point features in the map and by visible links within a page that direct the user to additional, but important, information relevant to springs. The interface created is intuitive and every interaction with the application gives the response that is logically expected. On the other hand, the interface was made simple enough so that the user can fully focus on the contents rather than being distracted by the interface itself. The simplicity of the design made the site compact and fast loading, since some of the users will be consuming the map application service from places with a low Internet connection. Since screen size differs from user to user, the design was such that the Web application could compromise well with a full screen view constraints. 
The Web interface was designed to reflect the feel of the Tropical Health Alliance Foundation's main Web page by including its logo. Generally the major themes behind modern Web design include:

- Designer needs versus user needs

- The balance of form and function

- The quality of execution

- $\quad$ The interplay between convention and innovation (Powell, 2002)

\subsection{Page design}

HTML was used to create and structure the Web documents by defining the syntax and placement of the web page content, to allow the Web browser to display the map application appropriately. Special tags were created to identify the Web page elements by giving instructions on how to display the content. The Hypertext Markup Language is the most widely used language on the Web. The page designed consisted of one HTML file. The design was made to fit all information in one screen without scrolling. Only the most important information including the Web map application appears in the screen. This gives the user more overview of the total amount of information on the spring project.

It has been argued that "Internet users hate scrolling and most only look at what they see first and do not go further. Their curiosity needs to be tickled to encourage them to scroll on. To scroll down appears to be reasonably acceptable but scrolling across is not advisable and a combination of the two should be avoided”. In addition to that," for maps on the Internet scrolling is not always avoidable, but it is best to try to fit the map to the minimum screen size defined at the start of the site design. The horizontal width is especially important, defined in pixels, not in centimeters or inches, since the screen dimensions are also based on pixels” ( Menno-Jan Kraak, 2001). Windows were sized correctly so that important information could not be lost off the edges of the browser frame.

The rest of relevant, but also important information would be hyperlinked through hypertexts from the main page. This is the case of the master list of surveyed springs and their attributes. The list was designed in an HTLM format so that it can be easily updated without having to prepare the whole list anew. The following example shows the tags that make up the standard skeletal structure of an HTML document.

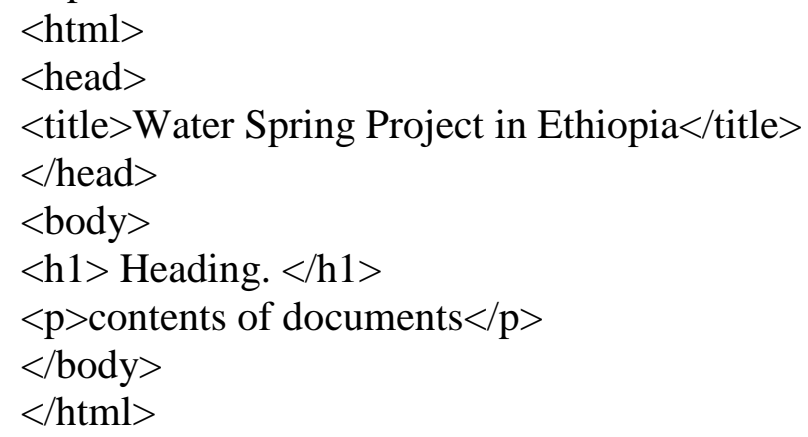

The title "Water Spring Project in Ethiopia” contained keywords that search engines can use to index the page. Therefore, it was obvious that the selection of this title was appropriate since it reflects the topic of the project. In addition to HTML, other client- 
side browser technologies such as CSS, and JavaScript were utilized to create the presentation of a page or provide interactive features of the published map service.

Another consideration taken into account is the user internet connection speed. Assuming that end users viewing and querying the Web application developed access the Internet at a wide range of speeds, it was convenient to keep files as small as possible. Photographs were compressed from megabytes to a few kilobytes, and the symbology assigned to the map features was rendered to be as simple as possible. This was done on top of JavaScript language that was chosen to make it possible for the Web application to be consumed via any browser, hence offsetting constraints imposed by low connection bandwidths. In addition, the number of photographs was minimized. In fact, graphics take longer to download. For that reason, tables to be displayed were designed as HTML text instead of a graphic (.pdf) that is likely to be many orders of magnitude larger than HTML text with the same content, resulting in slower downloads as argued by Niederst (2001).

The text was displayed in Helvetica, and the title contained the Tropical Health Alliance Foundation's logo, to give the page the feel of the client's home page. It was assumed that users will be familiar with such a font because it is also used as a default in Microsoft Internet Explorer. Most of the space on the Web page was occupied by the interactive Web map application since this was the core component and the ultimate expected information product of the project. The pane on the left-hand side of the Web page consisted of a brief description, the context, and a result summary for the project, the right pane consisted of the Web map application.

The page design was structured in such a way that the abstract of the project and a brief description of the implemented Web map application were placed on the left-hand side of the page. In fact, Fowler and Stanwick (2004) indicate that eye-scanning studies indicate that users commonly start looking at pages by scanning the left-hand list and then jumping to the list, if any, at the top of the screen. By exploring the description pane, users have a background and guiding information that leads them through the interactive map application.

\subsection{JavaScript for a dynamic Web application}

JavaScript, unlike Flex or Silverlight, does not require any plug-in support, and it is used by a wide range of programmers, from beginners to professionals (Fowler and Stanwick, 2004). Furthermore, it was chosen because it is supported by majority of browsers. It offers similar GIS functionality that includes mapping, querying, and geoprocessing services as do the other two mentioned earlier. It is free and easy to use and therefore accommodates a limited programming experience on the side of a developer. JavaScript is a lightweight way to embed maps and tasks to web applications. Fowler and Stanwick (2004) provide pros and cons for coding with JavaScript (Figure 5-10).

JavaScript was used to create the interactive Web map application for the project. It is a scripting language works well with HTML 


\section{TECHNICAL NOTE \\ Pros and Cons of Web Application Coding Systems}

Table 1-1 compares five of the most common systems used to develop web pages and web applications.

\begin{tabular}{|c|c|c|}
\hline System & Pros & Cons \\
\hline HTML & $\begin{array}{l}\text { Easy to learn and use. } \\
\text { Works on virtually every browser. } \\
\text { Does not need to be compiled. }\end{array}$ & $\begin{array}{l}\text { No special features. } \\
\text { Noninteractive. } \\
\text { Too simple. }\end{array}$ \\
\hline DHTML & $\begin{array}{l}\text { Relatively easy to learn and use. } \\
\text { Different versions work with } \\
\text { almost any browser. } \\
\text { Does not need to be compiled. }\end{array}$ & $\begin{array}{l}\text { Inconsistent compatibility } \\
\text { among browsers. } \\
\text { Severe screen design } \\
\text { (alignment) issues. }\end{array}$ \\
\hline XML & $\begin{array}{l}\text { Very powerful. } \\
\text { The processing technology is } \\
\text { widespread, easily available, } \\
\text { and cheap. } \\
\text { You can easily read and understand } \\
\text { the code (once trained). } \\
\text { Very flexible-you can define } \\
\text { other languages with it. } \\
\text { Separates process from content, } \\
\text { which makes applications faster } \\
\text { and reduces processing time. } \\
\text { Documents produced with it can be } \\
\text { validated using a validating parser. } \\
\text { There is an increasing number of } \\
\text { individuals with XML skills. } \\
\text { Is license-free, platform-neutral, } \\
\text { and widely supported. } \\
\text { Can be viewed with simple tools } \\
\text { such as browsers. } \\
\text { Is easily internationalized. }\end{array}$ & $\begin{array}{l}\text { Longer learning curve. } \\
\text { Is a space, processor, and } \\
\text { bandwidth hog. Is just } \\
\text { a document, not a } \\
\text { programming language. } \\
\text { Every XML format can } \\
\text { become a "proprietary" } \\
\text { XML format. } \\
\text { Is awful for binary data } \\
\text { (but great for text). } \\
\text { Is a regression from } \\
\text { centralized, efficient } \\
\text { database systems to } \\
\text { inefficient file processing. } \\
\end{array}$ \\
\hline JavaScript & $\begin{array}{l}\text { Wide browser support. Most } \\
\text { browsers speak some dialect. } \\
\text { Easy access to document } \\
\text { objects for manipulation. } \\
\text { No long download times. } \\
\text { No plug-in support required. } \\
\text { Relatively secure. }\end{array}$ & $\begin{array}{l}\text { No standard support } \\
\text { across browsers. } \\
\text { Web pages are useless if } \\
\text { the script has a bug. } \\
\text { May be disabled by the } \\
\text { browser's settings, } \\
\text { making scripts } \\
\text { unreadable. } \\
\text { Certain complicated } \\
\text { JavaScripts can run } \\
\text { slowly. }\end{array}$ \\
\hline
\end{tabular}

Figure 5-9: Coding system pros and cons (Source: Fowler and Stanwick (2004) 
A sample code from ArcGIS Resource Center (Figure 5.11) was used as a guide and was configured to fit the requirements of the application for the project. The line of code that initialized the operational map layer was replaced by the URL that referenced the actual local ArcGIS Server map service created for the project. The initial extent of the map to the extent of the local data was set. Query functionality was configured to enable users to get information about spring data via an InfoWindow. Querying is a common requirement in Web maps, as it provides insight into what is going on beyond the geometries.

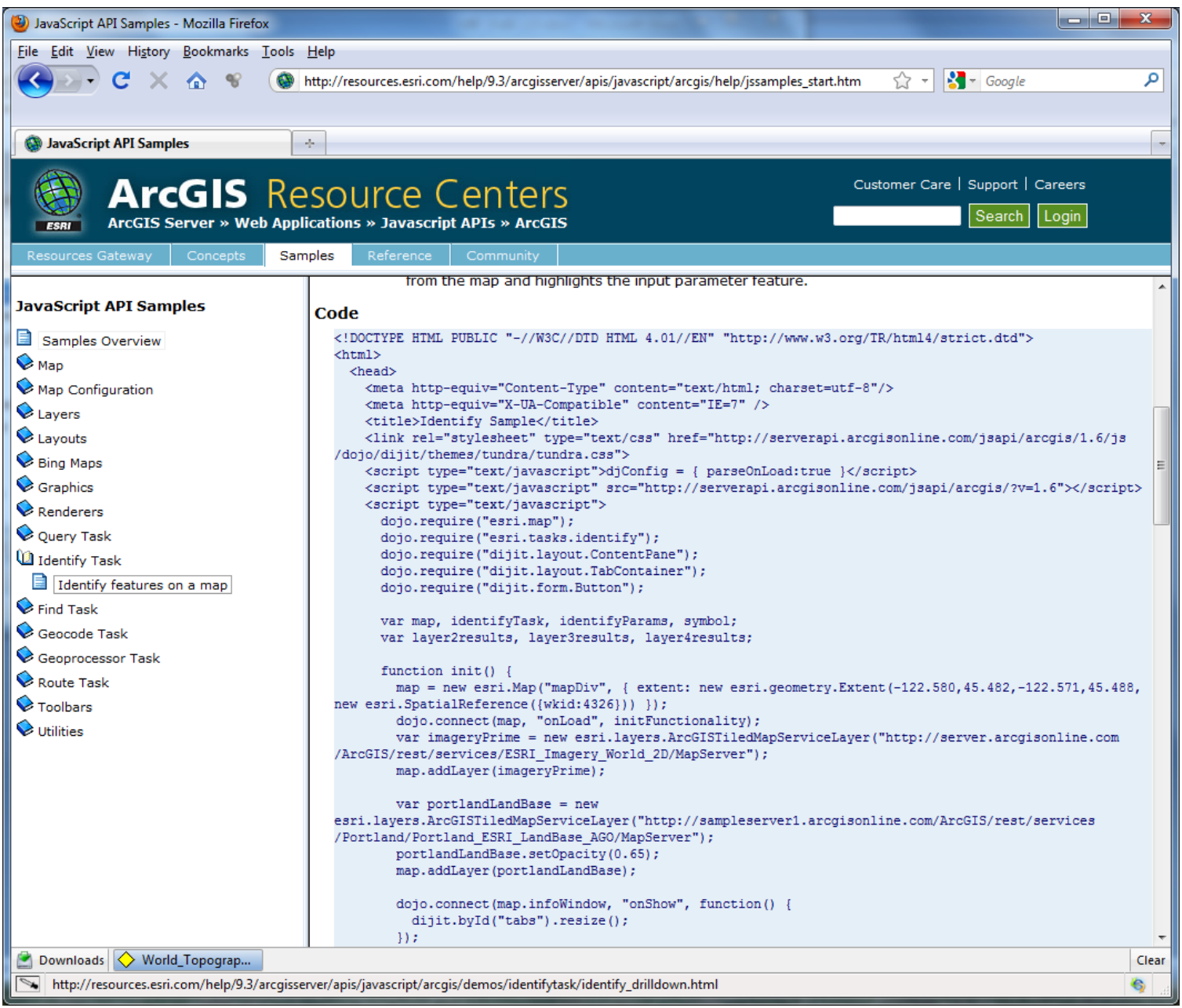

\section{Figure 5-10: A sample code from ArcGIS Resource Center}

A query task in ArcGIS API for JavaScript can include a spatial or attribute filter and can be executed independently of the Web map. Therefore, the layers that are being queried do not need to be displayed on the map; however, they have to be in ArcGIS Services Directory folder that contains the published map service that is not necessary displayed in the application. Code configuration involved also the displaying behavior of the Web application. Under an assumption that browsers use computers with varying screen sizes, the code was further developed to address the issue so that the Web application would fit into any screen size. 
A $<$ script $>$ tag was used to embed JavaScript into HTML page, that is < script type="text/javascript" $></$ script $>$. HTML executes JavaScript code in response to the client Web browser. The programming using ArcGIS API for JavaScript was made easier by using Dojo Toolkit which is one of many libraries of interactive features. Defects in HTML and JavaScript code were identified and fixed through a debugging process that used Firebug. Firebug is a very common and free -to- download debugging tool for JavaScript (Figure 5.12). It is an add-on to Mozilla Firefox Web browser. There are other text editors for the development of the code, like Aptana, Visual Web Developer, but these don't offer an easier way to debug like Firebug does. Another interesting aspect with Firebug is that it offers debugging options for CSS, HTML, or JavaScript codes, and changes or corrections brought to a code can be readily traced and previewed in the Web page. A click on any component of the page displays its corresponding code in the Firebug window. After debugging process, the code was copied to Notepad which is convenient for storing an html code.

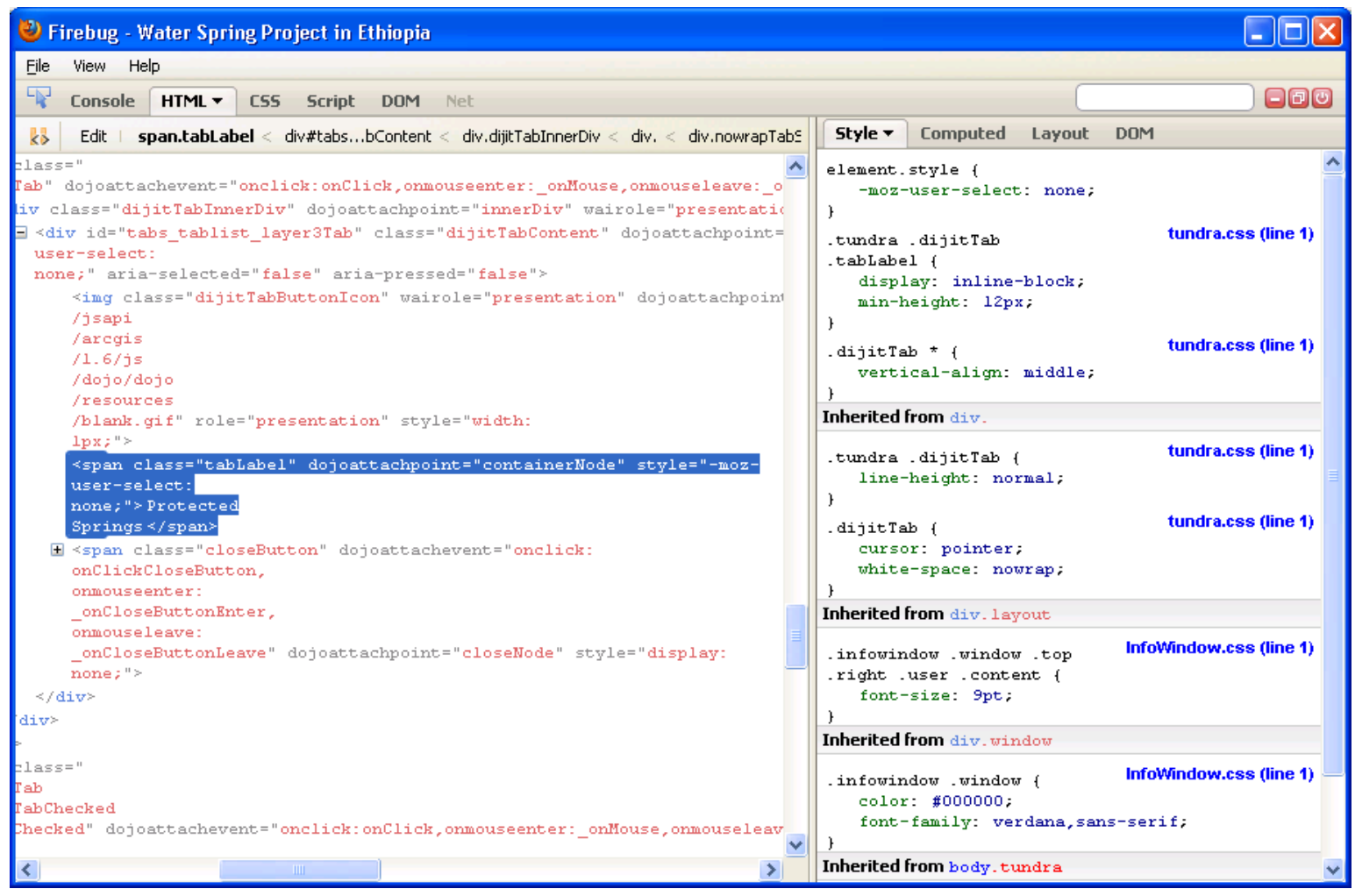

Figure 5-11: Firebug window for HTML code

\subsubsection{Functions used with JavaScript}

The JavaScript code contains numerous functions that run in a sequence as described in the following: 
The "init" function sets up the map and adds an imagery base map from ArcGIS Online, as well as a dynamic layer of a published spring map, as follows:

function init()

$$
\{
$$

$$
\text { sizePage(); }
$$$$
\text { map = new esri.Map("mapDiv", \{ extent: new }
$$

esri.geometry.Extent(34.7189, 8.4463, 34.8596, 8.7241, new

esri.SpatialReference(\{wkid:4326\})) \});

dojo.connect(map, "onLoad", initFunctionality);

var imageryPrime $=$ new

esri.layers.ArcGISTiledMapServiceLayer("http://server.arcgisonline.com/ArcGIS/rest/ser vices/ESRI_Imagery_World_2D/MapServer");

map.addLayer(imageryPrime);

var dynamicLayer $=$ new

esri.layers.ArcGISDynamicMapServiceLayer("http://664-

04/ArcGIS/rest/services/Ethiopia_Spring_Project/MapServer");

map.addLayer(dynamicLayer);

dojo.connect(map.infoWindow, "onShow", function() \{

dijit.byId("tabs").resize();

\} \}$)$;

An "IdentifyTask" was defined in a code in order to perform an identify operation on the layers of a map service resource exposed by the ArcGIS Server REST API. Those layers include "protected springs" and "unprotected springs". A URL representing the published map service was required to perform the task. The URL could be obtained using the Service Directory and the REST API:

function initFunctionality(map) \{ dojo.connect(map, "onClick", doIdentify); identifyTask = new esri.tasks.IdentifyTask("http://66404/ArcGIS/rest/services/Ethiopia_Spring_Project/MapServer");

The "IdentifyParameters" is required to specify the criteria used to identify the features. These criteria include the tolerance, Ids of layers to be queried on:

identifyParams = new esri.tasks.IdentifyParameters(); identifyParams.tolerance $=5$; identifyParams.returnGeometry = true; identifyParams.layerIds = $[0,1,2]$; identifyParams.layerOption $=$ esri.tasks.IdentifyParameters.LAYER_OPTION_ALL; \}

A "doIdentify" function is called when someone clicks the map. Clears any existing graphics, adds the clicked point coordinates to the identify parameters, and executes the identify:

function doIdentify(evt) \{ map.infoWindow.hide(); map.graphics.clear(); featureSet = null; 
identifyParams.geometry = evt.mapPoint;

identifyParams.mapExtent = map.extent;

identifyTask.execute(identifyParams, function(idResults) \{

addToMap(idResults, evt); \});

\}

The "addToMap" function is called when the Identify task completes,loops through each result and adds it to an array, depending on which layer the result came from. This produces three arrays; one for each layer. These are then designated as content for the TabContainer Dijit. This function also displays an info window with the tabbed result information about protected and unprotected springs.

function addToMap(idResults, evt) \{

layer1results $=\{$ displayFieldName:null,features:[]\};

layer2results $=\{$ displayFieldName:null,features:[] $\}$;

layer3results $=\{$ displayFieldName:null,features:[]\};

for ( $\operatorname{var} \mathrm{i}=0$, il=idResults.length; $\mathrm{i}<\mathrm{il} ; \mathrm{i}++)\{$

var idResult $=$ idResults[i];

if (idResult.layerId $===1$ ) \{

if (!layer1results.displayFieldName) \{layer2results.displayFieldName = idResult.displayFieldName\};

layer1results.features.push(idResult.feature);

\} else if (idResult.layerId $===0$ ) \{

if (!layer2results.displayFieldName) \{layer2results.displayFieldName = idResult.displayFieldName\};

layer2results.features.push(idResult.feature); \}

/I

dijit.byId("layer2Tab").setContent(layerTabContent(layer1results,"layer1results"));

dijit.byId("layer3Tab").setContent(layerTabContent(layer2results,"layer2results"));

dijit.byId("layer4Tab").setContent(layerTabContent(layer1results,"layer1results")); map.infoWindow.show(evt.screenPoint,

map.getInfoWindowAnchor(evt.screenPoint));

\}

The "layerTabContent" function is called as a helper function to addToMap. It formats the result information for inclusion in the TabContainer Dijit.

function layerTabContent(layerResults, layerName) \{

var content = "'";

switch (layerName) \{

case "layer2results":

content $=$ "<i>Total features returned: " + layerResults.features.length +

"</i >"; ..............

return content;

\} 
The "showFeature" function is called when someone clicks the "Show" link in the result tab. Clears any existing features from the map and highlights the input parameter feature.

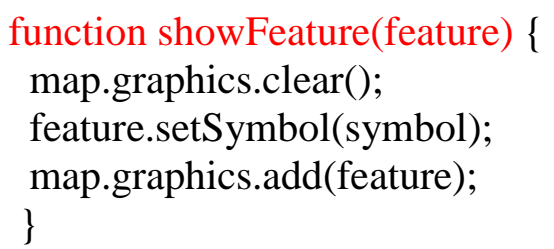

A complete code is detailed in Appendix B. 


\section{Chapter 6 - Results and Analysis}

This chapter will examine the results obtained from the development and implementation of the Web map application prototype and the benefits they represent for the Tropical Health Alliance Foundation. Opportunities and constraints experiences in the course of the development and implementation of the project are also discussed. Benefits of a more efficient dissemination of information among various THAF's partners and donors are made evident with this application. Results achieved at the end of the project constitute a starting point for further similar research. In this chapter, results are presented in a form of maps and tables to give an overall understanding of spring condition in Western Ethiopia.

Photographs of springs are not directly presented in the results since they are displayed only through the Web map querying action. Results presented demonstrate the use of existing technology to conserve natural resources in the neediest areas and constitute the very essence of the project. The chapter further discusses aspects of the project that went well and those that did not go right as expected.

Unprotected springs were found in fifty-two villages, with a total of 3,507 households served. If we calculate the total number of people who benefit from unprotected springs, based on the official estimate of seven people for each household, then total would be estimated 24,509. Forty-two villages out of seventy-one villages covered have no single protected spring, which represent a percentage of $63 \%$ of villages which do not have any protected spring. The average number of households that benefit from a spring is estimated to be 56 (Figure 6-1).

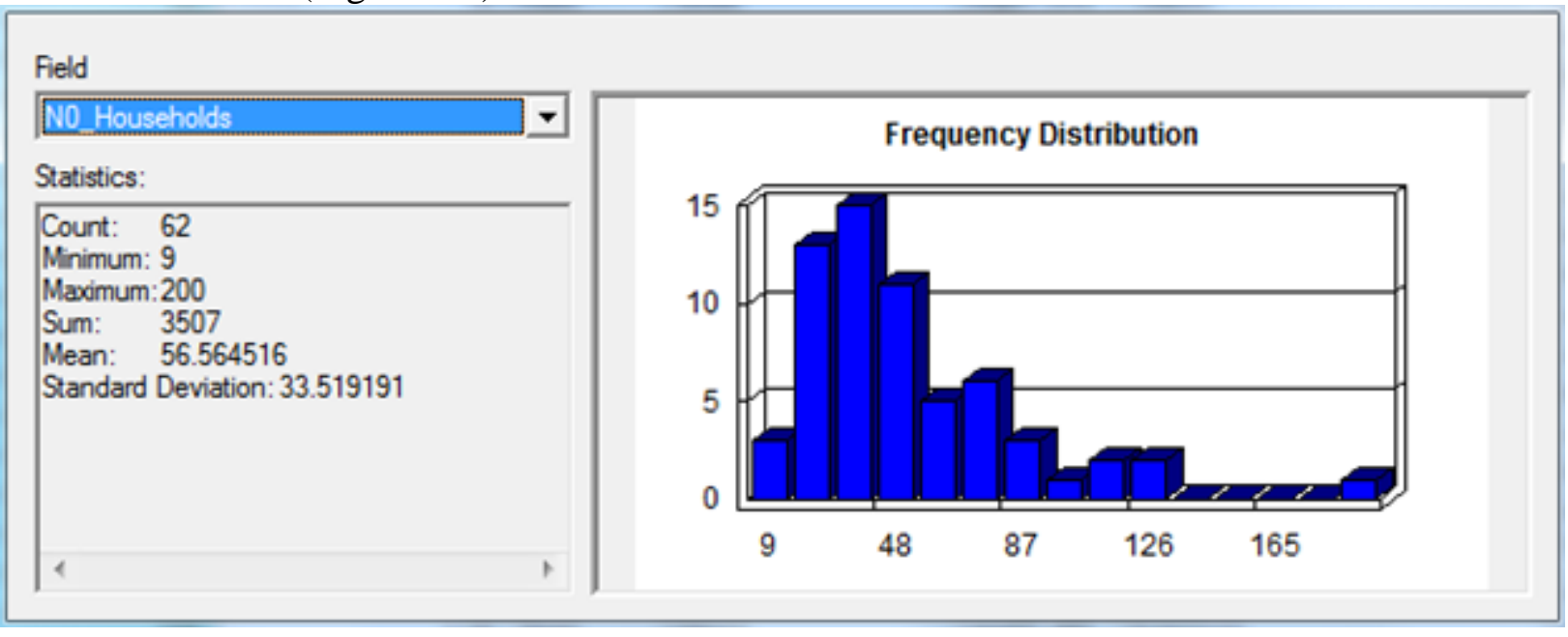

\section{Figure 6-1: Statistics of unprotected springs}

Thirty springs were found protected (Figure 6-2) and they were situated in only twentyseven villages, representing a total of 19,845 people with access to safe drinking water. 


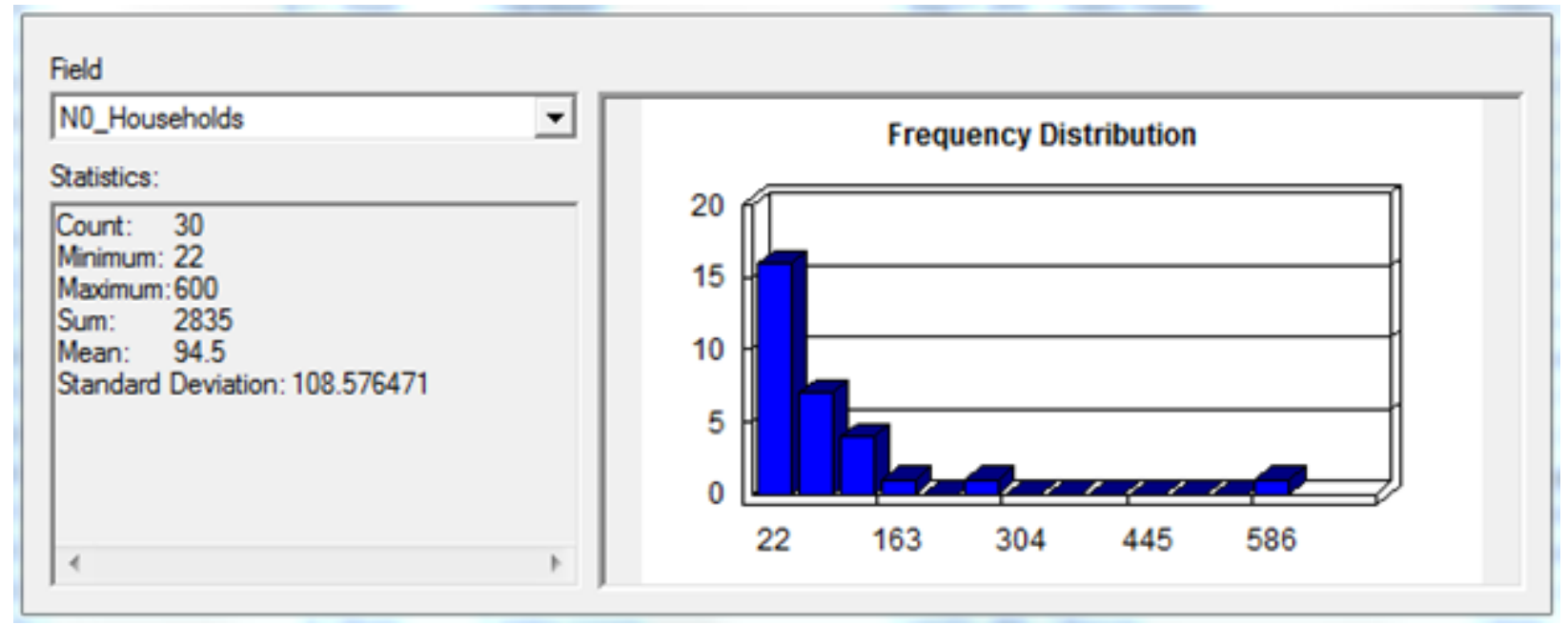

\section{Figure 6-2: Statistics of protected springs}

Unavailability of census demographics at a district, Kabale, and village level made it difficult to make estimations of the proportion of people with access to safe drinking water with respect to the total population of a village, Kabale, or district. However the number of households benefiting from each spring could be estimated. An interesting observation made, based on survey results, is that

Protected springs that represent a proportion of $32.6 \%$ of the total springs surveyed serve $44.7 \%$ of the total population served by springs. This can be attributed to the fact that a protected spring tends to attract more users even if it entails additional travel cost compared to the original situation before the spring was protected.

Dispersion and distribution of springs through various villages can be calculated to evaluate the access of villages to springs, how springs are more clustered in some villages than in others. However, unavailability of high-resolution census demographics at a village level was a big hindrance to such analysis. The number of households (Nb.H) served by each spring is important information that will help the THAF orient interventions to the neediest. Water discharge (W.D) is another important attribute indicative of the outflow of every spring. Unfortunately, this parameter was not measured on a seasonal basis to offer a more accurate estimation of how much of water is available. However, measures taken during the study period allow for a comparative approach and identification of springs that have more water discharge than others. This determines the types of structures needed for the spring protection. Low -discharging streams might need big reservoirs and cisterns to accumulate water and serve communities during day time or even during a dry season. High-discharging springs might serve more than villages actually served by setting up cisterns and distributing pipes.

This master spring list table is valuable especially in areas with a very limited or inexistent access to the Internet; therefore, a hard copy or a digital copy of this list can be very useful. You will notice that a field for photo file names has been left out, in contrast to a description of the logical design of the database in the previous chapters of this document. This is simply because it would not make any sense to keep picture file names if you don't have at least a digital copy of them. However, this field is in the table that 
has been loaded into the geodatabase and was referenced to display photographs of every spring, in the Web application.

The created spring table was used to author a map document (Figure 6-4). The map document was also useful, but, being solely static, it could not be queried and provide further information other than that displayed readily. Before the map was published, the satellite imagery layer was removed since the server would call an online ready-to-use base map provided by ESRI, following a URL that references it.

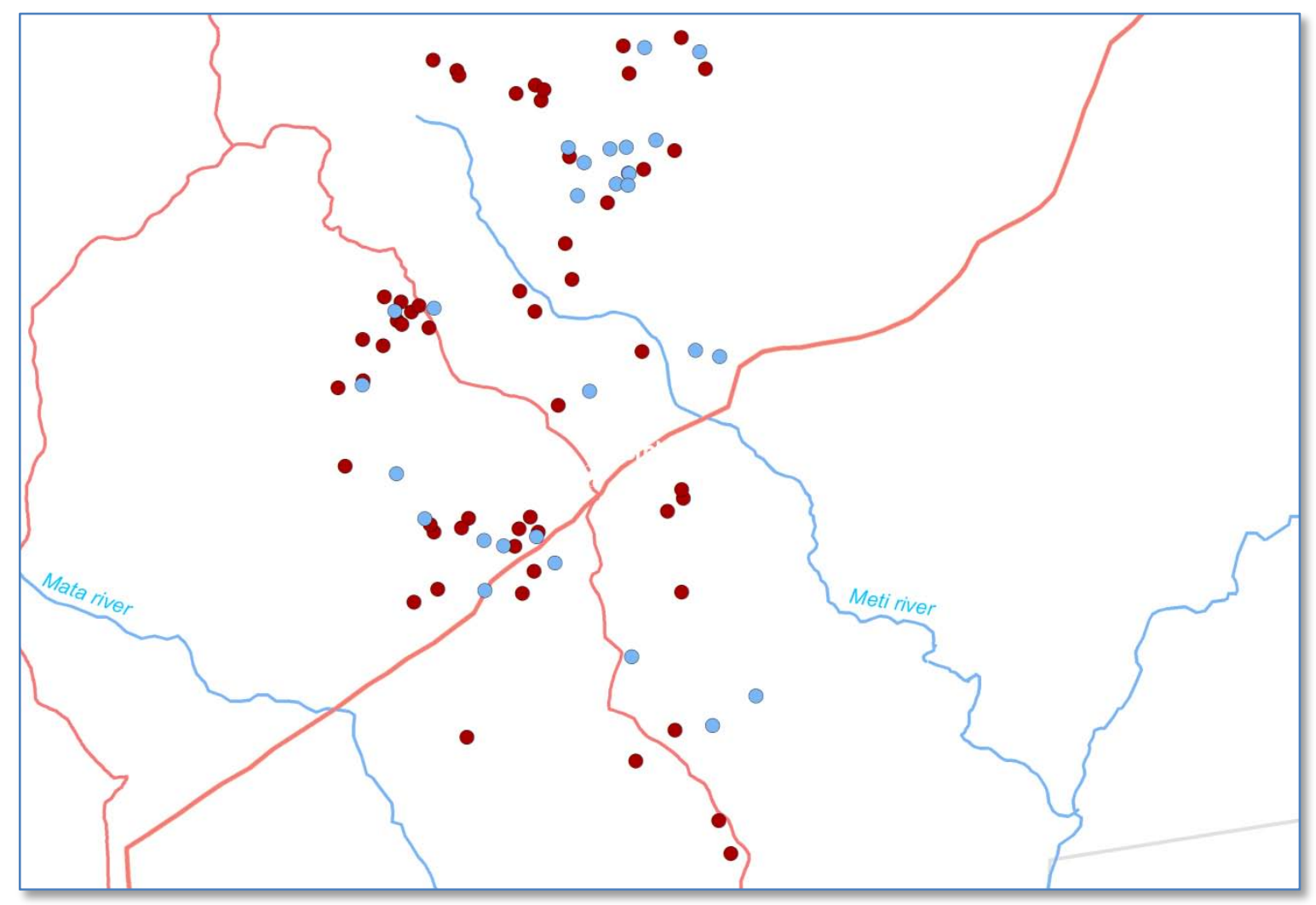

Figure 6-3: Spring map

The authored map was published to ArcGIS Server as a dynamic layer and was overlaid on top of satellite imagery for visualization purposes. The main drawback with ESRI online base maps is that they do not have a fine resolution for remote areas, especially in developing countries; however, they are suited for reference purpose and they provide a nice background for Web map services. Roads and rivers were digitized from existing ESRI online topographic map and were overlaid on the satellite imagery base map to reinforce the background, and especially to provide direction to spring locations. Another limitation is the unavailability of a boundary map for the Sayo District with locations of its villages as well as demographics at the village level. This can help for a better visualization of travel costs with respect to springs locations, and a better understanding of how much difference springs make in providing water if the whole village population is taken into account. Demographics in particular would have 
helped understand the extent of water supply need and not merely relay on the number of households served by any particular spring. This approach would have aided prioritization process in terms of ranking springs that need protection, from the neediest to the least needy ones. However, this was beyond the scope of the present study. In addition, since there was no local road map available, more time for the project would have been mapped. A road map is best suited for guiding to the location of a particular feature or incidence.

Most of spring photographs used in the Web application were very good because they were taken under suitable atmospheric conditions, but sometimes the weather was not suitable for taking pictures, and since the timeframe for the project was limited, it was difficult to go back to the same spring another time for better pictures.

Most of times, roads were in such a bad condition that the only alternative was to walk for the rest of the day, going up and down steep or slippery hills sometimes. These constraints substantially limited the number of visits to springs and eventually reduce the bulk of data. Nevertheless, since this is a prototype, the client would be interested to continue the work and cover a much larger area.

\subsection{Web Mapping Application}

A Web map application was created using ArcGIS Server. The THAF partners and other governmental non governmental agencies as well as individuals involved in freshwater conservation in Welega Province, Ethiopia, can now consume the Web map service about spring locations and their status in the Sayo District (Figure 6-5).

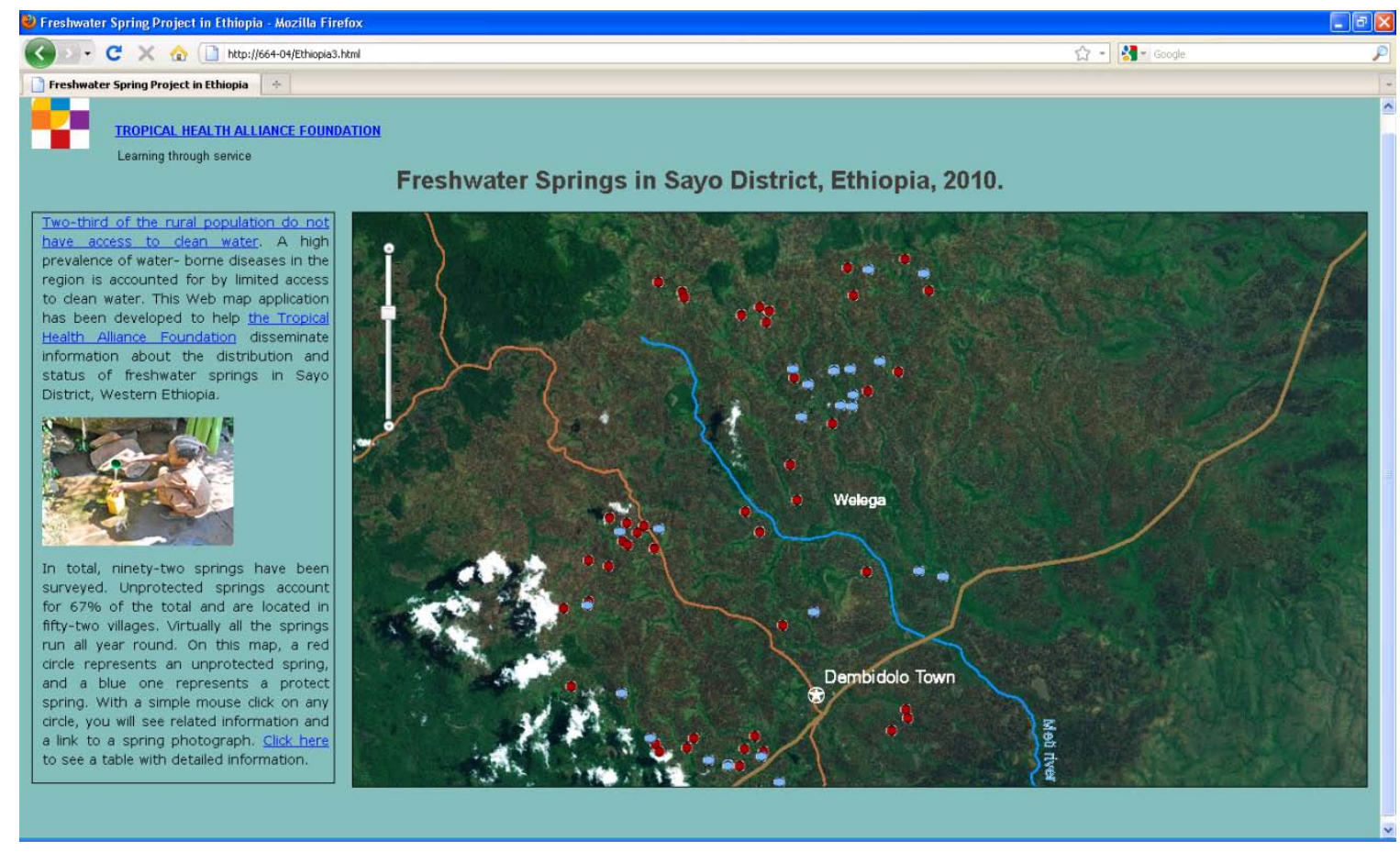

Figure 6-4: Web application user interface 
The Web page consists of three main parts: an abstract section, a description pane, and a body section. The abstract pane gives a summary of the project rationale and results, and the description section tells briefly about the functionality of the application. And the body consists of an interactive map application.

When a user clicks a point feature on the interactive map, an InfoWindow pops up with important information about the spring. Displayed attribute information includes a spring ID, its geographic coordinates, its name and its location. It shows also the number of households that benefit from it and its protection status (Figure 6-6). In addition to the interactive map, there is a table provided using html coding and which opens in a new window. The table is hyperlinked with a hypertext in the description section of the main page. The table displays the same information as that generated by the map application. The difference is that it displays all the springs' names and their attributes. This option enables the users to quickly query a specific spring attribute if they know its name. By clicking on the spring name hypertext, a corresponding photograph opens up into a new window in a similar way as with the interactive map. This table can be easily updated and copied as much as needed.

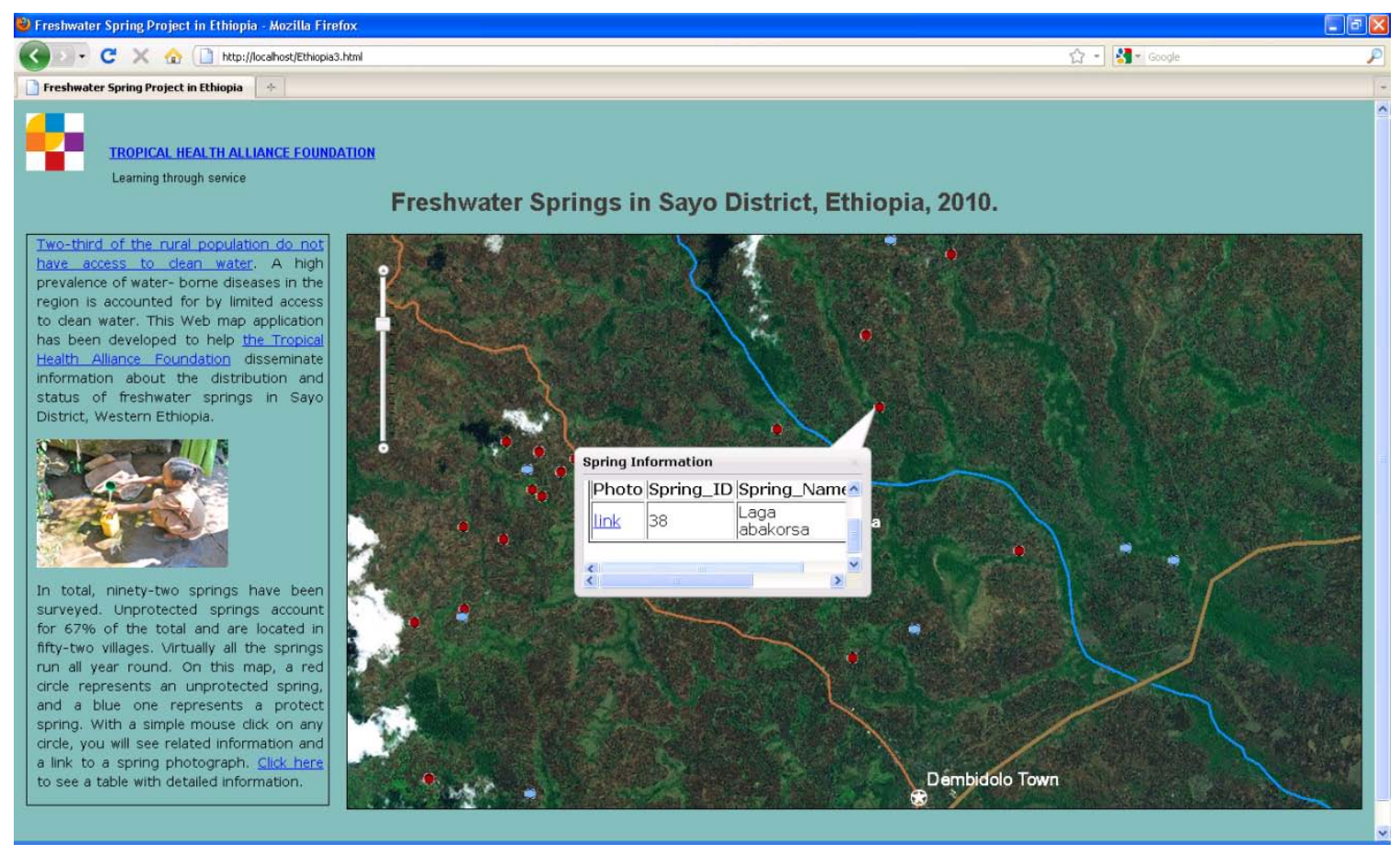

Figure 6-5: Web application interface with an InfoWindow

In order to display labels and Ethiopian provinces boundaries, as well as Dembidolo town, it was necessary to render the symbology and the labeling to make it white in order to get a better contrast with the green background of the World imagery base map. This is evident as end users zoom out the map as depicted in the Figure 6.7. The same result can be achieved by panning the map. 


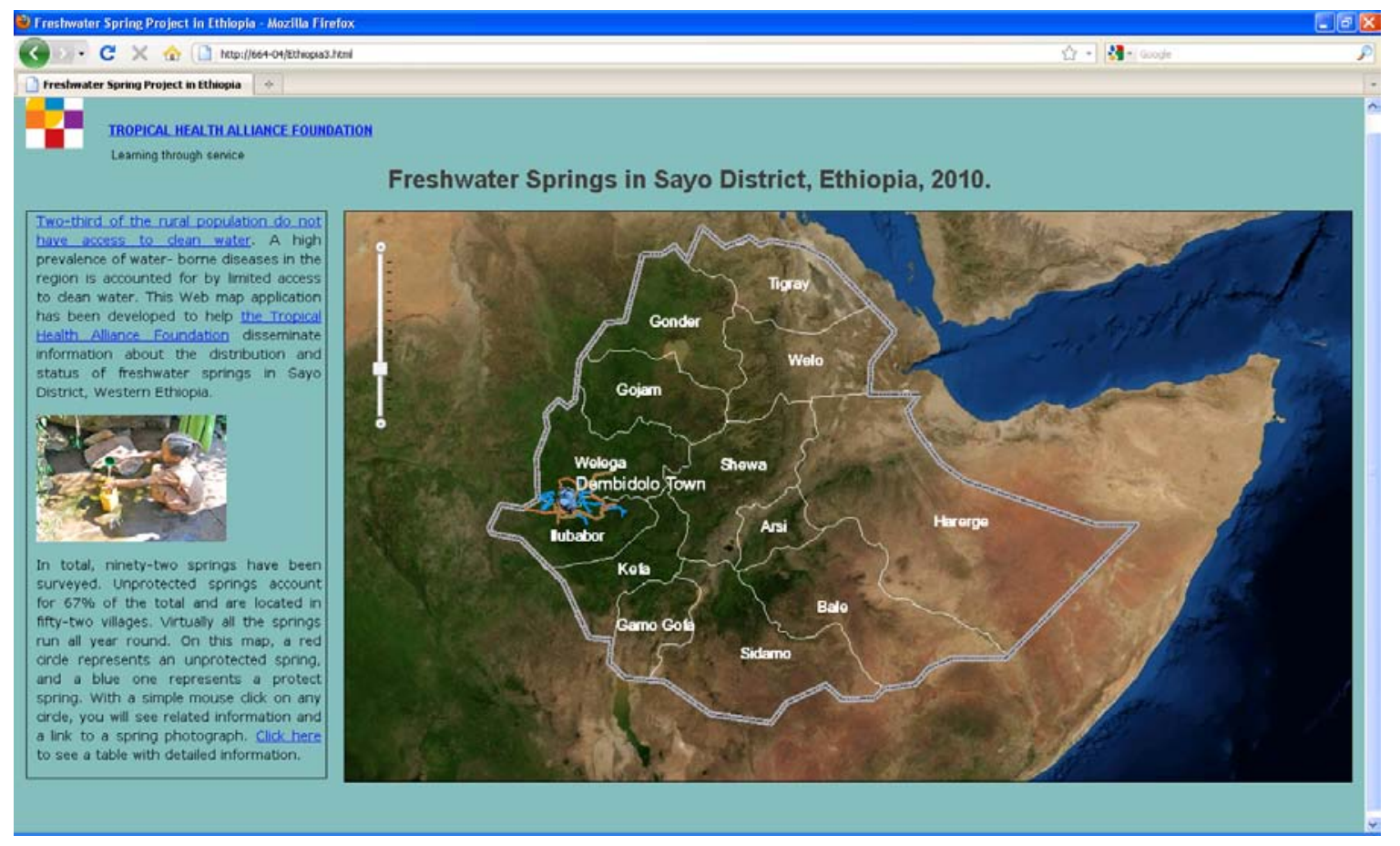

Figure 6-6: Small-scale zoom of the map application

The published Web map service includes a table of all the springs surveyed including their spatial and non-spatial attributes. Users can copy them on their own machines or they can print them and use them in the field. Spring photographs can also be copied or printed. It is worth noting that the symbology for the Web map is rendered in two colors, the blue and the red. The blue -colored solid circle represents a protected spring, and a red-colored one represents unprotected one. In addition, an InfoWindow displays a pinkcolored clickable "link" hypertext that opens up a photograph of the spring in a new window, providing a visual understanding of the status of any particular spring (Figure 68, Figure 6-9).

A limited experience with effective and aesthetically attractive Web design was a hindrance, but after a Web application testing phase and discussion with the client, the design was improved substantially. 


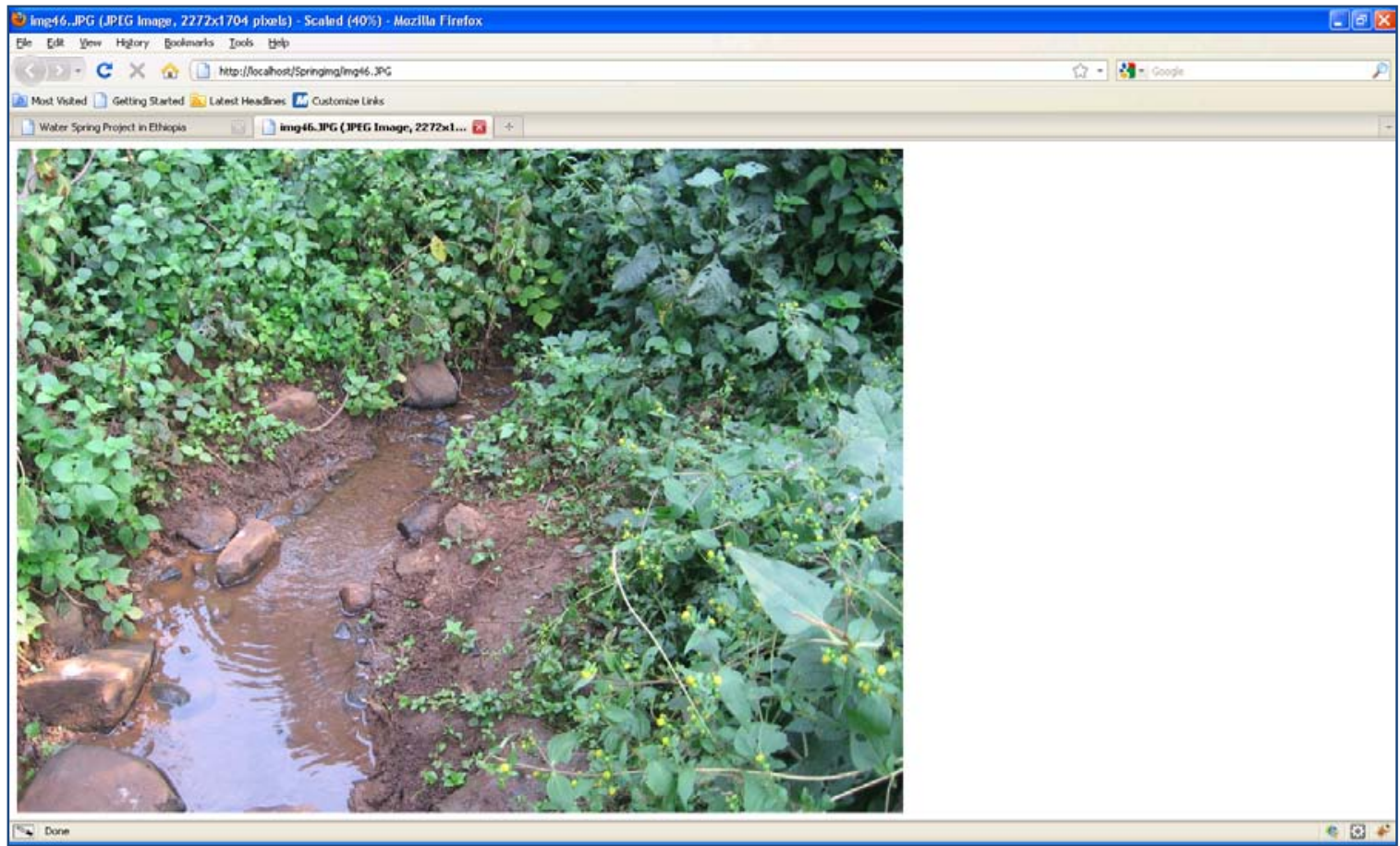

Figure 6-7: Photograph of an unprotected spring

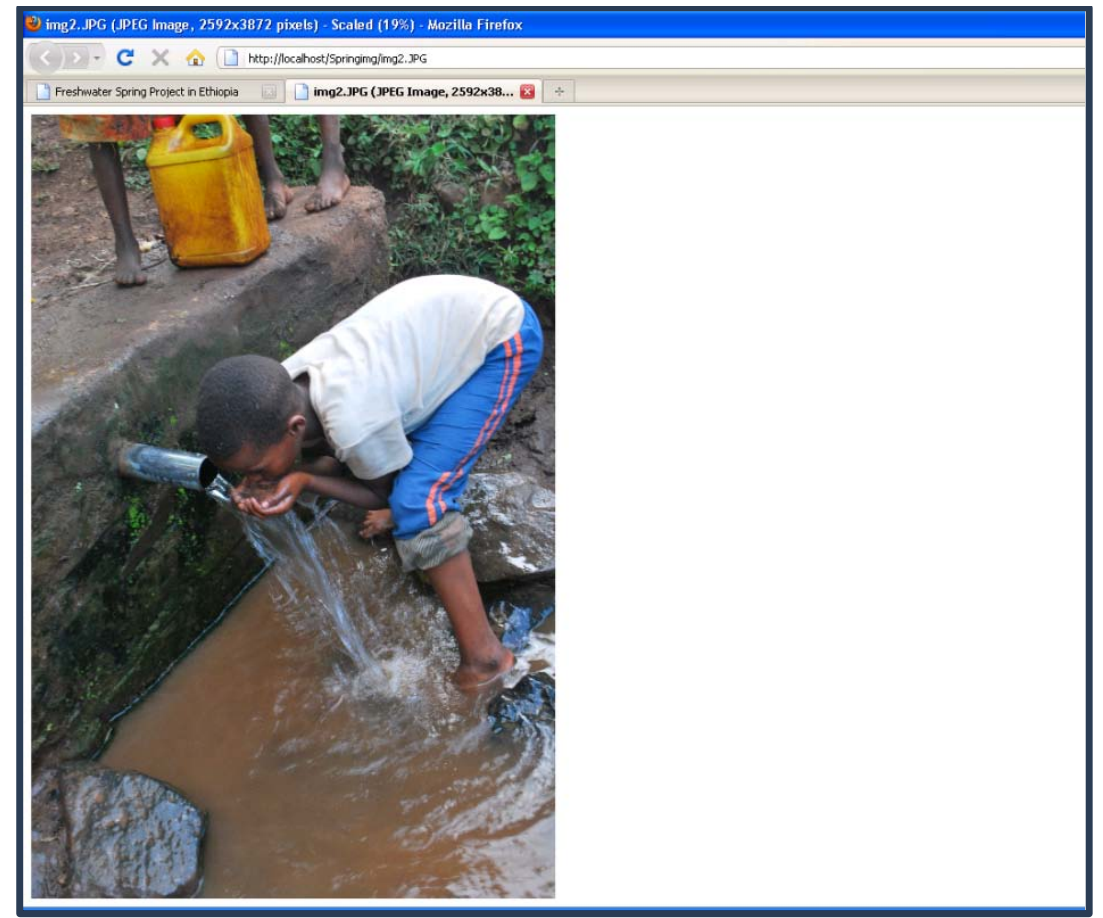

Figure 6-8: Photograph of a protected spring 
A description pane on the left-hand side of the user interface of the map application provides brief background information and the rationale underpinning this project (Figure 6-10). In addition, it offers a summary of results as well as hyperlinks to additional information related to the Tropical Health Alliance Foundation with respect to spring freshwater supplies in Ethiopia, and to a complete list of all the springs surveyed.

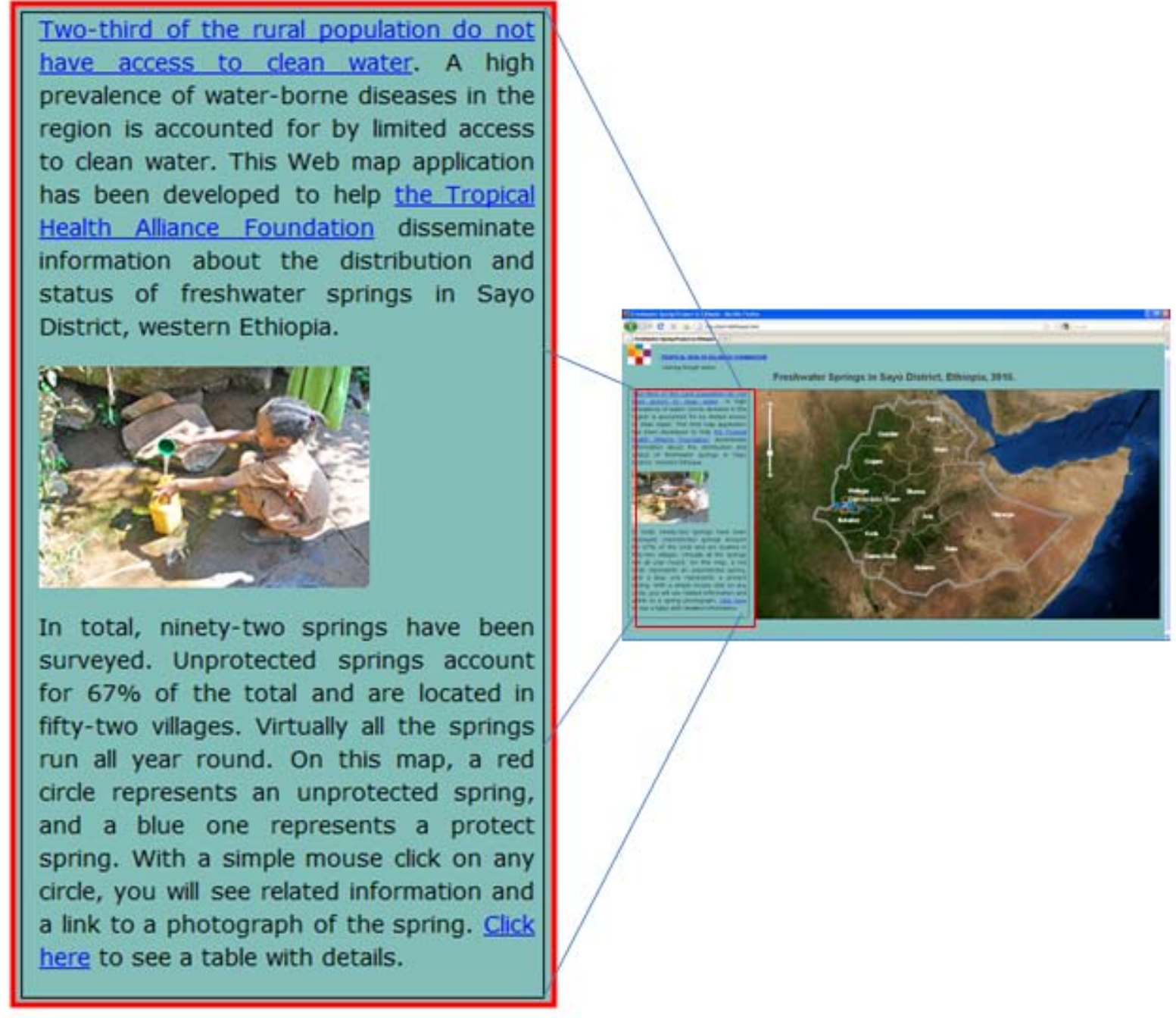

Figure 6-9: Description pane for the Web application interface 


\section{Chapter 7 - Conclusions and Future Work}

This chapter summarizes the work that was involved through the process of the project to address the problem of lack of effective information sharing about spring locations and their status in Western Ethiopia. The need for the Tropical Health Alliance Foundation to share this information with a global audience is very suited with its mission to improve people's health in the Third World countries has been addressed. One of THAF's strategic goals is to provide funding for front line organization in Western Ethiopia committed to establishing spring protection systems, digging wells and purchasing much needed water catchment tanks. This chapter demonstrates the client's satisfaction in regard to his functional and non-functional requirements. Furthermore, recommendations and opportunities for future relevant work are formulated in order to expand the research's horizon and to improve achievements. The underpinning driving force for the way forward is the goal to achieve a more significant and sustainable protection of freshwater springs in Ethiopia.

The ultimate goal for this project was to develop, implement, and deploy a system that enables a wide range of internet users to share information about the location of freshwater springs in Western Ethiopia and their conditions with regard to their protection status. An interactive Web-based GIS application was created to help visualize and disseminate spatial and tabular data to a large group of end-users via a Web browser. Therefore, THAF will benefit from this support tool by reaching out to a larger number of donors and boost funds for spring protection. This project used ESRI products that include ArcGIS desktop 9.3, ArcGIS Diagrammer, and ArcGIS Server 9.3, as well as other products like Microsoft Office Visio and Microsoft Word and Excel to successfully meet the client's functional and non-functional requirements. At the very beginning of the project, the client's needs were clearly defined and thoroughly described. This first stage helped perform a needs analysis and establish a scope of operation for this singlepurpose project. A GIS plan was designed with the following components: Information products, data, software needed for the system to generate required information products, hardware to support the system design, procedures that refer to the migration from a static GIS to an interactive and dynamic Web GIS, and skills or expertise needed for the implementation of the project. The planning was implemented through an iterative process that characterizes an agile system design approach, to ensure a smooth and successful progress of the project. Frequent and regular meetings with the client and the project advisor helped address issues that came up in the course of the project. An interactive Web map application was designed, developed, and implemented to meet the client's requirement needs.

Data was collected into the field, with logistical and financial support from the Tropical Health Alliance Foundation, the University of Redlands, and the Catholic Church Mission based in Dembidolo town in Western Ethiopia. Data collected included geographic coordinates of spring locations, administrative locations names, the number of households served by each spring and photographs showing the condition of each spring. In total 92 springs were covered. The project identified which springs were protected and which ones were not in order to enable THAF have an effective priority-oriented focus in terms of spring protection funds allocation and ensure a better monitoring of efforts 
success. Conceptual and logical database models enabled the implementation of an effective GIS-based filed geodatabase that supported spring data collected from field.

A map service required to build an interactive Web map application was authored and optimized using primary data collected from the field. Arc Map application of ArcGIS desktop 9.3 was used to create a map document. ArcGIS online provided secondary data that was used to create streets and rivers located in Welega Province, through a digitizing process. The map document was optimized in order to further increase the performance of the server. Optimization was implemented by keeping the physical data storage at its possible minimum, by leaving out attributes that did not directly participate in the Web application, by compressing spring photographs to their minimal acceptable size and deleting unnecessary photographs that were not referenced to in the application, by rendering a simple symbolization and a delineation of the required extent for the intended purpose, and finally by leaving out features that represented very minor function in the application.

A Web map application was developed using ArcGIS Server 9.3 and JavaScript API for the ArcGIS platform. JavaScript, API functionality compares well with other APIs including ArcGIS API for Flex, and ArcGIS API for Silverlight. However, it was preferred to the others for various reasons as described in detail in chapter 5 of this document. JavaScript is supported by majority of browsers that include Internet Explorer, Mozilla Firefox, Google chrome, and others. It is free and easy to use and therefore more suited for programmers with limited experience or programming beginners. JavaScript is a lightweight way to embed maps and tasks to web applications. JavaScript is a scripting language that works well with HTML. A developed interactive Web map application displays point features on a map. A click on a feature triggers an InfoWindow that displays spring attributes, including a hyperlink to a photograph that shows the status of the spring. Navigation tools enable the user to pan, zoom in, zoom out the map. In addition, a table of surveyed springs was an additional and complementary component of the page, ESRI online satellite imagery was very useful and served as a background on top of which the operational map layers could be displayed.. Not only this map application can be leveraged to increase the awareness about the limited access to clean water by a majority of the rural population in Western Ethiopia, but also it serves as a decision support and monitoring tool for donors and various THAF's partners and stakeholders who are interested in spring water. THAF will use this interactive Web map application as an effective fundraising for increasing necessary funds for a more extensive spring protection and thus improve health by mitigating the incidences of water-borne diseases in Welega Province.

The implementation of a Web GIS application for water spring location and their status in Western Ethiopia was successfully implemented and fully satisfied the client's functional and non-functional requirements. This achievement was a result of a continual and committed collaboration between the project manager, the project supervisor and the chairman of the Tropical Health Alliance Foundation.

The project experienced technological limitations due to the fact that so far, there are functionalities that are hard to create in JavaScript environment, these include the creation of geoprocessing tools that enable online analysis and interactive communication between various THAF,s partners, donors, and stakeholders interested in natural spring water conservation and heath condition improvement in Western Ethiopia. 
Future work should focus on the following possible extensions to this project. The first opportunity would be to organize a systematic data collection that would cover the whole Welega Province. This would involve training local people in data collection methods and have them cover the whole Welega Province. A Web map application would be created, not only for spring locations and their condition, but also demographic data and village administrative boundaries would be integrated into a statistic analysis. The system should support more effective decisions in terms of prioritizing the neediest area in spring protection.

The second opportunity can be concerned with differential spring water quality. The project should look at water-borne disease agents present in unprotected springs, gather information from local health centers about water-borne disease incidences in all the villages in Welega Province, gather information about which health centers people from any particular village go to, and the name of springs the draw water from. This again requires the participation of trained local people to quickly gather information in a short period. The related training should focus on how to collect data and how to use data collection tools. The study should go further and compare protected spring and unprotected springs with respect to water quality. Springs can be mapped and categorized in different classes based on the quality of their water. A Web interactive map application can be created and users can query the map and get information, in an InfoWindow, about any spring's condition, its dominant pathogens, and what health problems people using that spring have as related to drinking unclean water. Developing effective field data collection workflows can facilitate the gathering of required information for the project.

Suggestions mentioned above regards study initiatives that can be undertaken by the client or various stakeholders with interest in the domain. However, when it comes to possible major individual projects, a particular topic would be a prioritization analysis that would integrate demographic data, village locations centroids and freshwater spring outflow, to indicate priority levels for spring protection. Analysis results would then be published along with a Web map application.

A solution to the client's concerns was found. However, in order to ensure its sustainability and maintain its viability, it is up to the client to make use of the Web application implemented and involve donors and partners to use it. More work still needs to be done to expand and keep the application updated if a sustainable and durable protection of springs is envisaged, not only for human communities in the Sayo District, but also for the entire western Ethiopia. 



\section{Works Cited}

Ayenew, T. (2001). Numerical groundwater flow modeling of the Central Main Ethiopian Rift lakes basin. Ethiopia Journal of Science, 24, 167-84.

Boisson, S., Schmidt, W-P., Berhanu, T., Gezahegn, H., \& Clasen, T. (2009). Randomized Controlled Trial in Rural Ethiopia to Assess a Portable Water Treatment Device. Environmental Science \& Technology, 43(15), 5934-5939.

Eleveld, M. A., Wagtendonk, A. J., Pasterkamp, R., \& De Reus, N. O. (2007). WATeRS: an open Web Map Service with near-real time MODIS Level-2 standard chlorophyll products of the North Sea. International Journal of Remote Sensing, 28, 3693-3699.

Fowler, S., \& Stanwick, V. (2004). Web Application Design Handbook: Best Practices for Web-based Software.

Gleick, H.P. (1998). Water in Crisis: Paths to Sustainable Water Use. Ecological Applications, 8(3), 571-579.

Huang, B., Jiang, B., \& Li, H. (2001). An integration of GIS, virtual reality and the Internet for visualization, analysis and exploration of spatial data. International

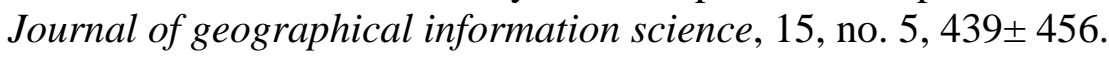

Jankowski, P., Nyerges, T., Robischon, S., Ramsey, K.., \& Tuthill, D. (2006). Design Considerations and Evaluation of a Collaborative, Spatio-Temporal Decision Support System. Transactions in GIS, 10(3), 335-354.

Jankowski, P., Tsou, M.-H., \& Wright, R. D. (2007). Applying Internet Geographic Information System for Water Quality Monitoring. Geography Compass, 1/6, 1315-1337.

Kraak, M.J., \& MacEachren, A.M. (1999). Visualization for exploration of spatial data. International Journal of Geographical Information Sciences, 13(4), 285-288.

Kraak, M.J., \& Brown, A. (2001). Web Cartography: Developments and prospects.

Kraak, M-J. (2004). The role of the map in a Web-GIS environment. Journal of Geographical Systems, 6, 83-93.

Laudien, R., Brocks, S., Weyler, S., Cristmann, A., Köhn, N., \& Bareth, G. (2009, Fall). Tools for Modeling Water Supplies. ArcUser, The Magazine for ESRI Software Users, 16-18. 
Legesse, D., Alemayehu, T., \& Furi, W. (2006). Impact of water overexploitation on highland lakes of eastern Ethiopia. Environ. Geol., 52, 147-154.

Niederst, J. (2001). Web Design in a Nutshell, Second Edition. California: O'Reilly \& Associates, Inc.

Peng, Z-R. (1999). An assessment Framework of the Development Strategies of Internet GIS. Environment and Planning B: Planning and Design, 26, 117-132.

Peng, Z-R. (2001). Internet GIS for public participation. Environment and Planning B: Planning and Design, 28, 889 - 905.

Peng, Z.-R., \& Tsou, M.-H. (2003). Internet GIS: distributed geographic information services for the internet and wireless networks. New Jersey: John Wiley \& Sons, Inc.

Peng, Z.-R., \& Zhang, C. (2004). The roles of geography markup language (GML), scalable vector graphics (SVG), and Web feature service (WFS) specifications in the development of Internet geographic information systems (GIS). Journal of Geographical Systems, 6, 95-116.

Plewe, B. (1997). GIS Online: Information Retrieval, Mapping, and the Internet. Santa Fe, New Mexico: onWord Press.

Powell, T.A. (2002). Web Design: The Complete Reference, Second Edition. New York: The McGraw-HIll Companies, Inc.

Rango, T., Bianchini, G., Beccaluva, L., Ayenew, T., \& Colombani, N. (2009). Hydrogeochemical study in the Main Ethiopian Rift: new insights to the source and enrichment mechanism of fluoride. Environ Geol, 58, 109-118.

Tomlinson, R. (2007). Thinking About GIS: Geographic Information System Planning for Managers. New York: ESRI Press.

Tsou, M.-H. (2004). Integrating web-based GIS and image processing tools for environmental monitoring and nature resource management. Journal of Geographical Systems, 6, 155-174.

Zeiler, Michael. (1999). Modeling our world: The ESRI guide to geodatabase design. Redlands, CA: ESRI Press. 


\section{Appendix A. Overall Project Flow}

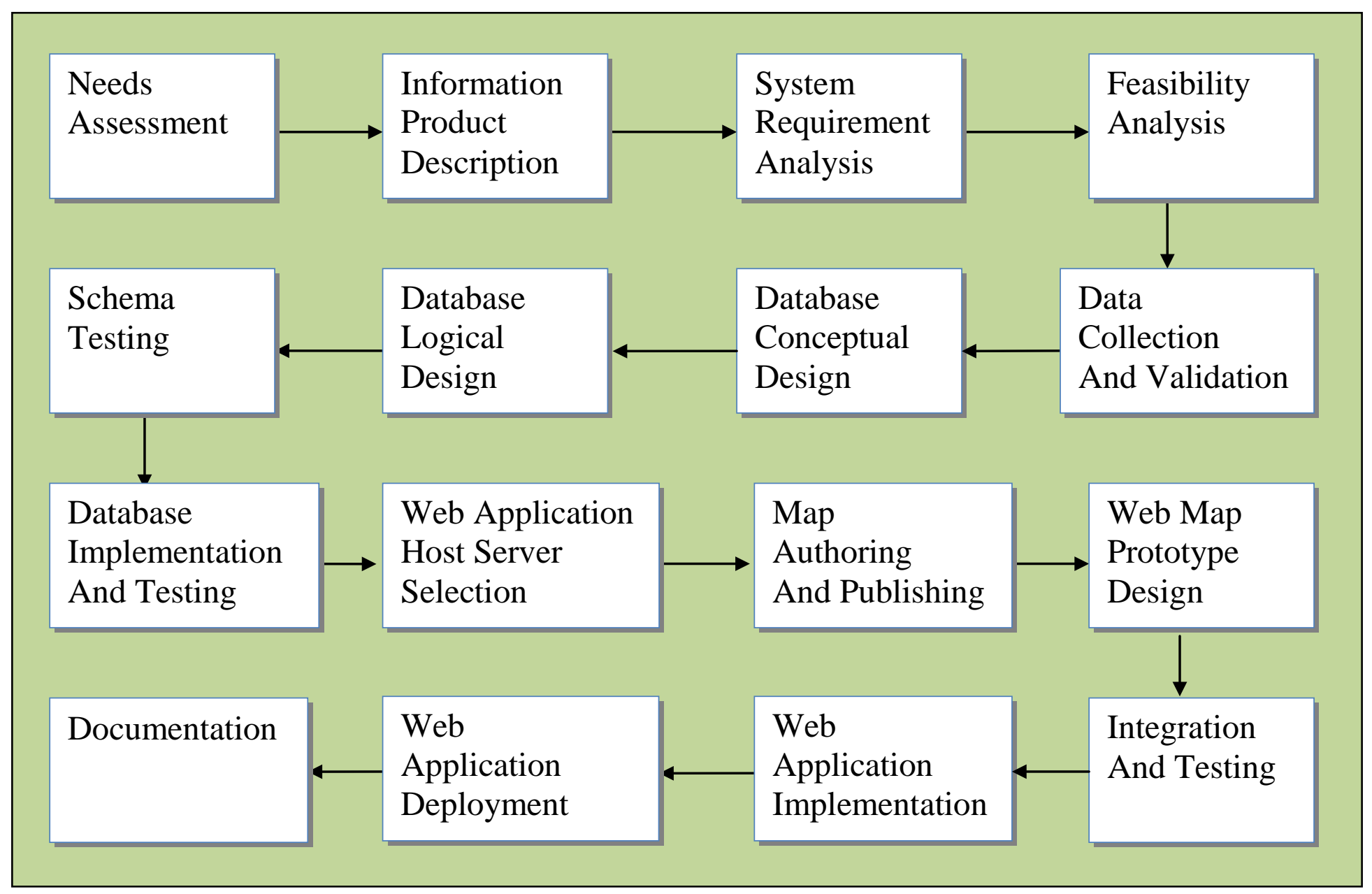




\section{Appendix B. Web Mapping Application Programming Code}

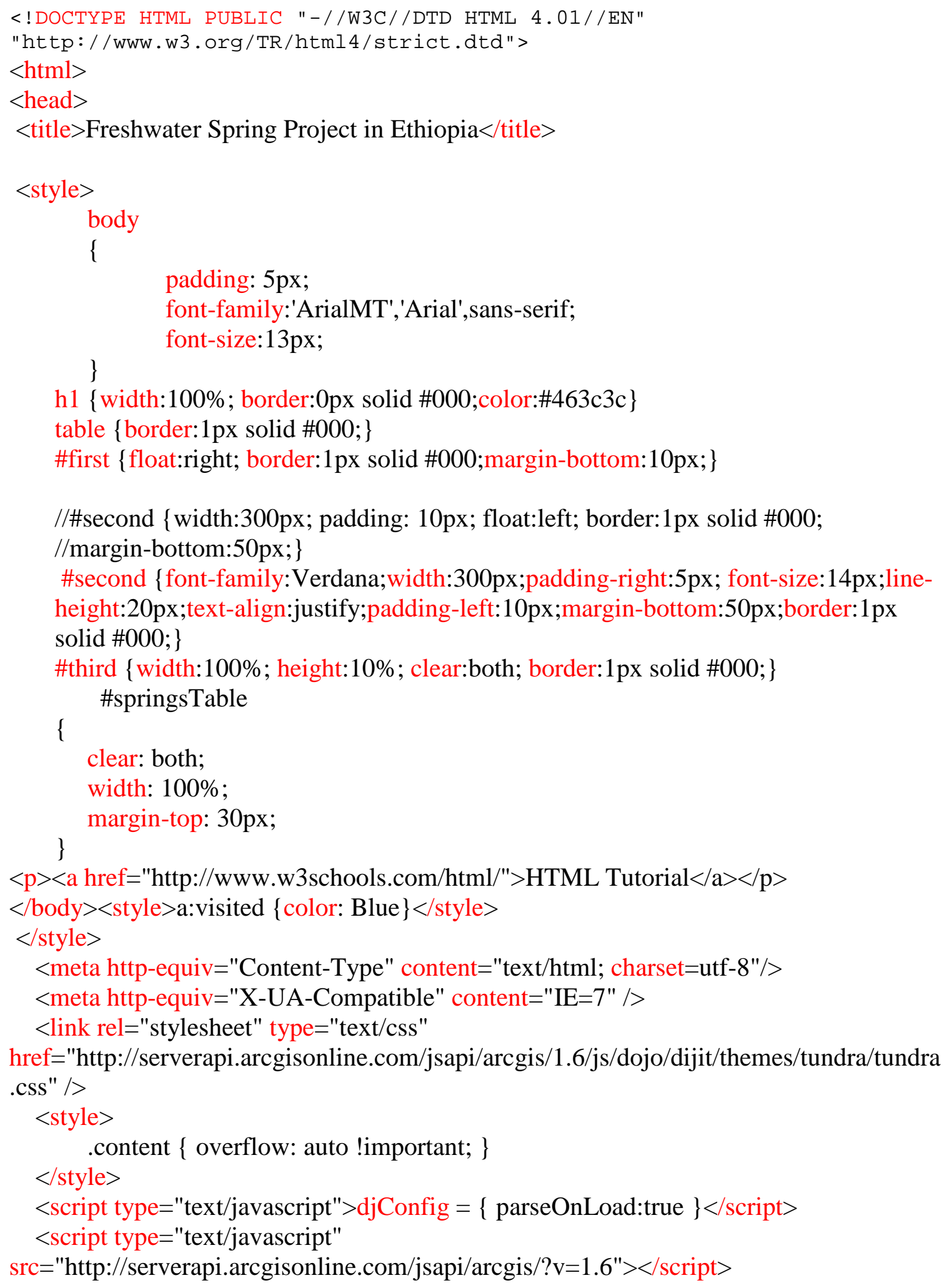




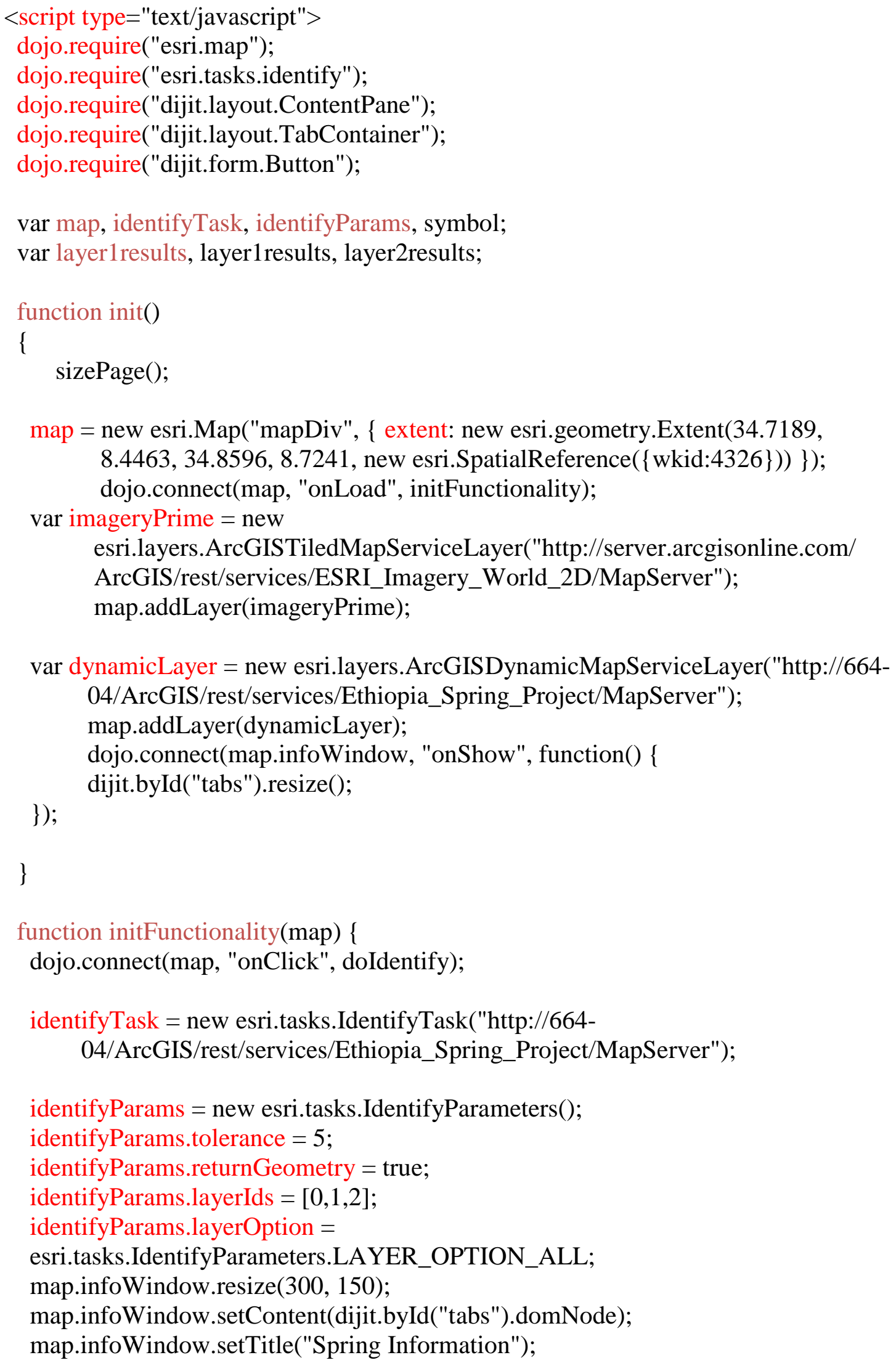


symbol $=$ new

esri.symbol.SimpleFillSymbol(esri.symbol.SimpleFillSymbol.STYLE_SOLID, new esri.symbol.SimpleLineSymbol(esri.symbol.SimpleLineSymbol.STYLE_SOLID, new dojo.Color([255,0,0]), 2), new dojo.Color([255,255,0,0.5]));

\}

function doIdentify(evt)

\{

map.infoWindow.hide();

map.graphics.clear();

featureSet = null;

identifyParams.geometry = evt.mapPoint;

identifyParams.mapExtent = map.extent;

identifyTask.execute(identifyParams, function(idResults)

\{ addToMap(idResults, evt); \});

\}

function addToMap(idResults, evt) \{

layer1results $=\{$ displayFieldName:null,features:[] $\}$;

layer2results $=\{$ displayFieldName:null,features:[] $\}$;

layer3results $=\{$ displayFieldName:null,features:[] $\}$;

for (var i=0, il=idResults.length; $i<i l ; i++)\{$

var idResult = idResults[i];

if (idResult.layerId $===1$ ) \{

if (!layer1results.displayFieldName) \{layer2results.displayFieldName = idResult.displayFieldName\};

layer1results.features.push(idResult.feature);

\} else if (idResult.layerId $===0$ ) \{

if (!layer2results.displayFieldName) \{layer2results.displayFieldName = idResult.displayFieldName\};

layer2results.features.push(idResult.feature);

\}

\}

// dijit.byId("layer2Tab").setContent(layerTabContent(layer1results,"layer1results")); dijit.byId("layer3Tab").setContent(layerTabContent(layer2results,"layer2results")); dijit.byId("layer4Tab").setContent(layerTabContent(layer1results,"layer1results"));

map.infoWindow.show(evt.screenPoint, map.getInfoWindowAnchor(evt.screenPoint));

\}

function layerTabContent(layerResults, layerName) 


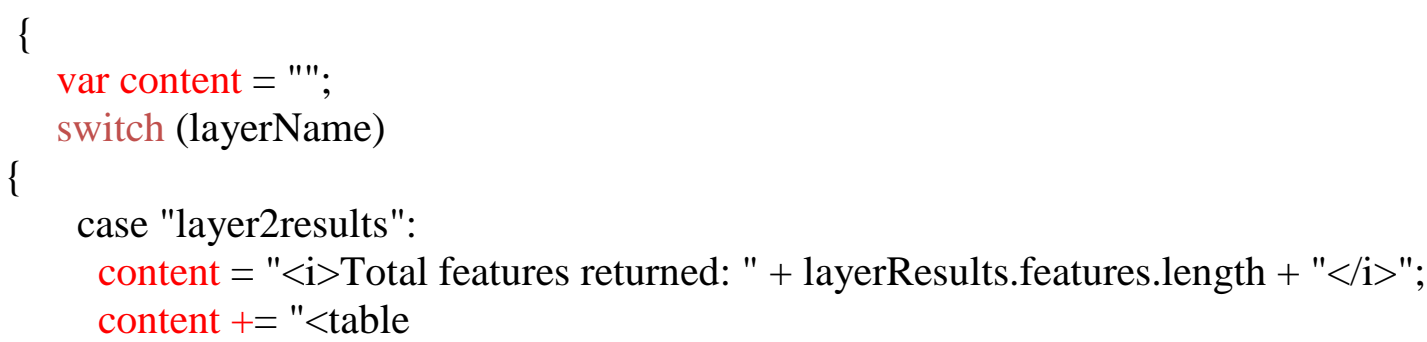

border=' $1^{\prime}><$ tr $><$ th $>$ Photo $<$ th $><$ th $>$ Spring_ID $</$ th $><$ th $>$ Spring_Name $</$ th $><$ th $>$ Locatio n_Kabale $</$ th $><$ th $>$ \# Households $</$ th $></$ tr $>$ ";

for (var i=0, il=layerResults.features.length; $\mathrm{i}<\mathrm{il} ; \mathrm{i}++)\{$

console.log(layerResults.features[i]); content $+="<\mathrm{tr}><\mathrm{td}><\mathrm{a}$ href=|"/Springimg/" +

layerResults.features[i].attributes['Photos'] + "।" target=l"_blankl">link $</ a></ \operatorname{td}>$ "; content $+="<\mathrm{td}>$ "+layerResults.features[i].attributes['Spring ID']+" $</ \mathrm{td}>"$; content $+="<\mathrm{td}>$ "+layerResults.features[i].attributes['Spring Name']+" $</ \mathrm{td}>"$; content $+="<\mathrm{td}>$ "+layerResults.features[i].attributes['Location Kabale']+" $<$ ttd $>$; content $+="<\mathrm{td}>"+$ layerResults.features[i].attributes['N0 Households'] $+"</ \mathrm{td}>"$;

border=' $1^{\prime}><$ tr $><$ th $>$ Photo $<$ th $><$ th $>$ Spring_ID $</$ th $><$ th $>$ Spring_Name $</$ th $><$ th $>$ Locatio

n_Kabale $</$ th $><$ th $>$ N0_Households $</$ th $></$ tr $>$ ";

for (var $\mathrm{i}=0$, il=layerResults.features.length; $\mathrm{i}<\mathrm{il} ; \mathrm{i}++)\{$ content $+="<\mathrm{tr}><\mathrm{td}><\mathrm{a}$ href=|"/Springimg/" +

layerResults.features[i].attributes['Photos'] + "|" target=|"_blankl">link $</ \mathrm{a}></ \mathrm{td}>$ "; content $+="<\mathrm{td}>$ "+layerResults.features[i].attributes['Spring ID']+" $</ \mathrm{td}>"$; content $+="<\mathrm{td}>$ "+layerResults.features[i].attributes['Spring Name']+" $<$ tdd $>$; content $+="<\mathrm{td}>$ "+layerResults.features[i].attributes['Location Kabale']+"</td $>$ "; content $+="<\mathrm{td}>"+$ layerResults.features[i].attributes['N0 Households']+" $</ \mathrm{td}>"$;

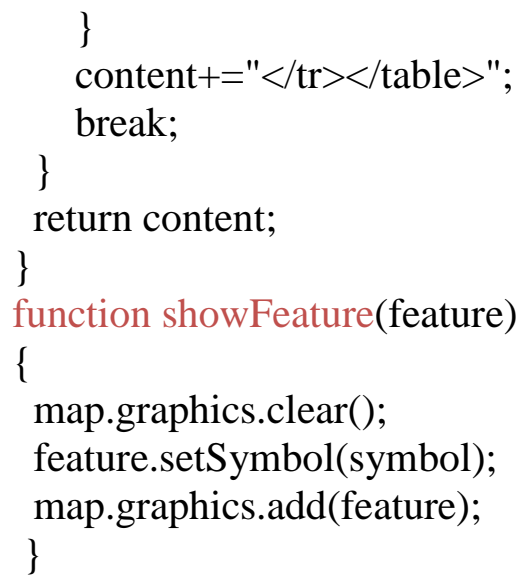




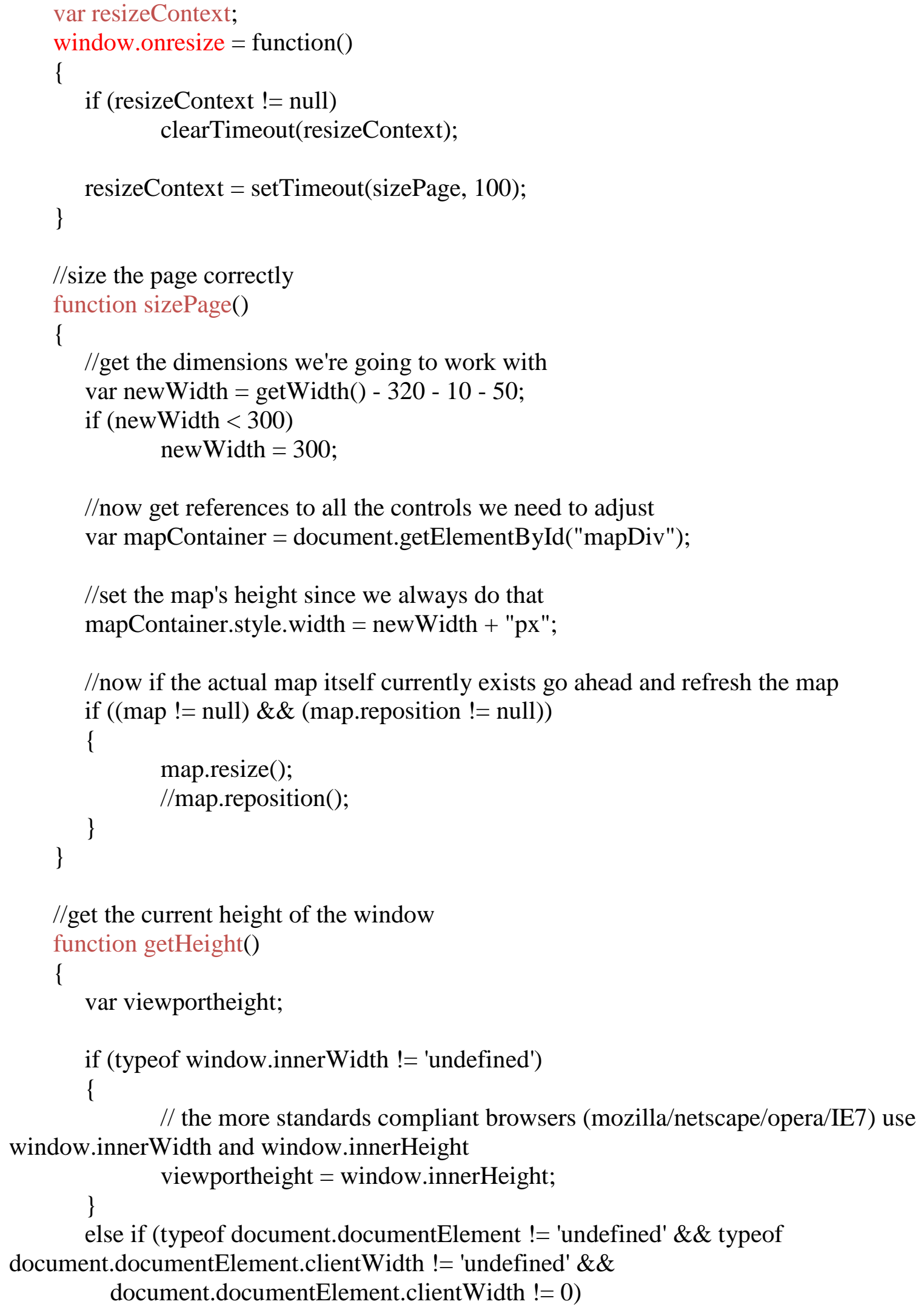




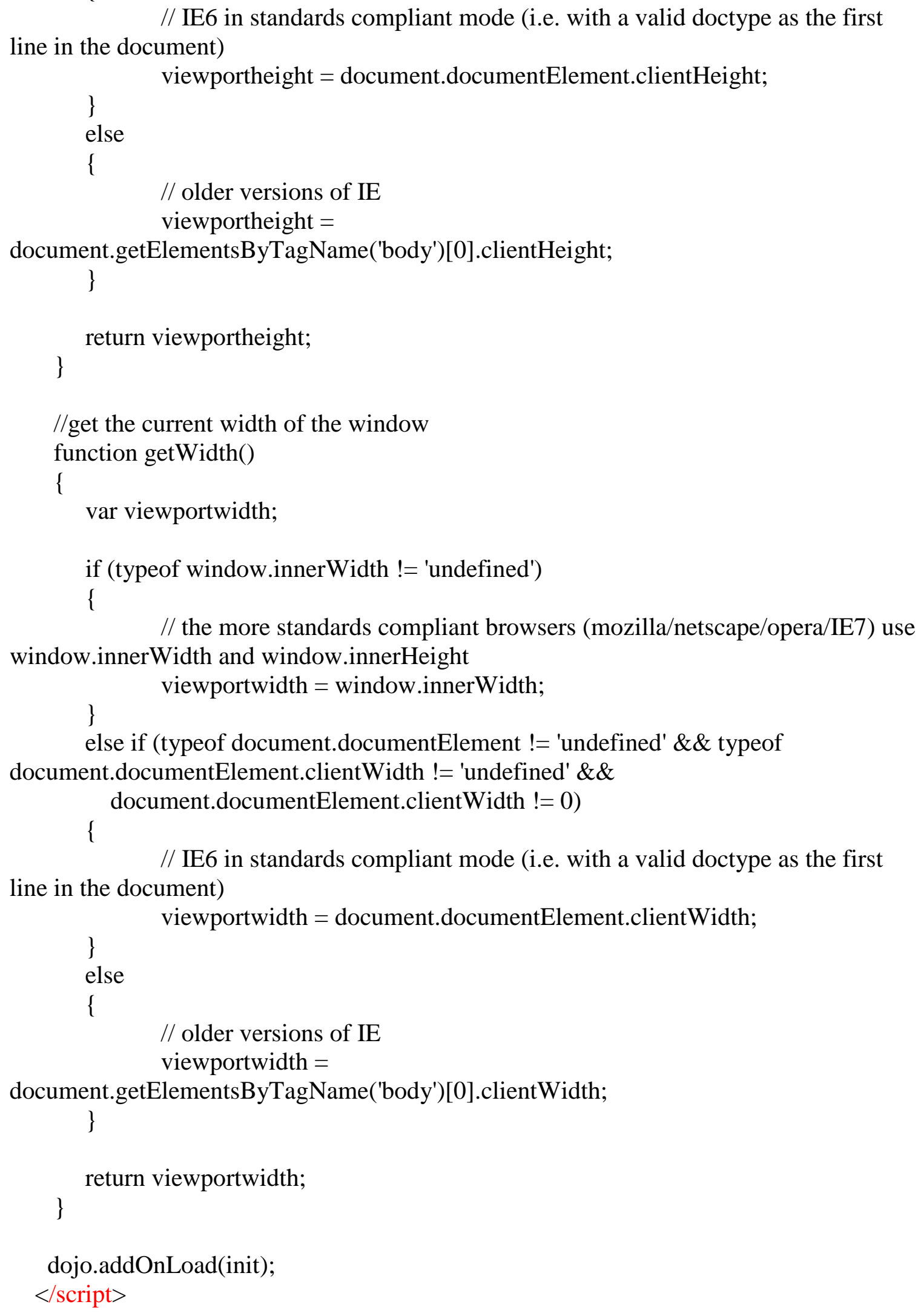


$</$ head $>$

<body class="tundra" BGCOLOR="\#83BFb8">

<div style="height: 80px; width: 80px; height: 80px; left: 15px; position: absolute; top:

$</ \operatorname{div}>$

11px; width: 80px; z-index: 1; " class="tinyText style_SkipStroke_4 stroke_4">

<img src="thaf.jpg" alt="" style="border: none; height: 60px; width: 60px; "/>

$<$ h1 ALIGN="CENTER" BGCOLOR="\#DFD1D1">Freshwater Springs in Sayo District, Ethiopia, 2010.</h1 $>$

$<$ div id="first" >

$<$ div id="mapDiv" style= "width:700;height:600px;" $></$ div $>$

$<$ div id="tabs" dojoType="dijit.layout.TabContainer"

style="width:385px;height:150px;">

$<$ div id="layer3Tab" dojoType="dijit.layout.ContentPane" title="Protected

Springs" $></$ div $>$

$<$ div id="layer4Tab" dojoType="dijit.layout.ContentPane" title="Unprotected

Springs" $></$ div $>$

$</$ div $>$

$</ \operatorname{div}>$

$<$ div id="second" $><$ a

href="http://www.thaf.org/WWW.THAF.ORG/SAFE_WATER_PROJECT.html">

Two-third of the rural population do not have access to clean water $</ a>$.

A high prevalence of water-borne diseases in the region is accounted for by limited

access to clean water. This Web map application has been developed to help $<\mathrm{a}$

href="http://www.thaf.org/WWW.THAF.ORG/HOME_PAGE.html">

the Tropical Health Alliance Foundation</a $>$ disseminate information about the $<\mathrm{br} />$

distribution and status of freshwater springs in Sayo District, western Ethiopia.

$<$ p $><$ img src="Springimg/thumbnails/img1.jpg" $/><$ br $/></$ p $>$

$<$ p $>$ In total, ninety-two springs have been surveyed. Unprotected springs

account for $67 \%$ of the total and are located in fifty-two villages. Virtually all

the springs run all year round.

On this map, a red circle represents an unprotected spring, and a blue one represents a protect spring.

With a simple mouse click on any circle, you will see related information and a link to a photograph of the spring.

<a href="http://localhost/Sayo_Spring_Table.html"/>Click here</a> to see a table with details.

$</ p>$

$</ \operatorname{div}>$ 
<div id="id1" style="height: 35px; left: 100px; position: absolute; top: 33px; width: 444px; z-index: 1; " class="style_SkipStroke">

$<$ div class="text-content graphic_textbox_layout_style_default_External_444_35" style="padding: 0px; "> $<$ div class="graphic_textbox_layout_style_default"> $<$ p style="padding-bottom: 0pt; padding-top: 0pt; "

class="paragraph_style" $><\mathrm{b}><\mathrm{a}$

href="http://www.thaf.org/WWW.THAF.ORG/HOME_PAGE.html" $>$ TROPICAL HEALTH ALLIANCE FOUNDATION $</ \mathrm{a}></ \mathrm{b}></ \mathrm{p}>$

$<$ p $><$ a href="http://www.w3schools.com/html/" $</$ a $></$ p $></$ body $><$ style $>$ a:visited \{color: Blue $\}<$ style $>$

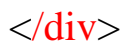

$<$ div id="id2" style="height: 26px; left: 103px; position: absolute; top: 59px; width: 164px; z-index: 1; " class="style_SkipStroke">

<div class="text-content graphic_textbox_layout_style_default_External_164_26" style="padding: 0px; ">

$<$ div class="graphic_textbox_layout_style_default"> $<$ p style="padding-bottom: Opt; padding-top: Opt; " class="paragraph_style_1" $>$ Learning through service $</$ p $>$ $</ \operatorname{div}>$

$</$ body $>$

$</$ html $>$ 


\section{Appendix C. Questionnaire about springs surveyed}

This questionnaire was jointly addressed to local community elders, spring users, local church elders and local government officials. The questionnaire was used during interviews conducted at every spring visited.

Question 1: What is the local name for this spring?

Question 2: Does this spring have any other name? What is the name?

Question 3: What is the name of the village this spring is located in?

Question 4: What is the name of the Kabale this village is situated in?

Question 5: Does this spring run all year around?

Question 6: What months of the year is the spring dry?

Question 7: How many villages use this spring?

Question 8: How many households from each village use this spring on a regular basis?

Question 9: How much time does it take you to travel from your houses to get here?

Question 10: Who protected this spring (if a spring is protected)? And when?

Question 11: What problem do you have with this spring? (If unprotected)

Question 12: What do you use the water from the spring for? 


\section{Appendix D. Project Timeline}

\begin{tabular}{|c|c|c|c|c|c|c|c|c|c|c|}
\hline $\begin{array}{l}\text { Task Name } \\
\text { I. INITIATION AND ANALYSIS PHASE }\end{array}$ & October & November & \begin{tabular}{|c|} 
December \\
$\quad 12 / 11$
\end{tabular} & January & February & March & April & May & June & July \\
\hline 1. Information product analysis & $9_{1}$ & & & & & & & & & \\
\hline 2. System requirement analysis & & & & & & & & & & \\
\hline 3. Risk analysis & & & & & & & & & & \\
\hline 4. Feasibility analysis & & & & & & & & & & \\
\hline 5. Project plan (deliverable) & & & & & & & & & & \\
\hline II. DESIGN PHASE & & & & & $2 / 1$ & & & & & \\
\hline 1. Geodatabase design & & & & & & & & & & \\
\hline 2. Geodatabas prototype & & & & & & & & & & \\
\hline 3. Web application design & & & & & & & & & & \\
\hline III. IMPLEMENTATION PHASE & & & & & & & & 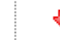 & & \\
\hline 1. Data entry and processing & & & & & & & & & & \\
\hline 2. Geodatabase validation and delivery ( & & & & & 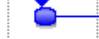 & & & & & \\
\hline 3. Web map application development & & & & & & & & & & \\
\hline 4. Web application integration and testin & & & & & & & & & & \\
\hline 5. Web map publication (deliverable) & & & & & & & & & & \\
\hline IV. ROLLOUT PHASE & & & & & & & & & & $\Leftrightarrow 7 \pi$ \\
\hline 1. Client's training & & & & & & & & & & \\
\hline 2. Documentation and reporting (deliveré & & & & & & & & & & \\
\hline 3. Formal presentations & & & & & & & & & & \\
\hline
\end{tabular}




\section{Appendix E. Spring Data Table}

Protected springs are highlighted in dark grey.

\begin{tabular}{|c|c|c|c|c|c|c|c|}
\hline ID & Latitude & Longitude & Spring_Name & Village & Kabale & $\mathrm{Nb.H}$ & W.D \\
\hline 1 & 8.52298 & 34.82797 & Badessa & Kasea wachu & Ifa Galaanoo & 90 & 9.9 \\
\hline 2 & 8.56583 & 34.80025 & Yase & Jaarsoo & Yaangi & 73 & 10.3 \\
\hline 3 & 8.52754 & 34.83374 & Tinga & Onu & Ifa Galaanoo & 60 & 7 \\
\hline 4 & 8.53072 & 34.83314 & Mume & Jarso & Hacalaanoo & 40 & 5.2 \\
\hline 5 & 8.49412 & 34.83315 & Mitiko Meleta & Bocoloo & Danka parish & 42 & 4.9 \\
\hline 6 & 8.44631 & 34.84415 & Laga badu & Laga badu & Walgai bubuka & 70 & 13 \\
\hline 7 & 8.45695 & 34.85967 & Butuji & Butuji & Walgai bubuka & 150 & 7.8 \\
\hline 8 & 8.5783 & 34.84663 & Dawoshulki & Limo & Amomekail & 170 & 13.2 \\
\hline 9 & 8.58001 & 34.81893 & Hachoo & Suphinsa & Aleku Abboo & 76 & 6.6 \\
\hline 10 & 8.58052 & 34.83809 & Totto & Kota'o & Aleku Abboo & 120 & 7 \\
\hline 11 & 8.63989 & 34.80976 & Chancho & Dinbanko & Aleku Abboo & 30 & 5.1 \\
\hline 12 & 8.63322 & 34.80663 & Walamo & Walamo & Aleku Abboo & 25 & 6.3 \\
\hline 13 & 8.64508 & 34.81948 & Lagaa Adii & Baru & Ambela & 40 & 7.9 \\
\hline 14 & 8.63571 & 34.79581 & Chai & Aleku Abboo & Aleku Abboo & 23 & 6.7 \\
\hline 15 & 8.64375 & 34.8141 & Danissa Handagwe & Aleku Kaisa & Aleku Kaisa & 22 & 8 \\
\hline 16 & 8.64371 & 34.81428 & Danissa & Aleku Kaisa & Aleku Kaisa & 30 & 9 \\
\hline 17 & 8.63943 & 34.81385 & Danissa3 & Aleku Kaisa & Aleku Kaisa & 80 & 9.7 \\
\hline 18 & 8.68859 & 34.81987 & Laga Kola & $\begin{array}{l}\text { Gimbi abba } \\
\text { Irana }\end{array}$ & Hawa Finchoo & 33 & 7.8 \\
\hline 19 & 8.67944 & 34.81437 & Abba Daannoo & Limiti & Hawa Finchoo & 26 & 6.2 \\
\hline 20 & 8.68924 & 34.81226 & $\begin{array}{l}\text { Laga Waraba } \\
\text { Abbaa }\end{array}$ & Guto & Hawa Finchoo & 75 & 10.6 \\
\hline 21 & 8.67526 & 34.78077 & Laga harbu & Wanaaga & $\begin{array}{l}\text { Aleku } \\
\text { Baddessoo }\end{array}$ & 33 & 9 \\
\hline 22 & 8.6697 & 34.78296 & Leemmanii & Wanagasunta & $\begin{array}{l}\text { Aleku } \\
\text { Baddessoo }\end{array}$ & 60 & 11.9 \\
\hline 23 & 8.67367 & 34.78395 & Laga Kilo & Wanaga Fincho & Badeso & 51 & 6.4 \\
\hline 24 & 8.67228 & 34.77402 & Laga Abba dangula & Gelei & Badeso & 30 & 8 \\
\hline 25 & 8.65286 & 34.79251 & Etesa & Wanaga roge & Alake lobo & 60 & 7 \\
\hline 26 & 8.64968 & 34.79296 & Laga Wakayo & Wanaga Alga & Aleku Abboo & 30 & 7 \\
\hline 27 & 8.64752 & 34.79822 & Laga Sembo & Wanaga Dacha & Aleku Abboo & 106 & 12.3 \\
\hline 28 & 8.71984 & 34.7476 & Shoole & Shoole & Aleku Sanagaa & 35 & 6 \\
\hline 29 & 8.72793 & 34.75425 & Laga Leemmanii & Hardof & Aleku Sanagaa & 29 & 8.3 \\
\hline 30 & 8.7297 & 34.74923 & Mume & Hardof & Aleku Sanagaa & 9 & 6 \\
\hline 31 & 8.7291 & 34.74572 & Qesi & Hardof III & Aleku Sanagaa & 50 & 5.2 \\
\hline
\end{tabular}




\begin{tabular}{|c|c|c|c|c|c|c|c|}
\hline ID & Latitude & Longitude & Spring_Name & Village & Kabale & Nb.H. & W.D. \\
\hline 32 & 8.73537 & 34.7492 & Laga Kake & Hardof IV & Aleku Sanagaa & 70 & 5.3 \\
\hline 33 & 8.72255 & 34.73239 & Gaagagsa & Gaagagsa & Aleku Sanagaa & 44 & 5 \\
\hline 34 & 8.72419 & 34.73418 & Gaagagsa II & $\begin{array}{l}\text { Gaagagsa } \\
\text { II }\end{array}$ & Aleku Sanagaa & 35 & 7 \\
\hline 35 & 8.72268 & 34.74083 & Gaagagsa III & $\begin{array}{l}\text { Gaagagsa } \\
\text { III }\end{array}$ & Aleku Sanagaa & 50 & 8.8 \\
\hline 36 & 8.71677 & 34.73987 & Lalise & Sasi & Aleku Sanagaa & 30 & 5.6 \\
\hline 37 & 8.71454 & 34.74452 & Dukani & Sasi & Aleku Sanagaa & 70 & 11 \\
\hline 38 & 8.60576 & 34.79388 & Laga abakorsa & Hofa & Aleku Gambi & 38 & 10.5 \\
\hline 39 & 8.61868 & 34.79148 & Hror & Chore & Aleku Gambi & 136 & 11 \\
\hline 40 & 8.68422 & 34.74432 & Tererse & Gori supe & Aleku Kusaayee & 30 & 8 \\
\hline 41 & 8.68051 & 34.75284 & Toli & Toli & Aleku Kusaayee & 28 & 7 \\
\hline 42 & 8.67871 & 34.75359 & Welete & Toli & Aleku Kusaayee & 52 & 7 \\
\hline 43 & 8.653 & 34.8133 & Danissa & Adami & Aleku Abboo & 60 & 11.2 \\
\hline 44 & 8.6524 & 34.80752 & Shuaa & Adami & Aleku Abboo & 22 & 6.7 \\
\hline 45 & 8.6555 & 34.82384 & Tibe & Tibe & Aleku Abboo & 37 & 8 \\
\hline 46 & 8.65191 & 34.83051 & Abba Dhaba & Harrere & Anfare Harrere & 73 & 2 \\
\hline 47 & 8.68103 & 34.84155 & Laga harbu & Billoo & Hawa Babo & 35 & 18.75 \\
\hline 48 & 8.68709 & 34.83951 & Qargahaa & Anfare & Hawa Gelam & 49 & 8.3 \\
\hline 49 & 8.69227 & 34.83296 & Hindachoo & Hindachoo & Hawa Moii & 50 & 7 \\
\hline 50 & 8.49517 & 34.74598 & Kabbdoo & Kabbdoo & Addo Sakkoo & 80 & 6.1 \\
\hline 51 & 8.49043 & 34.73745 & Dugushi & $\begin{array}{l}\text { Alba } \\
\text { Dhesa }\end{array}$ & Addo Sakkoo & 125 & 9.7 \\
\hline 52 & 8.51256 & 34.76255 & Chugi & Chugi & Addo Sakkoo & 270 & 13.5 \\
\hline 53 & 8.51061 & 34.76942 & ljomako & Bakara & Addo Sakkoo & 126 & 11 \\
\hline 54 & 8.41247 & 34.84631 & Bubuka (Karo) & Bubuka & Kuregaib & 40 & 3 \\
\hline 55 & 8.40063 & 34.85075 & Laga Warke & $\begin{array}{l}\text { Kakin } \\
\text { (Karo) }\end{array}$ & Kuregaib & 55 & 5 \\
\hline 56 & 8.44478 & 34.83073 & Chorestu & Chorestu & Kuregaib & 76 & 8.3 \\
\hline 57 & 8.47102 & 34.81524 & Koye & Gaibi & Kuregaib & 600 & 7.25 \\
\hline 58 & 8.43367 & 34.81678 & Shigo & Shigo & Karoba & 30 & 5 \\
\hline 59 & 8.50148 & 34.78041 & Laga Bakala & Chora & Humbi Karroo & 90 & 9 \\
\hline 60 & 8.50456 & 34.7878 & Mume waldo & Waldo & Humbi Karroo & 115 & 7.2 \\
\hline 61 & 8.51385 & 34.7812 & Rude & Odogda & Humbi Karroo & 55 & 7.75 \\
\hline 62 & 8.51549 & 34.78186 & Abba Esrael & Borta & Humbi Karroo & 42 & 3.6 \\
\hline 63 & 8.52093 & 34.77899 & Ursa & Harrere & Addo Sakkoo & 50 & 12 \\
\hline 64 & 8.5167 & 34.77502 & Odo Bire & Bakara & Addo Sakkoo & 75 & 15 \\
\hline 65 & 8.51048 & 34.77355 & Mume & Chora & Humbi Karroo & 74 & 4.2 \\
\hline 66 & 8.49363 & 34.77612 & Shenari & Shenari & Humbi Karroo & 63 & 2.5 \\
\hline 67 & 8.49473 & 34.76278 & Abba Kibitu & Humbi & Addo Sakkoo & 30 & 1.5 \\
\hline 68 & 8.44215 & 34.75641 & Shembe & Shembe & Addo Sakkoo & 107 & 36 \\
\hline
\end{tabular}




\begin{tabular}{|c|c|c|c|c|c|c|c|}
\hline ID & Latitude & Longitude & Spring_Name & Village & Kabale & Nb.H. & W.D. \\
\hline 69 & 8.59412 & 34.73659 & Sina & Bangio & Mata & 64 & 4.2 \\
\hline 70 & 8.59648 & 34.73918 & Ababuze & Chombi Bangio & Mata & 40 & 5 \\
\hline 71 & 8.59559 & 34.74464 & Abba Yonas & Bangio & Mata & 49 & 5 \\
\hline 72 & 8.58852 & 34.74286 & Galata & Bangio & Mata & 60 & 2.3 \\
\hline 73 & 8.59949 & 34.7268 & Abba Mangali & $\begin{array}{l}\text { Chombe } \\
\text { Karabsho }\end{array}$ & Mata & 30 & 6 \\
\hline 74 & 8.59449 & 34.73061 & Makanisa & $\begin{array}{l}\text { Chombe } \\
\text { Karabsho }\end{array}$ & Mata & 70 & 8 \\
\hline 75 & 8.59774 & 34.73278 & Dafissa & $\begin{array}{l}\text { Chombe } \\
\text { Karabcho }\end{array}$ & Mata & 40 & 12 \\
\hline 76 & 8.59099 & 34.73149 & Mucoo II & Bari & Mata & 35 & 7 \\
\hline 77 & 8.58979 & 34.73318 & Mucoo I & Bari & Mata & 35 & 6.5 \\
\hline 78 & 8.58431 & 34.71919 & Waakennee & Meti & Mata & 33 & 7 \\
\hline 79 & 8.58207 & 34.72642 & Chore & Focho & Mata & 60 & 12 \\
\hline 80 & 8.56815 & 34.71893 & Tumsa & Hamdochaka & Mata & 60 & 10 \\
\hline 81 & 8.56953 & 34.71923 & Nagari & Hamdoreti & Mata & 40 & 12 \\
\hline 82 & 8.56709 & 34.71037 & Tashoma & Hamdochaka & Mata & 21 & 6 \\
\hline 83 & 8.52037 & 34.75697 & Dhaladu & Alatkilo & $\begin{array}{l}\text { Addo } \\
\text { Sakkoo }\end{array}$ & 200 & 6 \\
\hline 84 & 8.517 & 34.75438 & $\begin{array}{l}\text { Lagga } \\
\text { Warkina }\end{array}$ & Alatkilo & $\begin{array}{l}\text { Addo } \\
\text { Sakkoo } \\
\end{array}$ & 130 & 7 \\
\hline 85 & 8.51547 & 34.74465 & Abba Tafara & Bari Dobe & $\begin{array}{l}\text { Addo } \\
\text { Sakkoo }\end{array}$ & 30 & 12 \\
\hline 86 & 8.52034 & 34.74137 & Suki & Bari Shinkri & $\begin{array}{l}\text { Addo } \\
\text { Sakkoo }\end{array}$ & 160 & 30 \\
\hline 87 & 8.56074 & 34.78896 & Chore & Gutemura & Yangi & 120 & 1.25 \\
\hline 88 & 8.59437 & 34.78066 & Bego & Dibe & Tabor & 90 & 5 \\
\hline 89 & 8.60171 & 34.77537 & Duke & Odobuta & Tabor & 40 & 5 \\
\hline 90 & 8.53637 & 34.73117 & Chalte & Shogo & $\begin{array}{l}\text { Abichu } \\
\text { Shogo }\end{array}$ & 80 & 12 \\
\hline 91 & 8.53904 & 34.71293 & Sholli & Tolachi & $\begin{array}{l}\text { Abichu } \\
\text { shogo }\end{array}$ & 60 & 12 \\
\hline 92 & 8.5182 & 34.74321 & $\begin{array}{l}\text { Laga Abba } \\
\text { Bushu }\end{array}$ & Dobe & $\begin{array}{l}\text { Addo } \\
\text { Sakkoo }\end{array}$ & 15 & 5 \\
\hline
\end{tabular}

